\title{
Recent Advances in Metabolically Engineered Microorganisms for the Production of Aromatic Chemicals Derived From Aromatic Amino Acids
}

OPEN ACCESS

Edited by:

Shihui Yang,

Hubei University, China

Reviewed by:

Mingfeng Cao,

University of llinois at

Urbana-Champaign, United States

Congqiang Zhang,

Agency for Science, Technology and Research (A*STAR), Singapore

${ }^{*}$ Correspondence:

Jian-Zhong Liu

Issliz@mail.sysu.edu.cn

Specialty section: This article was submitted to

Synthetic Biology,

a section of the journal Frontiers in Bioengineering and Biotechnology

Received: 28 February 2020 Accepted: 14 April 2020 Published: 05 May 2020

Citation:

Shen $Y$-P, Niu F-X, Yan Z-B, Fong LS, Huang Y-B and Liu J-Z (2020) Recent Advances in Metabolically Engineered Microorganisms for the Production of

Aromatic Chemicals Derived From Aromatic Amino Acids.

Front. Bioeng. Biotechnol. 8:407. doi: 10.3389/fbioe.2020.00407

\author{
Yu-Ping Shen, Fu-Xing Niu, Zhi-Bo Yan, Lai San Fong, Yuan-Bin Huang and \\ Jian-Zhong Liu*
}

Guangdong Province Key Laboratory of Improved Variety Reproduction in Aquatic Economic Animals, Biomedical Center, School of Life Sciences, Institute of Synthetic Biology, Sun Yat-sen University, Guangzhou, China

Aromatic compounds derived from aromatic amino acids are an important class of diverse chemicals with a wide range of industrial and commercial applications. They are currently produced via petrochemical processes, which are not sustainable and eco-friendly. In the past decades, significant progress has been made in the construction of microbial cell factories capable of effectively converting renewable carbon sources into value-added aromatics. Here, we systematically and comprehensively review the recent advancements in metabolic engineering and synthetic biology in the microbial production of aromatic amino acid derivatives, stilbenes, and benzylisoquinoline alkaloids. The future outlook concerning the engineering of microbial cell factories for the production of aromatic compounds is also discussed.

Keywords: aromatic amino acid derivatives, stilbenes, benzylisoquinoline alkaloids, metabolic engineering, microorganism, strain construction

\section{INTRODUCTION}

Aromatic compounds are an important class of diverse chemicals. They have extensive applications in the production of various solvents, plastics, fine chemicals, food and feed additives, nutraceuticals, and pharmaceuticals (Averesch and Kromer, 2018; Wang J. et al., 2018). Moreover, many aromatic products have various biological activities and are widely used in pharmaceutical industries. Typically, aromatic compounds are chemically synthesized from petroleum-derived feedstocks, such as benzene, xylene, and toluene. With the progressive exhaustion of traditional feedstocks and the continuous deterioration of the environment, the biotechnological production of aromatic chemicals from renewable sugar feedstock in an eco-friendly manner has received considerable attention as a promising alternative for the synthesis of aromatic compounds.

Aromatic compounds can be produced by various plants, algae, fungi, and bacteria via the shikimate pathway. The shikimate pathway begins with the condensation of phosphoenolpyruvate (PEP) in the Embden-Meyerhof-Parnas pathway (EMP) and that of D-erythrose 4-phosphate (E4P) in the pentose phosphate pathway (PPP) to form 3-deoxy-D-arabino-heptulosonate-7-phosphate (DAHP). Six additional enzymatic steps are necessary for the synthesis of chorismite, which is converted to phenylpyruvate (PP) or 4-hydroxyphenylpyruvate (4HPP) via prephenate, through the Phe-Tyr branch that is catalyzed by chorismate mutase/prephenate dehydratase (PheA) or the chorismate mutase/prephenate dehydrogenase (TyrA) complex. Chorismate is also converted to anthranilate (AA) by the Trp branch in a reaction catalyzed by the anthranilate synthase (TrpED) complex. Finally, Phe, Tyr, and Trp are synthesized via their own biosynthetic pathways using PP, 


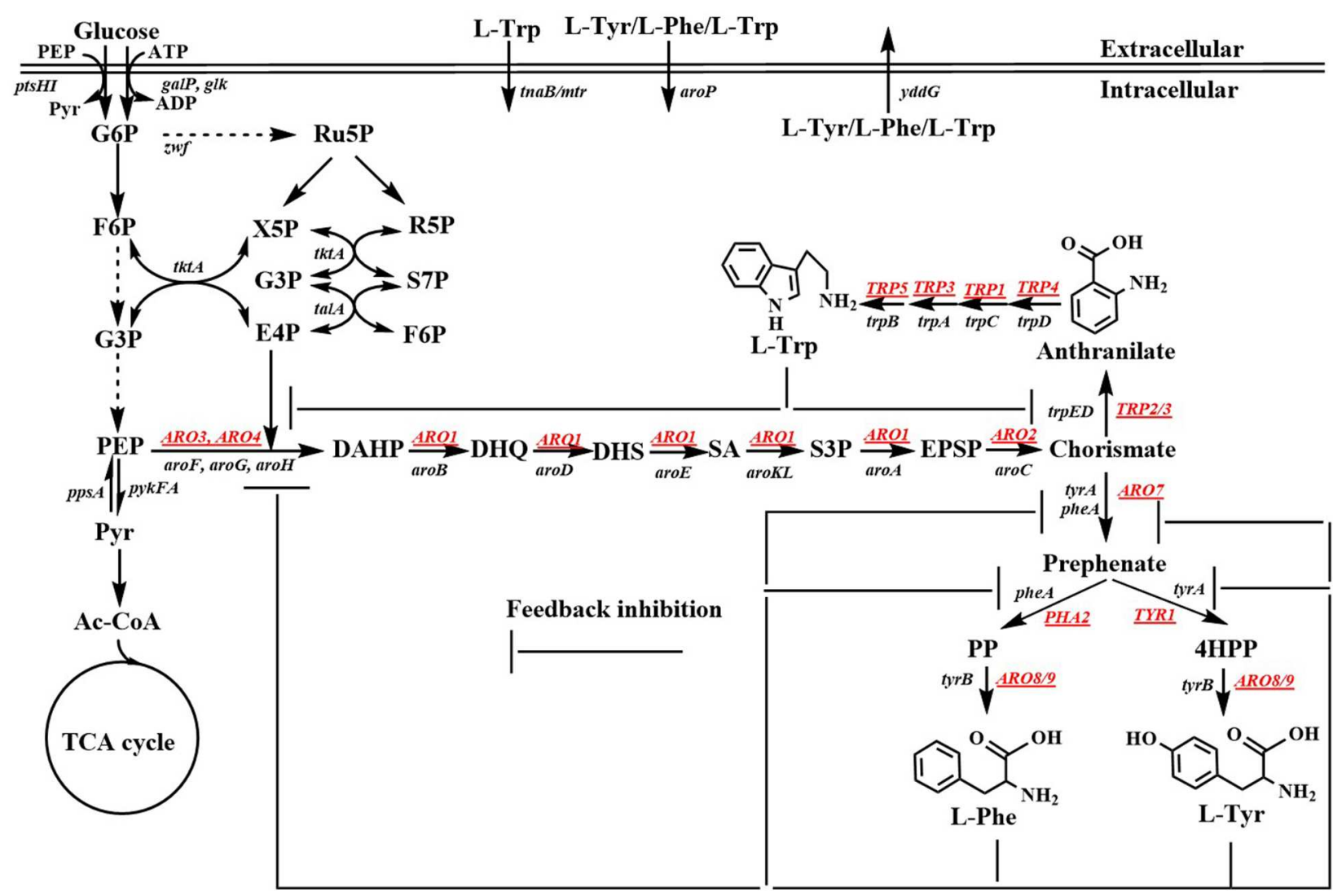

FIGURE 1 | Biosynthetic pathway of aromatic amino acids. Black, Escherichia coli genes; Underlined genes, Saccharomyces cerevisiae genes; G6P, glucose-6-phosphate; F6P, fructose-6-phosphate; G3P, glyceraldehde-3-phosphate; PEP, phosphoenolpyruvate; Pyr, pyruvate; Ac-CoA, acetyl-CoA; TCA cycle, tricarboxylic acid cycle; Ru5P, ribulose-5-phosphate; X5P, xylulose-5-phosphate; R5P, ribose-5-phosphate; S7P, sedoheptulose-7-phosphate; E4P, D-erythrose 4-phosphate; DAHP, 3-deoxy-D-arabino-heptulosonate-7-phosphate; DHQ, 3-dehydroquinate; DHS, 3-dehydroshikimate; SA; shikimic acid; S3P,

shikimate-3-phosphate; EPSP, 5-enolpyruvylshikimate 3-phosphate; PP, phenylpyruvate; 4HPP, 4-hydroxyphenylpyruvate; L-Phe, L-phenylanine; L-Tyr, L-tyrosine; L-Trp, L-tryptophan. ptsHI, phosphocarrier protein HPr and PTS enzyme I genes; galP, galactose, $\mathrm{H}(+)$ symporter gene; glk, glucokinase gene; zwf, glucose-6-phosphate dehydrogenase gene; tkt, transketolase 1 gene; tal, transaldolase A gene; ppsA, phosphoenolpyruvate synthase; pykFA, pyruvate kinase I and II genes; aroF/aroG/aroH, 3-deoxy-D-arabino-heptulosonate-7-phosphate synthase genes; aroB, 3-dehydroquinate synthase gene; aroD, 3-dehydroquinate dehydratase gene; aroE, dehydroshikimate reductase gene; aroK/aroL, shikimate kinase genes; aroA, EPSP synthase gene; aroC, chorismate synthase gene; pheA/tyrA, chorismate mutase/prephenate dehydrogenase gene; tyrB, aromatic-amino-acid transaminase gene; trpD/trpE, anthranilate synthase gene; trpC, phosphoribosylanthranilate isomerase gene; trpA, indoleglycerol phosphate aldolase gene; trpB, tryptophan synthase gene; tnaB/mtr, tryptophan: $\mathrm{H}(+)$ symporter gene; aroP, aromatic amino acid: $\mathrm{H}(+)$ symporter gene; $y d d G$, aromatic amino acid exporter gene; $A R O 3 / A R O 4$, 3-deoxy-D-arabino-heptulosonate-7-phosphate synthase genes; $A R O 2$, chorismate synthase; $A R O 7$, chorismate mutase gene; TYR1, prephenate dehydrogenase gene; $A R O 8 / A R O 9$, aromatic acid aminotransferase gene; PHA2, prephenate dehydratase gene; TRP2/TRP3, anthranilate synthase gene; TRP4, anthranilate phosphoribosyl transferase gene; TRP1, $\mathrm{N}$-(5'-phosphoribosyl)-anthranilate isomerase gene; TRP3, indole-3-glycerol phosphate synthase gene; TRP5, tryptophan synthetase gene.

4HPP, or anthranilate, respectively, as precursors (Figure 1). The enzymes and regulations involved in the aromatic amino acid biosynthetic pathway have been well-studied and characterized. Cao et al. (2020) well-summarized the transcriptional regulation mechanism. Herein, we only outline the feedback inhibition mechanism in Escherichia coli and Saccharomyces cerevisiae (Figure 1). In E. coli, DAHP synthase, which is encoded by aroF, aroG, and $\operatorname{aroH}$ is feedback-inhibited by L-tyrosine (L-Tyr), Lphenylalanine (L-Phe), and L-tryptophan (L-Trp), respectively. Additionally, aroF, aroG, and aroH are negatively regulated by TyrR, a transcriptional regulatory protein. Chorismate mutase or prephenate dehydrogenase encoded by tyrA or pheA is also regulated through feedback inhibition by L-Tyr or L-Phe, respectively. DAHP synthase, 3-dehydroquinate (DHQ) synthase
(AroB), shikimate kinase (AroKL), 5-enolpyruvoylshikimate 3phosphate (EPSP) synthase (AroA), and choirmate synthase (AroC) are the rate-limiting enzymes in the shikimate pathway (Dell and Frost, 1993). In S. cerevisiae, DAHP synthase is encoded by $A R O 4$ and $A R O 3$, and regulated through feedback inhibition by L-Tyr and L-Phe. ARO1 is a pentafunctional enzyme that catalyzes steps 2 through 6 during the biosynthesis of chorismate.

With the developments of metabolic engineering and synthetic biology, significant advances have been made by engineering the shikimate pathway to produce natural or non-natural aromatic compounds at the gram level in microorganisms, especially in E. coli and S. cerevisiae (Averesch and Kromer, 2018; Wang J. et al., 2018; Wu et al., 2018; Huccetogullari et al., 2019). Here, we provide a comprehensive 


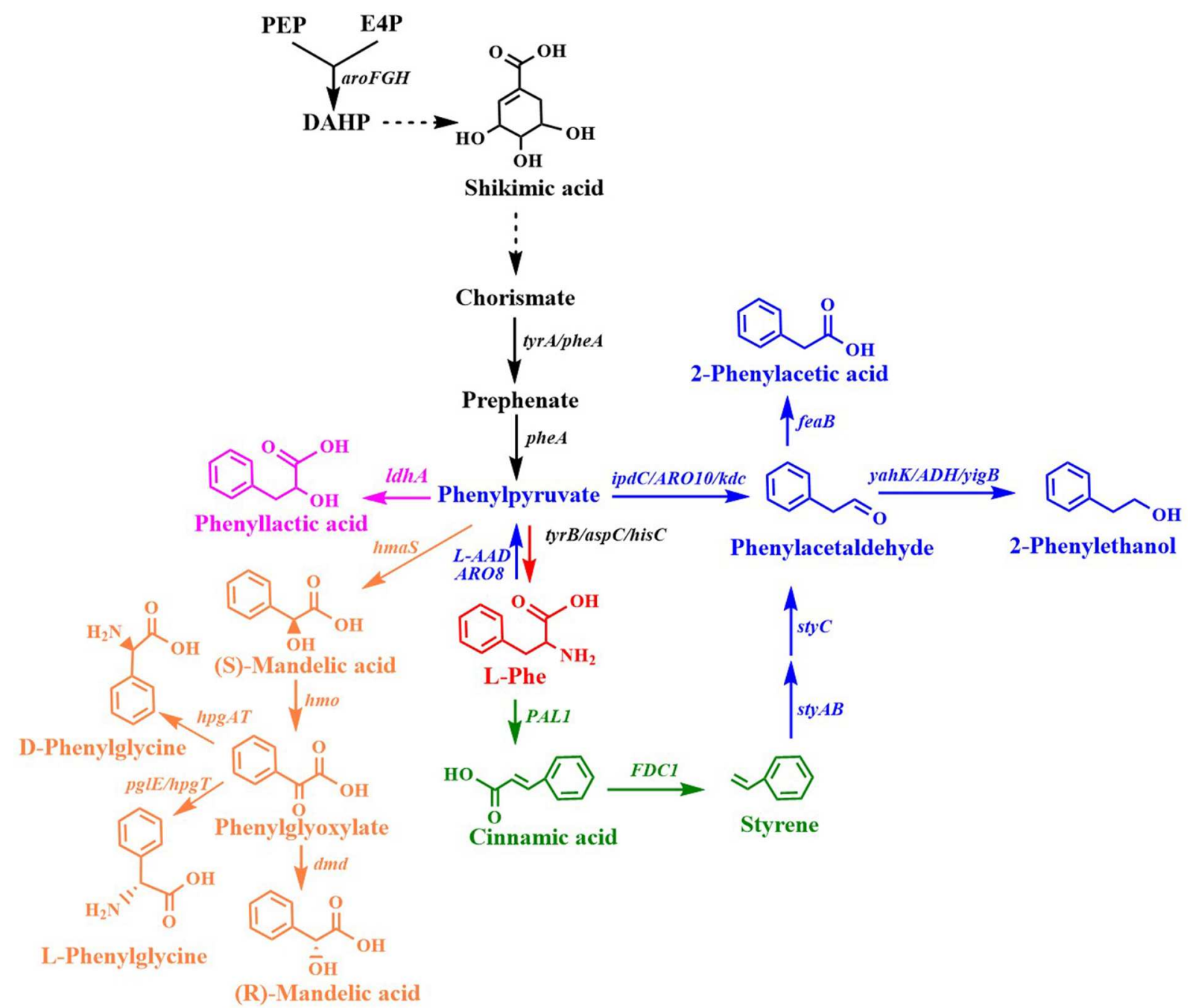

FIGURE 2 | Biosynthesis of L-phenylalanine derivatives. IdhA, lactate dehydrogenase gene; ipdC/ARO10/kdc, phenylpyruvate decarboxylase gene; yahK/ADH6/yigB/adh, aldehyde reductase; feaB, phenylacetaldehyde dehydrogenase gene; $L-A A D$, $L$-amino acid deaminase gene; $A R O 8$ : $P A L 1$, phenylalanine ammonia lyase gene; $F D C 1$, ferulic acid decarboxylase 1 gene; sty $A B$, styrene monooxygenase genes; styC, styrene oxide isomerase gene; hmaS, S-mandelate synthesis gene; $h m o, 1-4$-hydroxymandelate oxidase gene; hpgT, l-4-hydroxyphenylglycine transaminase gene; pglE, phenylglycine aminotransferase; $h p g A T$, D-(4-Hydroxy)phenylglycine aminotransferase gene; dmd, D-mandelate dehydrogenase gene.

and systematic overview of the recent advancements in metabolic engineering and synthetic biology used to achieve the microbial production of aromatic compounds derived from aromatic amino acids. These aromatic compounds include aromatic amino acid derivatives, stilbenes, and benzylisoquinoline alkaloids. More aromatic amino acid derivatives were reviewed in this study. Some groups gave some good reviews about the metabolic engineering strategies and the progress for the production of aromatic amino acid derivatives before 2019 (Averesch and Kromer, 2018; Huccetogullari et al., 2019; Cao et al., 2020). Overexpression of the feedback-resistant mutants and transketolase are the common strategies for engineering microorganisms to produce aromatic ammonic acids. These strategies will not be specially mentioned. To avoid repeating, we will focus on the production of aromatic compounds using metabolic engineering microorganisms.

\section{PRODUCTION OF AROMATIC AMINO ACID DERIVATIVES}

Aromatic amino acid derivatives are a class of important aromatic compounds derived from aromatic amino acids.

\section{Phenylalanine Derivatives}

Many aromatic chemicals can be derived from L-Phe or its precursor phenylpyruvate by a suitable biosynthetic pathway (Figure 2, Table 1). Phenylpyruvate derivatives, such as phenyllactic acid (PLA), 2-phenylethanol (2PE), 2-phenylacetic acid and mandelic acid, are synthesized using phenylpyruvate as a common precursor (Figure 2, Table 1). PLA is an antifungal compound. The replacement of the acs and mtlA with the Cupriavidus necator JCM20644 lactate dehydrogenase gene ldhA under the control of the T7 promoter in the L-Phe 
TABLE 1 | De novo production of phenylalanine derivatives by engineered microorganisms.

\begin{tabular}{|c|c|c|c|c|c|c|c|}
\hline Products & Host & Applications & Metabolic engineering strategies & Culture conditions & Titer & Yield & References \\
\hline L-Phenyllactic acid & Escherichia coli & Antifungal compound & 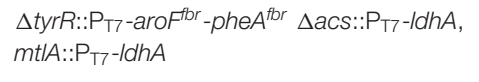 & Shake-flask fermentation & $6.4 \mathrm{mM}$ & & Koma et al., 2012 \\
\hline D- Phenyllactic acid & E. coli NST37 & & $\begin{array}{l}\text { Expressing Wickerhamia fluorescens ppr } \\
\text { on a plasmid (pHSG298), and } \\
\text { pheA } A^{\text {tbr }- \text { aro }} \text { ftor }^{\text {on another plasmid }}\end{array}$ & $\begin{array}{l}0.4 \mathrm{~L} \text { bioreactor } \\
\text { fed-batch fermentation }\end{array}$ & $29.2 \mathrm{~g} / \mathrm{L}$ & & Fujita et al., 2013 \\
\hline \multirow[t]{7}{*}{ 2-Phenylethnol } & E. coli & Flavor and fragrance & $\begin{array}{l}\Delta t y r R:: P_{\mathrm{T} 7}-a r o F^{\text {tbr }}-\text { phe } A^{\text {tbr }} \\
\Delta m t \mid A:: \mathrm{P}_{\mathrm{T} 7}-\mathrm{ipdC}, \Delta \text { acs:: } \mathrm{P}_{\mathrm{T} 7}-y a h K \Delta \text { feaB }\end{array}$ & Shake-flask fermentation & 7.7 mM (940.6 mg/L) & & Koma et al., 2012 \\
\hline & E. coli & & $\begin{array}{l}\text { Expressing the Plac promoter-controlled } \\
\text { phe } A^{\text {tbr }} \text {-aroF on a pCL } 1920 \text { plasmid. } \\
\text { Expressing adh1-kdc on a pBR322 origin } \\
\text { plasmid }\end{array}$ & Shake-flask fermentation & $285 \mathrm{mg} / \mathrm{L}$ & & Kang et al., 2014 \\
\hline & $\begin{array}{l}\text { E. coli ATCC } \\
31884 \text { (NST74) } \\
\text { (L-Phe } \\
\text { over-producer) }\end{array}$ & & $\begin{array}{l}\triangle f e a B \triangle C r r \triangle p y k F A \text {. Expressing } A . \\
\text { thaliana PAL2 and S. cerevisiae } F D C 1 \text { on a } \\
\text { p15A origin plasmid. Expressing P. putida } \\
\text { sty } A B C \text { on a ColA origin plasmid }\end{array}$ & Shake-flask fermentation & $1.94 \mathrm{~g} / \mathrm{L}$ & & Machas et al., 2017 \\
\hline & E. coli BL21 (DE) & & $\begin{array}{l}\text { Expressing L-amino acid deaminase and } \\
\alpha \text {-keto acid decarboxylase from Proteus } \\
\text { mirabilis JN458 on a pACYCDuet-1 } \\
\text { plasmid. Expressing alcohol } \\
\text { dehydrogenase from P. mirabilis JN458 and } \\
\text { glucose dehydrogenase from Bacillus } \\
\text { subtilis ATCC } 13952 \text { on a pACYCDuet-1 } \\
\text { plasmid }\end{array}$ & $\begin{array}{l}\text { Shake-flask } \\
\text { bioconversion }\end{array}$ & $2.88 \mathrm{~g} / \mathrm{L}$ from Phe & $97.38 \% \mathrm{~mol} / \mathrm{mol}$ & Liu J. B. et al., 2018 \\
\hline & E. coli BL21 (DE) & & $\begin{array}{l}\text { Expressing the T7 promoter-controlled } \\
\text { aroG }{ }^{\text {tbr }} \text { and pheA } A^{\text {tbr }} \text { on a pBBRMCS1 } \\
\text { plasmid. Expressing the T7 } \\
\text { promoter-controlled S. cerevisiae kdc, E. } \\
\text { coli yigB and S. cerevisiae ARO8 on a } \\
\text { pET28a plasmid }\end{array}$ & Shake-flask fermentation & $1016 \mathrm{mg} / \mathrm{L}$ & & Guo et al., 2018 \\
\hline & $\begin{array}{l}\text { Kluyveromyces } \\
\text { marxianus }\end{array}$ & & $\begin{array}{l}\text { An evolved } K \text {. marxianus strain resistant to } \\
\text { the phenylalanine analog, } \\
\text { p-fluorophenylalanine. Plasmid-expressing } \\
\text { S. cerevisiae } A R O 10 \text { and } A D H 2 \text {. } \\
\text { Plasmid-expressing } K \text {. marxianus aroG } G^{\text {fbr }}\end{array}$ & Shake-flask fermentation & $1.3 \mathrm{~g} / \mathrm{L}$ & & Kim et al., 2014 \\
\hline & $\begin{array}{l}\text { Saccharomyces } \\
\text { cerevisiae }\end{array}$ & & $\begin{array}{l}\triangle A L D 3 \text {. Expressing } A R O 80 \text { on a } \\
\text { pRS424ADH plasmid. Expressing } A R O 9 \text { on } \\
\text { a pRS425ADH plasmid and } A R O 10 \text { on a } \\
\text { pRS426ADH plasmid }\end{array}$ & $\begin{array}{l}\text { Two-phase Shake-flask } \\
\text { fermentation }\end{array}$ & $6.1 \mathrm{~g} / \mathrm{L}$ & $82.5 \% \mathrm{~mol} / \mathrm{mol}$ & Kim B. et al., 2014 \\
\hline 2-Phenylacetic acid & E. coli & $\begin{array}{l}\text { Precursor for the } \\
\text { chemical synthesis of } \\
\text { penicillin } \mathrm{G} \text {, the atenolol } \\
\text { drug, agrochemicals }\end{array}$ & 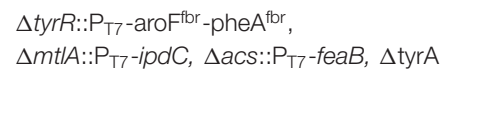 & Shake-flask fermentation & $8.8 \mathrm{mM}(1198.1 \mathrm{mg} / \mathrm{L})$ & & Koma et al., 2012 \\
\hline
\end{tabular}


TABLE 1 | Continued

\begin{tabular}{|c|c|c|c|c|c|c|c|}
\hline Products & Host & Applications & Metabolic engineering strategies & Culture conditions & Titer & Yield & References \\
\hline \multirow[t]{2}{*}{ S-Mandelic acid } & E. coli & $\begin{array}{l}\text { Precursor for the } \\
\text { synthesis of penicillins, } \\
\text { cephalosporins, } \\
\text { anti-obesity agents, } \\
\text { and pharmaceuticals } \\
\text { with anti-HIV or } \\
\text { anti-leukemic activities }\end{array}$ & $\begin{array}{l}\Delta \text { tyrB } \triangle a s p C \Delta \text { tyrA } \Delta \text { trpE. Expressing the } \\
\text { tac promoter-controlled phe } A^{\text {tbr }} \text { and } \\
\text { S-mandelate synthesis gene } h m a S \text { from } \\
\text { Amycolatopsis orientalis, and aroF } \\
\text { promoter-controlled arof } F^{\text {fbr }} \text { on a plasmid }\end{array}$ & Shake-flask fermentation & $1.02 \mathrm{~g} / \mathrm{L}$ & & Sun et al., 2011 \\
\hline & E. coli-E. coli & & $\begin{array}{l}\text { (S)-Mandelic acid producer L37: } \\
\text { Expressing Aspergillus niger pad1, A. } \\
\text { thaliana PAL2, styrene monooxygenase } \\
\text { gene (SMO) from Pseudomonassp. } \\
\text { VLB120, epoxide hydrolase gene (SpEH) } \\
\text { from Sphingomonas sp. HXN-200, alcohol } \\
\text { dehydrogenase gene (AlkJ) from P. } \\
\text { putida GPo1, phenylacetaldehyde } \\
\text { dehydrogenase gene (aldh) from E. coli. } \\
\text { L-Phe producing strain: NST74 }\end{array}$ & $\begin{array}{l}\text { Coculture whole-well } \\
\text { biocatalysis }\end{array}$ & $10 \mathrm{~g} / \mathrm{L}$ from glycerol & & Lukito et al., 2019 \\
\hline R-Mandelic acid & E. coli & & $\begin{array}{l}\Delta t y r B \Delta a s p C \triangle t y r A \Delta t r p E \text {. Expressing tac } \\
\text { promoter-controlled pheA } A^{\text {tbr }} \text { and } \\
\text { S-mandelate synthesis gene } h m a S \text { from } A \text {. } \\
\text { orientalis, trc promoter-controlled } \\
\text { 4-hydroxymandelate oxidase gene } h m o \\
\text { from Streptomyces coelicolor and } \\
\text { D-mandelate dehydrogenase gene dma } \\
\text { from Rhodotorula graminis, and aroF } \\
\text { promoter-controlled arof } F^{\text {tbr }} \text { on a p15A } \\
\text { origin plasmid (pSU2718) }\end{array}$ & Shake-flask fermentation & $0.88 \mathrm{~g} / \mathrm{L}$ & & Sun et al., 2011 \\
\hline Mandelic acid & S. cerevisiae & & 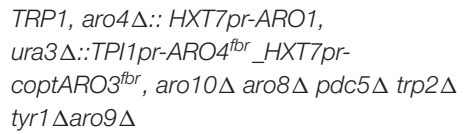 & Shake-flask fermentation & $236 \mathrm{mg} / \mathrm{L}$ & $1.7 \% \mathrm{~g} / \mathrm{g}$ & $\begin{array}{l}\text { Reifenrath and Boles, } \\
2018\end{array}$ \\
\hline \multirow[t]{2}{*}{$\begin{array}{l}\text { trans-Cinnamic } \\
\text { acid }\end{array}$} & E. coli W3110 & $\begin{array}{l}\text { Flavoring agent and } \\
\text { anti-bacterial } \\
\text { compound as well as a } \\
\text { precursor of chemicals }\end{array}$ & $\begin{array}{l}\Delta c r r \Delta t y r R \Delta \text { trpE } \Delta \text { tyrA } \Delta p y k A \text {. Expressing } \\
\text { Streptomyces maritimus pal on pTrc99A } \\
\text { plasmid. Expressing the } P_{\text {tac }} \text {-controlled } \\
\text { aroG8/15-ydiB-aroK-pheA } A^{\text {tbr }} \text {, the } P_{p c 113} \\
\text { promoter-controlled glk and the } \mathrm{P}_{\mathrm{pc} 113} \\
\text { promoter-controlled galP on a p15A origin } \\
\text { plasmid }\end{array}$ & Fed-batch fermentation & $6.9 \mathrm{~g} / \mathrm{L}$ & & Bang et al., 2018 \\
\hline & $\begin{array}{l}\text { S. cerevisiae } \\
\text { CEN.PK113-7D }\end{array}$ & & $\begin{array}{l}\text { aro10 } \Delta:: / O X P, \text { aro } 7 \Delta:: A R O 4^{K 229 L}, \\
\text { aro } 4 \Delta:: A R O 7^{\text {G141S. }} \text {. Expressing the } \\
\text { codon-optimized pal from Photorhabdus } \\
\text { luminescens on high copy plasmid }\end{array}$ & Shake-flask fermentation & $37.9 \mathrm{mg} / \mathrm{L}$ & & Gottardi et al., 2017 \\
\hline
\end{tabular}


TABLE 1 | Continued

\begin{tabular}{|c|c|c|c|c|c|c|c|}
\hline Products & Host & Applications & Metabolic engineering strategies & Culture conditions & Titer & Yield & References \\
\hline \multirow[t]{5}{*}{ Styrene } & $\begin{array}{l}\text { E. coli ATCC } \\
31884 \text { (NST 74), } \\
\text { L-Phe } \\
\text { overproducing } \\
\text { strain }\end{array}$ & Synthesizing polymers & $\begin{array}{l}\text { Expression PAL2 from A. thaliana on a } \\
\text { pACYC184 origin plasmid. Expressing } \\
\text { FDC1 from S. cerevisiae on a pBR322 } \\
\text { origin plasmid }\end{array}$ & Shake-flask fermentation & $260 \mathrm{mg} / \mathrm{L}$ & & $\begin{array}{l}\text { McKenna and Nielsen, } \\
2011\end{array}$ \\
\hline & $\begin{array}{l}\text { E. coli ATCC } \\
31884 \text { (NST 74) }\end{array}$ & & $\begin{array}{l}\text { Expression pal1 from } A \text {. thaliana on a } \\
\text { pACYC184 origin plasmid. Expressing } \\
\text { FDC1 from S. cerevisiae on a pBR322 } \\
\text { origin plasmid }\end{array}$ & $\begin{array}{l}\text { Solvent extraction } \\
\text { shake-flask fermentation }\end{array}$ & 836 mg/L & & McKenna et al., 2015 \\
\hline & E. coli BL (DE3) & & $\begin{array}{l}\text { Expression pal1 from } A \text {. thaliana, FDC1 } \\
\text { from } S \text {. cerevisiae, native ppsA and tktA on } \\
\text { a pBR322 origin plasmid. Expressing native } \\
\text { aroF and pheA on a p15A origin plasmid }\end{array}$ & $\begin{array}{l}\text { Solvent extraction } \\
\text { shake-flask fermentation }\end{array}$ & 350 mg/L & & Liu C. Q. et al., 2018 \\
\hline & E. coli 3110 & & 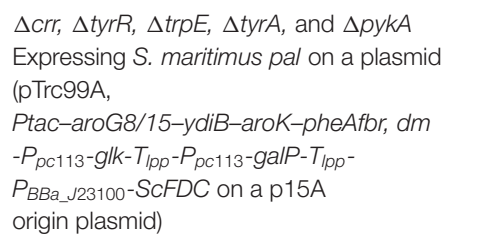 & $\begin{array}{l}5 \mathrm{~L} \text { fed-batch } \\
\text { fermentation using in situ } \\
\text { extraction and gas } \\
\text { stripping with } \\
\mathrm{n} \text {-dodecane }\end{array}$ & $5.3 \mathrm{~g} / \mathrm{L}$ & & Lee et al., 2019 \\
\hline & E. coli NST74 & & $\begin{array}{l}\text { Chromosomal expressing PAL2 from A. } \\
\text { thaliana and FDC1 from S. cerevisiae. } \\
\text { iCREATE strategy for } 54 \text { transcription } \\
\text { regulator }\end{array}$ & $\begin{array}{l}\text { 1-L bioreactor fed-batch } \\
\text { fermentation using gas } \\
\text { stripping strategy with } \\
\text { n-dodecane }\end{array}$ & $3.15 \mathrm{~g} / \mathrm{L}$ & & Liang et al., 2020 \\
\hline L-Phenylglycine & E. coli & $\begin{array}{l}\text { Synthesizing } \beta \text {-lactam } \\
\text { antibiotics and taxol }\end{array}$ & $\begin{array}{l}\Delta t y r B, \Delta a s p C \text { Expressing } S \text {. coelicolor } \\
h m a S, h m o \text { and } h p g T, \text { aroG } G^{\text {fbr }}, \text { pheA } \\
\text { aroK, }\end{array}$ & Shake-flask fermentation & $51.6 \mathrm{mg} / \mathrm{g} \mathrm{DCW}$ & & Liu et al., 2014 \\
\hline D- Phenylglycine & E. coli & & $\begin{array}{l}\Delta \text { pheA, } \Delta \text { tyrA, arof } \mathrm{F}^{\mathrm{tbr}}, \Delta \mathrm{tyrR}, \\
\Delta t y r B, \Delta a s p C \text { Expressing A. orientalis } \\
\text { hmaS, S. coelicolor hmo, Pseudomonas } \\
\text { putida hpgT and pheA } A^{\text {tbr }} \text { on a plasmid }\end{array}$ & Shake-flask fermentation & 102 mg/g DCW & & Muller et al., 2006 \\
\hline
\end{tabular}


producing E. coli strain resulted in the production of $6.4 \mathrm{mM}$ of L-PLA from glucose in shake flask cultures (Koma et al., 2012). Overexpression of Wickerhamia fluorescens phenylpyruvate reductase gene $(p p r)$, native feedback-resistant aro $G^{f b r}$ and $p h e A^{f b r}$ in the L-Phe producing strain E. coli NST37 resulted in the production of $29.2 \mathrm{~g} / \mathrm{L}$ of D-PLA from glucose in $0.4 \mathrm{~L}$ bioreactor fed-batch fermentations (Fujita et al., 2013). They also found that the replacement of $W$. fluorescens $p p r$ with lactate dehydrogenase gene $(L-l d h)$ from Pediococcus acidilactici generated L-PLA. Recently, whole-cell biocatalysis has been successfully used to produce L-PLA from L-Phe or phenylpyruvate. An E. coli expressing Lactobacillus plantarum lactate dehydrogenase gene $(L-l d h)$, Proteus mirabilis L-amino acid deaminase gene (L-aad), and Candida boidinii formate dehydrogenase gene $(f d h)$ was constructed for the production of L-PLA by using whole-cell biocatalysis (Hou et al., 2019). The resulting strain produced $54.0 \mathrm{~g} / \mathrm{L}$ of L-PLA from L-Phe with the aid of glucose, which was used as a co-substrate for cofactor regeneration.

2PE, which has high-value as flavor and fragrance compound, has a wide range of applications in the cosmetic, perfumery, and food industries. The indol-3-pyruvate/phenylpyruvate decarboxylase gene ipdC from Azospirillum brasilense NBRC102289 was introduced into a Phe overproducing $E$. coli strain, resulting in the production of 2PE (Figure 2) (Koma et al., 2012). The chromosomal overexpression of $A$. brasilense $i p d C$ and $E$. coli $y a h K$, and the deletion of $f e a B$ resulted in the production of $7.7 \mathrm{mM}(940.6 \mathrm{mg} / \mathrm{L})$ of $2 \mathrm{PE}$ from glucose in shake flask cultures (Koma et al., 2012). The overexpression of the phenylpyruvate decarboxylase gene $k d c$ from Pichia pastoris GS115 and alcohol dehydrogenase (ADH) gene adh1 from $S$. cerevisiae S288c in E. coli resulted in the production of 2PE (Kang et al., 2014). The co-overexpression of the four genes $k d c$, adh1, phe $A^{f b r}$, and aroF improved $2 \mathrm{PE}$ production to $285 \mathrm{mg} / \mathrm{L}$ from glucose in shake flask cultures. A novel route (styrene-derived pathway) has been established for 2PE production in E. coli (Machas et al., 2017). The styrene-derived pathway comprised PAL2 from Arabidopsis thaliana, FDC1 from S. cerevisiae, and sty $A B C$ from Pseudomonas putida S12. The introduction of the styrene-derived pathway, as well as the deletion of the competing pathways ( $f e a B, c r r$, and $p f k F A$ ) resulted in the production of $1.94 \mathrm{~g} / \mathrm{L}$ of $2 \mathrm{PE}$ from glucose in shake flask cultures. The results also demonstrated that the styrene-derived pathway more efficiently produced $2 \mathrm{PE}$ than the Ehrlich pathway. The pathway for 2PE production, which involves L-amino acid deaminase, $\alpha$-keto acid decarboxylase, and $\mathrm{ADH}$, was mimicked from the 2PE natural producer P. mirabilis JN458 (Liu J. B. et al., 2018). The recombinant $E$. coli harboring this $P$. mirabilis pathway produced $2.88 \mathrm{~g} / \mathrm{L} 2 \mathrm{PE}$ from Phe with a molar yield of $97.38 \%$. The plasmid-based overexpression of $S$. cerevisiae $k d c, E$. coli $y i g B$, and $S$. cerevisiae aro8, as well as the enhancement of the expression of the feedback-resistant aroG $G^{f b r}$ and $p h e A^{f b r}$ in E. coli resulted in the production of $1,016 \mathrm{mg} / \mathrm{L} 2 \mathrm{PE}$ from glucose (Guo et al., 2018). After the introduction of alcohol acetyltransferase gene ATF1 from $S$. cerevisiae into the $2 \mathrm{PE}$ producer, 2-phenylethyl acetate was produced and achieved 687 $\mathrm{mg} / \mathrm{L}$. Kiuyveromyces marxianus, S. cerevisiae, and P. pastoris are typical yeast systems that have been engineered to synthesize 2PE. The phenylpyruvate decarboxylase (ARO10) and $\mathrm{ADH}$ $(\mathrm{ADH} 2)$ genes of $S$. cerevisiae were expressed in an evolved $K$. marxianus that was resistant to the phenylalanine analog, p-fluorophenylalanine, which resulted in $2 \mathrm{PE}$ production (Kim et al., 2014). The overexpression of the feedback-resistant aro $G^{f b r}$ from $K$. marxianus further increased the production of $2 \mathrm{PE}$ from glucose to $1.3 \mathrm{~g} / \mathrm{L}$. In $S$. cerevisiae, the overexpression of $A R O 9, A R O 10$, and $A R O 80$ (the latter is a transcription activator of $A R O 9$ and $A R O 10$ ), and the deletion of ALD3 improved 2PE production (Kim B. et al., 2014). After optimizing the fermentation conditions, the engineered $S$. cerevisiae produced $6.1 \mathrm{~g} / \mathrm{L}$ of $2 \mathrm{PE}$ from glucose with a molar yield of $82.5 \%$. ARO8, which encodes aromatic aminotransferase I, was identified to be a transcriptional regulator of ARO10 (Romagnoli et al., 2015). The deletion of ARO8 improved 2PE production in S. cerevisiae (Romagnoli et al., 2015). P. pastoris, a type of the methylotrophic yeast, can rapidly grow to extremely high cell densities in very simple and defined media. $P$. pastoris can naturally synthesize low levels of 2PE. Overexpression of the biosynthetic pathway of 2PE from S. cerevisiae (ARO10-ADH6) in P. pastoris enhanced the $2 \mathrm{PE}$ titer to $416 \mathrm{mg} / \mathrm{L}$ from $26 \mathrm{mg} / \mathrm{L}$ (Kong et al., 2020). Increasing the availability of the precursor of phenylpyruvate furtherly improved the $2 \mathrm{PE}$ titer to $1,169 \mathrm{mg} / \mathrm{L}$ by overexpressing S. cerevisiae ARO8, E. coli aro $G^{f b r}$ and $p h e A^{f b r}$.

2-Phenylacetic acid and 4-hydroxyphenylacetic acid (4HPAA) are intermediates in the chemical synthesis of penicillin G, atenolol, agrochemicals, and other compounds. The production of 2-phenylacetic acid was achieved by the overexpression of endogenous $f e a B$ and $i p d C$ from $A$. brasilense NBRC102289 in E. coli using the Ehrlich pathway intermediates phenylacetaldehyde as precursors (Figure 2) (Koma et al., 2012). The overexpression of $A$. brasilense ipdC and $E$. coli feaB, as well as the deletion of tyrA in the Phe overproducing E. coli strain resulted in the de novo production of $8.8 \mathrm{mM}(1,198.1 \mathrm{mg} / \mathrm{L})$ of 2-phenylacetic acid in shake flask cultures (Koma et al., 2012).

Mandelic acid and 4-hydroxymandelic acid (4HMA) are valuable aromatic fine chemicals used as precursors for the production of pharmaceuticals, flavors, and cosmetics. Mandelic acid has been widely used in the synthesis of semisynthetic penicillins, cephalosporins, anti-obesity agents, and pharmaceuticals with anti-HIV or anti-leukemic activities, as well as for the resolution of racemic alcohols and amines (Reifenrath and Boles, 2018). The biosynthetic pathway for mandelic acid production has been successfully established in E. coli (Sun et al., 2011) and S. cerevisiae (Reifenrath and Boles, 2018). The biosynthetic pathway for mandelic acid (Figure 2) was first established in E. coli by introducing the Smandelate synthesis gene hmaS from Amycolatopsis orientalis (Sun et al., 2011). The overexpression of hmaS from $A$. orientalis and the feedback-resistant $p h e A^{f b r}$ and $a r o F^{f b r}$, along with the deletion of the competing pathways resulted in the de novo production of $1.02 \mathrm{~g} / \mathrm{L}$ of $\mathrm{S}$-mandelic acid in shake flask cultures. The co-expression of the 4-hydroxymandelate oxidase gene hmo from Streptomyces coelicolor and D-mandelate dehydrogenase gene dmd from Rhodotorula graminis in the aforementioned S-mandelic acid producing strain led to the de 
novo production of $0.88 \mathrm{~g} / \mathrm{L}$ of $\mathbf{R}$-mandelic acid in shake flask cultures. S-Mandelate synthase HmaS from A. orientalis can convert 4-hydroxyphenylpyruvate (4HPP) to $4 \mathrm{HMA}$, but also phenylpyruvate to mandelic acid in E. coli (Sun et al., 2011; Li et al., 2016). It was also found that the introduction of codonoptimized hmaS from $A$. orientalis in $S$. cerevisiae produced mandelic acid (Reifenrath and Boles, 2018). Mandelic acid production was increased by the replacement of hmaS from $A$. orientalis with the corresponding gene from Nocardia uniformis. The strategies used for the enhancement of the expression of the aromatic amino acid pathway as well as the deletion of the competing pathways were used to improve the production of mandelic acid. The resulting strain produced $236 \mathrm{mg} / \mathrm{L}$ mandelic acid with a mass yield of $1.7 \%$ in shake flask cultures (Reifenrath and Boles, 2018). Lukito et al. (2019) developed a whole cellbased cascade biotransformation for the production of (S)mandelic acid from styrene, L-Phe, glucose, or glycerol. The recombinant $E$. coli strain LZ37 expressing the 6-step enzyme cascades produced $160 \mathrm{mM}(\mathrm{S})$-mandelic acid from L-Phe with a yield of $80 \%$. Coupling the E. coli strain LZ37 with the L-Phe producing $E$. coli strain NST74 enabled the de novo production of $63 \mathrm{mM}(10 \mathrm{~g} / \mathrm{L})$ or $52 \mathrm{mM}(8 \mathrm{~g} / \mathrm{L})(\mathrm{S})$-mandelic acid from glycerol and glucose, respectively.

Cinnamic acid is used as a flavoring agent and antibacterial compound. The overexpression of Streptomyces maritimus Lphenylalanine ammonia lyase gene pal in an E. coli strain overproducing L-Phe resulted in the production of $6.9 \mathrm{~g} / \mathrm{L}$ of trans-cinnamic acid in a fed-batch fermentation process (Figure 2) (Bang et al., 2018). It was demonstrated that the bacterial phenylalanine ammonia lyase from Photorhabdus luminescens was superior to the plant enzyme from $A$. thaliana for the production of trans-cinnamic acid in yeast (Gottardi et al., 2017). After optimizing the biosynthetic pathway, the overexpression of $A R O 4^{K 229 L}, A R O 7^{G 141 S}$, and codon-optimized pal from P. luminescens, and deletion of ARO10 in S. cerevisiae CEN.PK113-7D resulted in the production of $37.9 \mathrm{mg} / \mathrm{L}$ of transcinnamic acid (Gottardi et al., 2017).

Styrene and its derivatives act as monomers and petroleumbased feedstocks, which is valuable because they can be used as raw materials in industrial processes. They have many uses, including in the manufacture of polystyrenes, plastics, and styrene-butadiene. Styrene can be synthesized from glucose by the co-expression of phenylalanine ammonia lyase and trans-cinnamate decarboxylase (Figure 2). Mckenna and Nielsen screened candidate isoenzymes for the two steps from bacterial, yeast, and plant (McKenna and Nielsen, 2011). Finally, the overexpression of PAL2 from A. thaliana and FDC1 from S. cerevisiae in an L-Phe overproducing $E$. coli strain led to the accumulation of $260 \mathrm{mg} / \mathrm{L}$ of styrene in shake flask cultures. To avoid the effects of the toxicity of styrene, solvent extraction fermentation was used to improve the amount of styrene produced, which achieved $836 \mathrm{mg} / \mathrm{L}$ (McKenna et al., 2015). A similar strategy was also used for achieving styrene production in $E$. coli $\mathrm{BL}$ (DE3), which yielded $350 \mathrm{mg} / \mathrm{L}$ of styrene in an extraction fermentation process using isopropyl myristate (Liu C. Q. et al., 2018). This titer was achieved by the overexpression of PAL2 from A. thaliana, FDC1 from S. cerevisiae, native $p p s A$,
tktA, aroF, and pheA, using a two-plasmid system. An L-Phe overproducing $E$. coli strain overexpressing $S$. maritimus pal and FDC1 from $S$. cerevisiae was engineered for the production of styrene (Lee et al., 2019). The resulting strain produced $5.3 \mathrm{~g} / \mathrm{L}$ of styrene in a 5 - $\mathrm{L}$ fed-batch fermentation process using in situ extraction and gas stripping with n-dodecane. The styrene synthetic pathway containing PAL2 from A. thaliana and FDC1 from $S$. cerevisiae was integrated into the SS9 site of an L-Phe overproducing strain E. coli NST 74 to obtain a styrene producing strain (Liang et al., 2020). After optimization of the expression levels of the two genes PAL2 and FDC1, iCREATE strategy for 54 transcription regulator genes was used to improve styrene-tolerance and the production of styrene. The resulting strain produced $3.15 \mathrm{~g} / \mathrm{L}$ in a $1-\mathrm{L}$ bioreactor fedbatch fermentation using gas stripping strategy with n-dodecane. Although S. cerevisiae (McKenna et al., 2014) and S. lividans (Fujiwara et al., 2016b) have been used as host strains for styrene production, the titer (about $30 \mathrm{mg} / \mathrm{L}$ ) is much lower than that obtained using engineered E. coli.

Phenylglycine, as one of the unnatural amino acids, has been widely used in the synthesis of penicillin, virginiamycin $\mathrm{S}$, pristinamycin I, and the antitumor compound taxol (Liu et al., 2014). Phenylglycine is synthesized from phenylpyruvate via phenylglyoxylate (Figure 2). An artificial biosynthetic pathway, which consists of HmaS (1-4-hydroxymandelate synthase), Hmo (1-4-hydroxymandelate oxidase), and HpgT (1-4-hydroxyphenylglycine transaminase) from $S$. coelicolor, was constructed for the production of L-phenylglycine in E. coli (Liu et al., 2014). Deletions of both $\operatorname{tyrB}$ and $\operatorname{aspC}$ as well as increasing the copies of both $h m o$ and $h p g T$ further increased the production of L-phenylglycine to $51.6 \mathrm{mg} / \mathrm{gDCW}$ (Liu et al., 2014). A novel L-phenylglycine biosynthetic pathway via the PglE reaction was reported in Streptomyces pristinaespiralis (Osipenkov et al., 2018). Zhou et al. (2016) constructed an artificial eight-step biosynthetic pathway containing 10 different enzymes for the production of L-phenylglycine from L-Phe. E. coli expressing the pathway produced $34 \mathrm{mM}(5.1 \mathrm{~g} / \mathrm{L})$ L-phenylglycine with a yield of $85 \%$ from L-Phe. An artificial biosynthetic pathway was created for the production of Dphenylglycine in E. coli (Muller et al., 2006). The pathway consists of HmaS from A. orientalis, Hmo from S. coelicolor, and HpgAT from $P$. putida. This pathway was introduced into the L-Phe producing E. coli strain KB532 for the de novo production of $\mathrm{D}$-phenylglycine. The deletion of both $\operatorname{tyr} B$ and $a s p C$ further improved the production of D-phenylglycine, which reached 102 mg/g DCW (Muller et al., 2006). Zhou Y. et al. (2017) created a biosynthetic pathway for the production of $\mathrm{D}$-phenylglycine from mandelic acid, styrene, or L-Phe. The biosynthetic pathway has eight steps catalyzed by nine enzymes: A. thaliana PAL2, Aspergillus niger phenylacrylic acid decarboxylase (PAD1), styrene monooxygenase (SMO) from Pseudomonas sp. VLB120, epoxide hydrolase (SpEH) from Sphingomonas sp. HXN-200, alcohol dehydrogenase gene (AlKJ) from P. putida GPo1, phenylacetaldehyde dehydrogenase (Aldh) from E. coli, (S)mandelate dehydrogenase (SMDH) from P. putida ATCC 12633, D-phenylglycine aminotransferase (DpgAT) from Pseudomonas stutzeri ST-201 and glutamate dehydrogenase (GluDH) from $E$. 


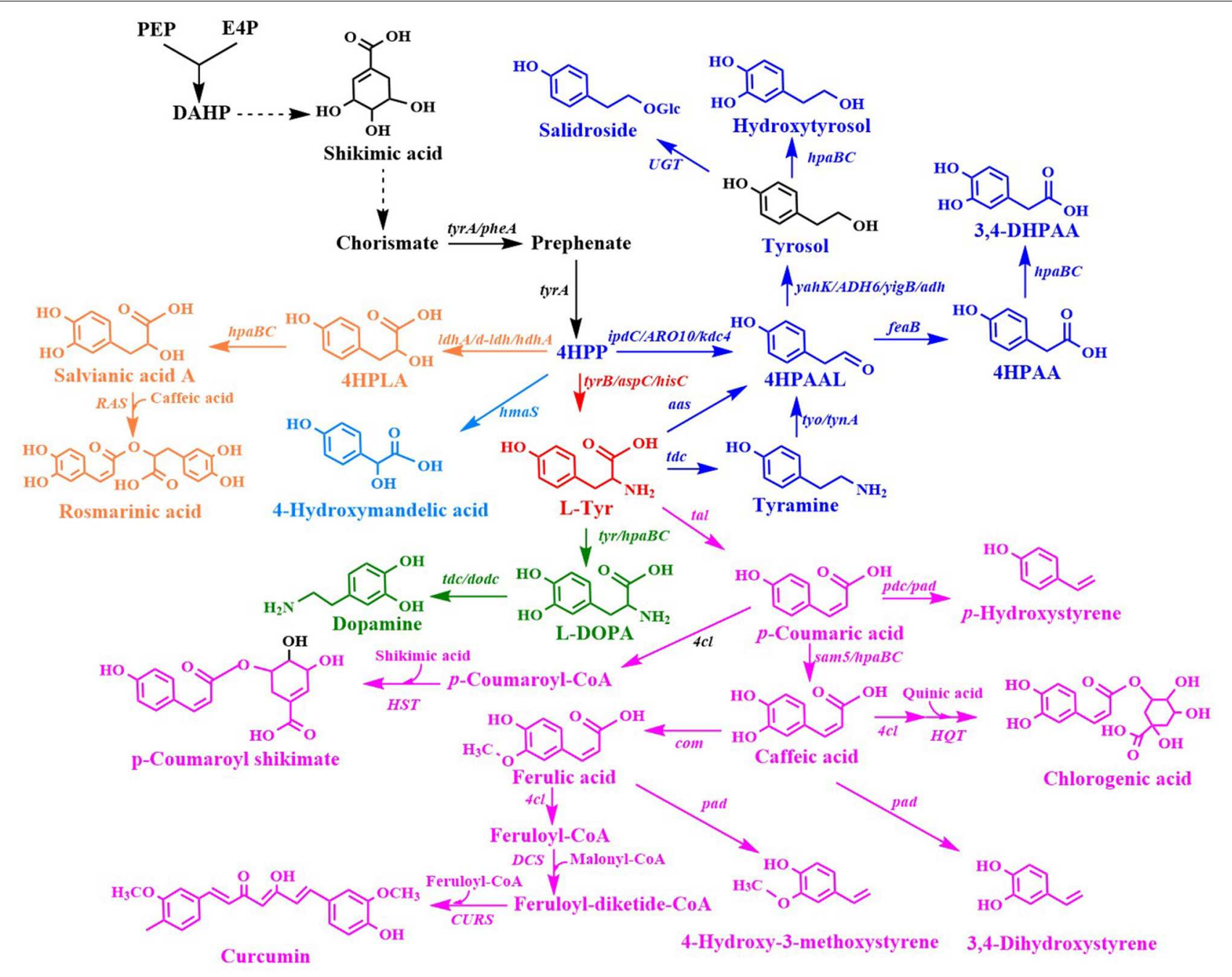

FIGURE 3 | Biosynthesis of L-tyrosine derivatives. 4HPLA, 4-hydroxyphenyllactic acid; 4HPAAL, 4-hydroxyphenylacetaldehyde; 4HPAA, 4-hydroxyphenylacetic acid; $I d h A / d-l d h$, D-lactate dehydrogenase gene; $h d h A, 2$-hydroxyacid dehydrogenase gene; hpaBC, $p$-hydroxyphenylacetate 3-hydroxylase genes; ipdC/ARO10/kdc, phenylpyruvate decarboxylase gene; yahK/ADH6, alcohol dehydrogenase gene; UGT, uridine diphosphate dependent glycosyltransferase gene; aas, aromatic aldehyde synthase gene; RAS, rosmarinic acid synthase gene; tyr, tyrosinase gene; tdc, tyrosine decarboxylase gene; tyo/tynA, tyramine oxidase gene; tal, tyrosine ammonia lyase gene; dodc, L-DOPA decarboxylase; pdc, p-coumaric acid decarboxylase gene; 4cl, 4-coumaroyl-coenzyme A ligases gene; sam5, 4-coumarate hydroxylase gene; com, caffeic acid methyltransferase gene; HQT, hydroxycinnamate-CoA quinate transferase gene; HST, hydroxycinnamate-CoA shikimate transferase gene; pad, phenolic acid decarboxylase gene; CURS, curcumin synthase gene.

coli. E. coli expressing the nine enzymes of the eight-step pathway produced $50 \mathrm{mM}$ D-phenylglycine from $60 \mathrm{mM}$ L-Phe with a yield of $83 \%$ using whole-cell catalysis (Zhou Y. et al., 2017).

\section{Tyrosine Derivatives}

L-Tyr derivatives were synthesized from 4hydroxyphenylpyruvate (4HPP) and L-Tyr (Figure 3). Many L-Tyr derivatives were also used as a precursor for the production of a wide range of valuable aromatic compounds with pharmaceutical value (Table 2).

4HMA serves as a building block for the synthesis of aromatic drugs and flavors. The biosynthetic pathway for 4HMA production has been successfully established in E. coli and $S$. cerevisiae (Li et al., 2016; Reifenrath and Boles, 2018). The overexpression of the codon-optimized hmaS from A. orientalis in the tyrosine-producing strain, E. coli BKT5, resulted in the formation of 4HMA (Figure 3) (Li et al., 2016). After optimizing the expression of hmaS by fine-tuning four promoters of different strengths which were combined with three plasmids with different copy numbers, and blocking the competing pathway by deleting tyrB and aspC, 4HMA production was improved. The resulting strain produced $15.8 \mathrm{~g} / \mathrm{L}$ 4HMA from a mixture of glucose and xylose in a 5-L bioreactor fed-batch fermentation process. It was also found that the introduction of the codonoptimized hmaS from A. orientalis in S. cerevisiae produced 4HMA (Reifenrath and Boles, 2018). The production of 4HMA was increased by the replacement of hmaS from A. orientalis with the corresponding gene from $N$. uniformis. The strategies used for 
TABLE 2 | De novo production of tyrosine derivatives by engineered microorganisms.

\begin{tabular}{|c|c|c|c|c|c|c|c|}
\hline Products & Host & Applications & Metabolic engineering strategies & Culture conditions & Titer & Yield & References \\
\hline \multirow[t]{2}{*}{$\begin{array}{l}\text { 4-Hydroxymandelic } \\
\text { acid }\end{array}$} & E. coli & $\begin{array}{l}\text { Synthesizing aromatic } \\
\text { drug and flavors }\end{array}$ & $\begin{array}{l}\Delta p t s G, \Delta t y r R, \triangle p y k F A, \Delta p h e A, \Delta t y r B, \\
\Delta a s p C, \text { overexpression of lacUV5 } \\
\text { promoter-controlled aro } G^{f b r} \text {-tyr } A^{\text {tbr }} \text {-aroE and } \\
\text { trc promoter controlled ppsA-tktA-glk on a } \\
\text { pMB1 origin plasmid, overexpression of trc } \\
\text { promoter-controlled } h m o \text { from S. coelicolor on } \\
\text { a CloDF13 origin plasmid }\end{array}$ & $\begin{array}{l}\text { 5-L bioreactor fed-batch } \\
\text { fermentation }\end{array}$ & $\begin{array}{l}15.8 \mathrm{~g} / \mathrm{L} \text { from glucose } \\
\text { and xylose }\end{array}$ & & Li et al., 2016 \\
\hline & S. cerevisiae & & 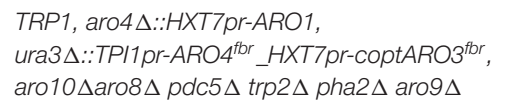 & Shake-flask fermentation & $1 \mathrm{~g} / \mathrm{L}$ & $6.4 \% \mathrm{~g} / \mathrm{g}$ & $\begin{array}{l}\text { Reifenrath and Boles, } \\
2018\end{array}$ \\
\hline $\begin{array}{l}\text { 4- } \\
\text { Hydroxyphenyllactic } \\
\text { acid }\end{array}$ & E. coli & Antifungal compound & $\Delta t y r R:: \mathrm{PT}_{\mathrm{T} 7}-a r 0 F^{f b r}$-tyra ${ }^{f b r} \Delta a c s:: \mathrm{P}_{\mathrm{T} 7}-l d h A$ & Shake-flask fermentation & $7.6 \mathrm{mM}$ & & Koma et al., 2012 \\
\hline Salvianic acid A & E. coli & $\begin{array}{l}\text { Antioxidant, } \\
\text { anti-cancer, } \\
\text { anti-inflammatory, and } \\
\text { other pharmacological } \\
\text { activities }\end{array}$ & 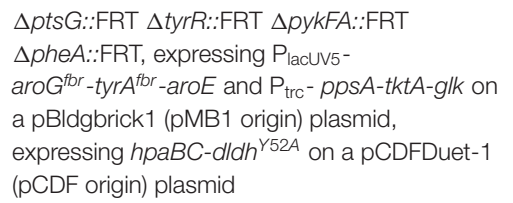 & $\begin{array}{l}500 \mathrm{~mL} \text { flasks fed-batch } \\
\text { fermentation }\end{array}$ & $7.1 \mathrm{~g} / \mathrm{L}$ & $47 \% \mathrm{~mol} / \mathrm{mol}$ & Yao et al., 2013 \\
\hline Rosmarinic acid & $\begin{array}{l}\text { E. coli-E. coli-E. } \\
\text { coli }\end{array}$ & $\begin{array}{l}\text { Antioxidant, } \\
\text { anti-microbial } \\
\text { anti-tumor, } \\
\text { anti-inflammatory, and } \\
\text { immune regulation } \\
\text { agent }\end{array}$ & 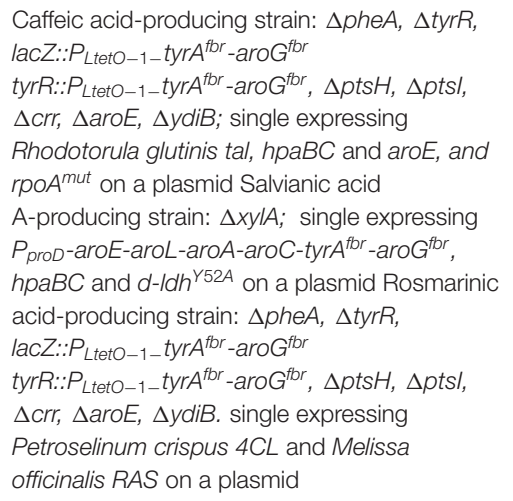 & Coculture in shake flasks & $172 \mathrm{mg} / \mathrm{L}$ & & Li et al., 2019c \\
\hline \multirow[t]{3}{*}{ Tyrosol } & E. coli & $\begin{array}{l}\text { Antioxidant, anti-cancer } \\
\text { and anti-inflammatory } \\
\text { activies }\end{array}$ & $\begin{array}{l}\triangle f e a B \text {. Expressing Micrococcus luteus tyo } \\
\text { and Papaver somniferum tdc on a pSC101 } \\
\text { origin plasmid }\end{array}$ & Shake-flask fermentation & $0.5 \mathrm{mM}$ & & Satoh et al., 2012 \\
\hline & E. coli & & 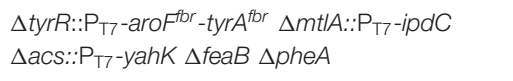 & Shake-flask fermentation & $8.3 \mathrm{mM}(1.15 \mathrm{~g} / \mathrm{L})$ & & Koma et al., 2012 \\
\hline & E. coli MG1665 & & $\begin{array}{l}\Delta f e a B \Delta \text { pykFA } \triangle \text { tyrR } \triangle \text { pheA. } \\
\text { Plasmid-expressing S. cerevisiae } A R O 10 \text { on a } \\
\text { pBR322 origin plasmid, plasmid-expressing } \\
\text { Ltet promoter-controlled tyrA }{ }^{\text {fbr }} \text {-aroG } G^{\text {for }} \text {-ppsA, } \\
\text { lacUV5 promoter-controlled tktA-aroE and } \\
\text { lacUV5 promoter-controlled aroD-aroB on a } \\
\text { p15A origin plasmid }\end{array}$ & Shake-flask fermentation & $926.9 \mathrm{mg} / \mathrm{L}$ & & Bai et al., 2014 \\
\hline
\end{tabular}


TABLE 2 | Continued

\begin{tabular}{|c|c|c|c|c|c|c|c|}
\hline Products & Host & Applications & Metabolic engineering strategies & Culture conditions & Titer & Yield & References \\
\hline & E. coli BL21 (DE3) & & $\begin{array}{l}\Delta f e a B \Delta \text { pheA. Plasmid-expressing } S . \\
\text { cerevisiae } A R O 10 \text { on a RSF1030 origin plasmid }\end{array}$ & Shake-flask fermentation & $4.15 \mathrm{mM}$ & & Xue et al., 2017 \\
\hline & E. coli BL21 (DE3) & & $\begin{array}{l}\Delta t y r R \Delta \text { feaB } \Delta \text { pheA. Plasmid-expressing } \\
\text { Petroselinum crispum aromatic aldehyde } \\
\text { synthase gene on a CloDE13 origin plasmid }\end{array}$ & Shake-flask fermentation & 539.4 mg/L & & Chung et al., 2017 \\
\hline & E. coli BW25113 & & $\begin{array}{l}\Delta \text { feaB, Plasmid-expressing S. cerevisiae } \\
A R O 10 \text { and } A D H 6 \text { on a ColE origin plasmid } \\
\text { (pZS12-luc), plasmid-expressing P PlacO1 } \\
\text { promoter-controlled tyr } A^{\text {tbr }} \text {-ppsA-tktA-aroG G }{ }^{\text {fbr }} \\
\text { on a p15A origin plasmid }\end{array}$ & Shake-flask fermentation & $550 \mathrm{mg} / \mathrm{L}$ & & Li X. et al., 2018 \\
\hline & E. coli BW25113 & & 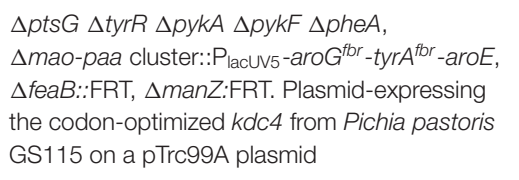 & Shake-flask fermentation & $1.47 \mathrm{~g} / \mathrm{L}$ from xylose & & Liu X. et al., 2018 \\
\hline \multirow[t]{4}{*}{ Hydroxytyrosol } & E. coli BL21 (DE3) & $\begin{array}{l}\text { Antioxidant, anti-cancer } \\
\text { and anti-inflammatory } \\
\text { activities }\end{array}$ & $\begin{array}{l}\Delta t y r R \quad \triangle \text { feaB } \Delta \text { pheA, plasmid-expressing } P . \\
\text { crispum aromatic aldehyde synthase gene and } \\
\text { E. coli hpaBC on a CloDE13 origin plasmid }\end{array}$ & Shake-flask fermentation & 208 mg/L & & Chung et al., 2017 \\
\hline & E. coli BW25113 & & 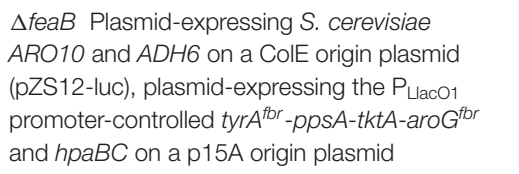 & Shake-flask fermentation & $647 \mathrm{mg} / \mathrm{L}$ & & LiX. et al., 2018 \\
\hline & E. coli BL21 (DE3) & & $\begin{array}{l}\Delta t y r R \Delta p h e A \text { feaB Expressing } \\
\text { aroG } G^{\text {fbr }} \text {-tyrA } A^{\text {fbr }} \text { on a } 15 \mathrm{~A} \text { origin plasmid, } \\
\text { expressing } E \text {. coli } W \text { hpaBC on } \mathrm{pET} \text {-duet, } \\
\text { expressing tyrosine decarboxylase (TDC) from } \\
\text { P. somniferum and tyrosine oxidase (TYO) from } \\
\text { M. luteus }\end{array}$ & Shake-flask fermentation & $268.3 \mathrm{mg} / \mathrm{L}$ & & Choo et al., 2018 \\
\hline & E. coli & & $\begin{array}{l}\Delta \text { feaB Expressing } h p a B C^{S 210 T / A 211 M / Q 212 G} \text {, } \\
\text { tyrosine decarboxylase gene (tdc) from } \\
\text { Enterococcus faecalis and tyramine oxidase } \\
\text { gene (tyo) from M. luteus }\end{array}$ & $\begin{array}{l}\text { Shake-flask fermentation } \\
\text { with feeding tyrosine by } \\
\text { three times }\end{array}$ & 1890 mg/L & & Chen et al., 2019 \\
\hline Salidroside & E. coli MG1665 & $\begin{array}{l}\text { Anti-aging, anoxia } \\
\text { resistance, and } \\
\text { anti-inflammation } \\
\text { activities, as well as } \\
\text { cardiovascular disease } \\
\text { prevention, anti-cancer, } \\
\text { nerve, and brain cell } \\
\text { protection properties }\end{array}$ & 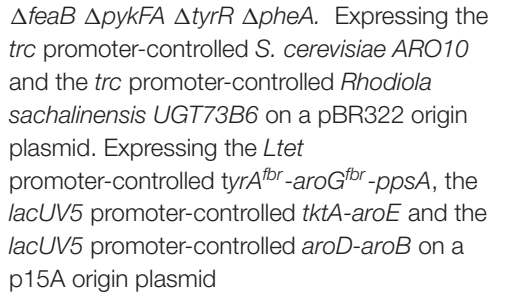 & Shake-flask fermentation & $56.9 \mathrm{mg} / \mathrm{L}$ & & Bai et al., 2014 \\
\hline
\end{tabular}


TABLE 2 | Continued

\begin{tabular}{|c|c|c|c|c|c|c|c|}
\hline Products & Host & Applications & Metabolic engineering strategies & Culture conditions & Titer & Yield & References \\
\hline & E. coli BL21 (DE3) & & $\begin{array}{l}\Delta t y r R \Delta \text { feaB } \Delta \text { pheA. Expressing } P \text {. crispum } \\
\text { aromatic aldehyde synthase gene on a } \\
\text { CloDE13 origin plasmid. Expressing } A \text {. thaliana } \\
\text { UGT85A1 on a f1 origin plasmid }\end{array}$ & Shake-flask fermentation & $287.9 \mathrm{mg} / \mathrm{L}$ & & Chung et al., 2017 \\
\hline & E. coli- E. coli & & 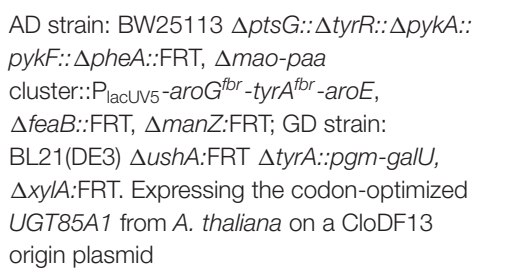 & 5-L bioreactor fed-batch & $6.03 \mathrm{~g} / \mathrm{L}$ & & Liu X. et al., 2018 \\
\hline Tyrosol/ salidroside & $\begin{array}{l}\text { S. cerevisiae } \\
\text { BY4742 }\end{array}$ & & 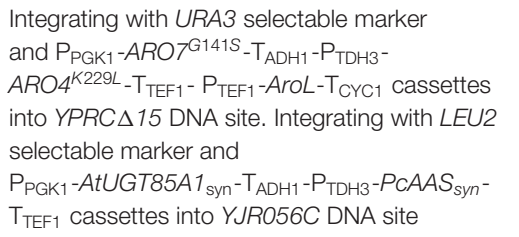 & $\begin{array}{l}5 \text { - } \mathrm{L} \text { bioreactor fed-batch } \\
\text { fermentation }\end{array}$ & $\begin{array}{c}732.5 \mathrm{mg} / \mathrm{L} \text { salidroside } \\
\text { and } 1394.6 \mathrm{mg} / \mathrm{L} \\
\text { tyrosol }\end{array}$ & & Jiang et al., 2018 \\
\hline \multirow[t]{2}{*}{$\begin{array}{l}\text { 4- } \\
\text { Hydroxyphenylacetic } \\
\text { acid }\end{array}$} & E. coli & $\begin{array}{l}\text { Synthesizing drugs, } \\
\text { agrochemicals, } \\
\text { biochemicals }\end{array}$ & 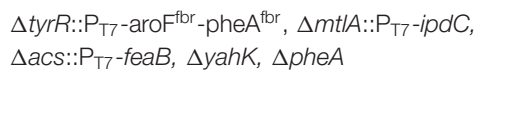 & Shake-flask fermentation & $6.1 \mathrm{mM}(928.1 \mathrm{mg} / \mathrm{L})$ & & Koma et al., 2012 \\
\hline & $\begin{array}{l}\text { E. coli DOPA-30N } \\
\text { (L-DOPA } \\
\text { producer) }\end{array}$ & & $\begin{array}{l}\text { Expressing the TIGR-mediated gene cluster of } \\
\text { the evolved } A R O 10_{6 D 5} \text { and feaB } B_{2 E 1} \text { under the } \\
\text { control of the Esa-PesaR activation system }\end{array}$ & $\begin{array}{l}2-\mathrm{L} \text { bioreactor fed-batch } \\
\text { fermentation }\end{array}$ & $17.39 \mathrm{~g} / \mathrm{L}$ & & Shen et al., 2019 \\
\hline \multirow[t]{4}{*}{$p$-Coumaric acid } & E. coli BL21 & $\begin{array}{l}\text { Precursor of flavonoids, } \\
\text { polyphenols, and } \\
\text { polyketides }\end{array}$ & $\begin{array}{l}\text { Expressing tyrosine ammonia lyase gene tal } \\
\text { from Saccharothrix espanaensis in a } \\
\text { tyrosine-overproducing } E \text {. coli expressing } E \text {. } \\
\text { coli aroG } G^{\text {tbe }} \text { and tyrA } A^{\text {tbr }} \text { on a p15A origin } \\
\text { plasmid (pACYDuet-1) }\end{array}$ & Shake-flask fermentation & 974 mg/L & & Kang et al., 2012 \\
\hline & $\begin{array}{l}\text { S. cerevisiae } \\
\text { CEN.PK102-5B }\end{array}$ & & 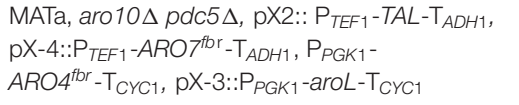 & Fed-batch fermentation & $1.93 \mathrm{~g} / \mathrm{L}$ & & $\begin{array}{l}\text { Rodriguez et al., } \\
2015\end{array}$ \\
\hline & $\begin{array}{l}\text { S. cerevisiae } \\
\text { S288C }\end{array}$ & & 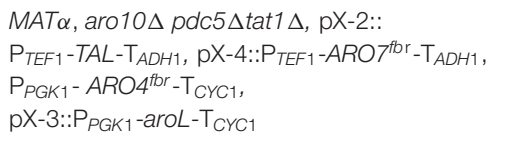 & Fed-batch fermentation & $3.56 \mathrm{~g} / \mathrm{L}$ & & $\begin{array}{l}\text { Rodriguez et al., } \\
2017\end{array}$ \\
\hline & $\begin{array}{l}\text { S. cerevisiae strain } \\
\text { CEN.PK113-5D- } \\
\text { derivative } \\
\text { IMX581 }\end{array}$ & & $\begin{array}{l}\text { Introducing a phosphoketalose-based pathway } \\
\text { and the replacement of promoters }\end{array}$ & Fed-batch fermentation & $12.5 \mathrm{~g} / \mathrm{L}$ & & Liu Q. et al., 2019 \\
\hline
\end{tabular}


TABLE 2 | Continued

\begin{tabular}{|c|c|c|c|c|c|c|c|}
\hline Products & Host & Applications & Metabolic engineering strategies & Culture conditions & Titer & Yield & References \\
\hline \multirow[t]{5}{*}{ Caffeic acid } & E. coli BL21 & $\begin{array}{l}\text { Pharmaceuticals, } \\
\text { esters, and polymers }\end{array}$ & $\begin{array}{l}\text { Expressing } S \text {. espanaensis tyrosine ammonia } \\
\text { lyase gene tal and } 4 \text {-coumarate hydroxylase } \\
\text { gene sam5 in a tyrosine-overproducing E. coli } \\
\text { expressing } E \text {. coli aroG } G^{\text {fbe }} \text { and tyrA } A^{\text {fbr }} \text { on a } \\
\text { p15A origin plasmid (pACYDuet-1) }\end{array}$ & Shake-flask fermentation & 150 mg/L & & Kang et al., 2012 \\
\hline & E. coli BW25113 & & $\begin{array}{l}\text { Expressing Rhodobacter capsulatus tyrosine } \\
\text { ammonia lyase gene tal and E. coli } \\
\text { 4-hydroxyphenylacetate 3-hydroxylase gene } \\
\text { hpaBC on a pZE12-luc plasmid. Expressing } \\
\text { the } P_{\text {Llaco } 1 \text {-controlled tyrA }} \text { tbr -ppsA-tktA-aroG }{ }^{\text {fbr }} \\
\text { on a p15A origin plasmid }\end{array}$ & Shake-flask fermentation & $50.2 \mathrm{mg} / \mathrm{L}$ & & Lin and Yan, 2012 \\
\hline & $\begin{array}{l}\text { E. coli ATCC } \\
31884 \text { (L-Phe } \\
\text { over-producer) }\end{array}$ & & 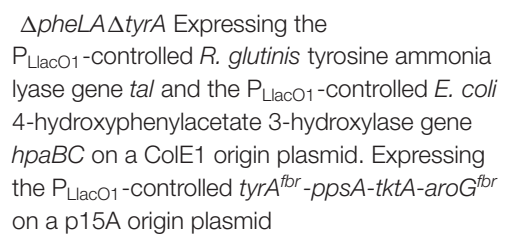 & Shake-flask fermentation & $766.68 \mathrm{~g} / \mathrm{L}$ & & Huang et al., 2013 \\
\hline & E. coli MG1655 & & 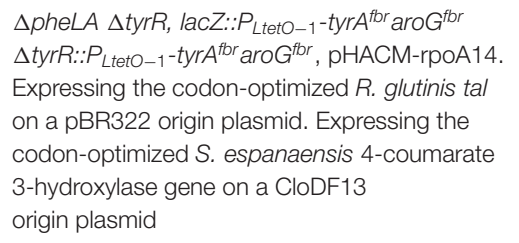 & Shake-flask fermentation & 106 mg/L & & $\begin{array}{l}\text { Zhang and } \\
\text { Stephanopoulos, } \\
2013\end{array}$ \\
\hline & S. cerevisiae & & $\begin{array}{l}\text { Expressing Rhodosporidium toruloides TAL on } \\
\text { a plasmid (pRS416), Pseudomonas aeruginosa } \\
\text { hpaB on a plasmid (pRS415), and } \\
\text { Salmonella enterica hpaC on a } \\
\text { plasmid (pRS413) }\end{array}$ & Shake-flask fermentation & $289.4 \mathrm{mg} / \mathrm{L}$ & & Liu L. et al., 2019 \\
\hline Ferulic acid & E. coli BL21 & $\begin{array}{l}\text { Cosmetics and } \\
\text { pharmaceuticals }\end{array}$ & $\begin{array}{l}\text { Expressing S. espanaensis tyrosine ammonia } \\
\text { lyase gene tal, 4-coumarate hydroxylase gene } \\
\text { sam5 and } A \text {. thaliana caffeic acid } \\
\text { methyltransferase gene com in a } \\
\text { tyrosine-overproducing } E \text {. coli expressing } E \text {. } \\
\text { coli aroG } G^{\text {tbe }} \text { and tyrA } A^{\text {tbr }} \text { on a } 15 \mathrm{~A} \text { origin } \\
\text { plasmid }\end{array}$ & 2-L bioreactor fermentation & 196 mg/L & & Kang et al., 2012 \\
\hline \multirow[t]{2}{*}{$p$-Hydroxystyrene } & $\begin{array}{l}\text { E. coli ATCC } \\
31884 \text { (NST 74) } \\
\text { (L-Phe } \\
\text { overproducer) }\end{array}$ & Polymers & $\begin{array}{l}\text { Expressing R. glutinis pal on a pKK2233 } \\
\text { plasmid. Expressing Lactobacillus plantarum } \\
\text { pdc on a pKSM } 715 \text { plasmid }\end{array}$ & Fed-batch fermentation & $0.4 \mathrm{~g} / \mathrm{L}$ & & Qi et al., 2007 \\
\hline & E. coli & $\begin{array}{l}\text { Synthesizing plastics } \\
\text { and rubbers }\end{array}$ & $\begin{array}{l}\Delta \text { tyrR::tyrA } A^{\text {ftor }} \text {-aroG } G^{\text {fbr }} \text {. Expressing } S . \\
\text { espanaensis tal and phenolic acid } \\
\text { decarboxylase gene pad from Bacillus } \\
\text { amyloliquefaciens on pET-28a (+) plasmid }\end{array}$ & Shake-flask fermentation & 355 mg/L & & Kang et al., 2012 \\
\hline
\end{tabular}


TABLE 2 | Continued

\begin{tabular}{|c|c|c|c|c|c|c|c|}
\hline Products & Host & Applications & Metabolic engineering strategies & Culture conditions & Titer & Yield & References \\
\hline & $\begin{array}{l}\text { Streptomyce } \\
\text { lividans }\end{array}$ & & $\begin{array}{l}\text { Expressing pad from S. Sviceus and tal from } \\
\text { Rhodobacter sphaeroids. Expressing } \\
\text { endoglucanase gene tfu0901 from } \\
\text { Thermobifida fusca YX }\end{array}$ & Shake-flask fermentation & $\begin{array}{l}250 \mathrm{mg} / \mathrm{L} \text { from } \\
\text { cellulose, } 360 \mathrm{mg} / \mathrm{L} \\
\text { from glucose }\end{array}$ & & Noda et al., 2015 \\
\hline & $\begin{array}{l}\text { Streptomyce } \\
\text { mobaraense }\end{array}$ & & Expressing tal from Rhodobacter sphaeroids & Shake-flask fermentation & $273 \mathrm{mg} / \mathrm{L}$ & & Fujiwara et al., 2016a \\
\hline & P. putida S12 & & $\begin{array}{l}\Delta f c s \text {. Expressing the } p a l \text { and } p d c \text { genes under } \\
\text { the control of the salicylate-inducable } \\
\text { NagR/pNagAa promoter and tac RBS }\end{array}$ & $\begin{array}{l}\text { 3-L two-phase } \\
\text { water-decanol fed-batch } \\
\text { fermentation }\end{array}$ & 147 mM (17.6 g/L) & & Verhoef et al., 2009 \\
\hline 3,4-Dihydroxystyrene & E. coli & & $\begin{array}{l}\Delta t y r R: \text { :tyr } A^{\text {fbr }} \text {-aro } G^{\text {fbr }} \text {. Expressing tal and } \\
\text { sam5 from S. espanaensis, and pad from B. } \\
\text { amyloliquefaciens on pET-28a (+) plasmid }\end{array}$ & Shake-flask fermentation & 63 mg/L & & Kang et al., 2015 \\
\hline $\begin{array}{l}\text { 4-Hydorxy-3- } \\
\text { methoxystyrene }\end{array}$ & E. coli & $\begin{array}{l}\text { Synthesizing plastics } \\
\text { and rubbers }\end{array}$ & $\begin{array}{l}\Delta t y r R: \text { :tyra } A_{\text {fbr }}^{\text {-aro }} G^{\text {tbr }} \text {. Expressing tal and } \\
\text { sam5 from S. espanaensis, A. thaliana com, } \\
\text { and B. amyloliquefaciens pad from on pET-28a } \\
\text { (+) plasmid }\end{array}$ & Shake-flask fermentation & $64 \mathrm{mg} / \mathrm{L}$ & & Kang et al., 2015 \\
\hline Chlorogenic acid & E. coli-E. coli & $\begin{array}{l}\text { Antioxidant, } \\
\text { anti-bacterial, antiviral, } \\
\text { antitumor, and } \\
\text { anti-inflammatory agent } \\
\text { as well as drugs }\end{array}$ & $\begin{array}{l}\text { Caffeic acid-producing strain: } \triangle t y r R \triangle P h e A \text {, } \\
\text { expressing S. espanaensis TAL, aroG and tyrA } \\
\text { on a p15A origin plasmid (pACYCDuet), and } \\
\text { hpaBC on a f1 origin plasmid (pETDUet) } \\
\text { Chlorogenic acid-producing strain: } \triangle \text { aroD, } \\
\text { expressing } N \text {. tabacum } H Q T \text { and Oryza sativa } \\
4 C L \text { on a p15A origin plasmid (pACYCDuet), } \\
\text { and native ydiB on a f1 origin } \\
\text { plasmid (pETDUet) }\end{array}$ & Coculture in shake flasks & $78 \mathrm{mg} / \mathrm{L}$ & & Cha et al., 2014 \\
\hline $\begin{array}{l}\text { p-Coumaroyl } \\
\text { shikimate }\end{array}$ & E. coli & $\begin{array}{l}\text { Antioxidant, } \\
\text { anti-bacterial, antiviral, } \\
\text { antitumor, and } \\
\text { anti-inflammatory agent } \\
\text { as well as drugs }\end{array}$ & $\begin{array}{l}\Delta \text { tyrR } \triangle \text { PheA } \triangle \text { aroL Expressing } S \text {. } \\
\text { espanaensis TAL, aroG and tyrA on a p } 15 A \\
\text { origin plasmid (pACYCDuet), and } N \text {. tabacum } \\
\text { HST and O. sativa } 4 C L \text { on a CloDE13 origin } \\
\text { plasmid (pCDFDuet) }\end{array}$ & Shake-flask fermentation & 236 mg/L & & Cha et al., 2014 \\
\hline Curcumin & E. coli & $\begin{array}{l}\text { Antioxidant, } \\
\text { anti-bacterial, antiviral, } \\
\text { antitumor, and anti- } \\
\text { inflammatory agent as } \\
\text { well as treatment of } \\
\text { Parkinson's and } \\
\text { Alzhemier's disease }\end{array}$ & $\begin{array}{l}\Delta t y r R: \text { :tyrA } A^{\text {tbr }} \text {-aroG Gbr Chromosomal } \\
\text { expressing S. espanaensis tal, S. espanaensis } \\
\text { sam5, A. thaliana com, Nicotiana tabacum } 4 C l \text {, } \\
\text { Curcuma longa DCS, and C. longa CURS2. } \\
\text { MAGE was used to optimizate the expression } \\
\text { ratios of the six enzymes }\end{array}$ & Shake-flask fermentation & $3.8 \mathrm{mg} / \mathrm{L}$ & & Kang et al., 2018 \\
\hline L-DOPA & E. coli & $\begin{array}{l}\text { Treating Parkinson's } \\
\text { disease }\end{array}$ & $\begin{array}{l}\text { Expressing Streptomyces castaneoglobisporus } \\
\text { tyrosinase gene on a pET-23a plasmid. } \\
\text { Expressing tyr } A^{f b r} \text {-aroG } G^{f b} \text {-tktA-ppsA on a } \\
\text { pCOLADuet- } 1 \text { plasmid }\end{array}$ & Shake-flask fermentation & 293 mg/L & & $\begin{array}{l}\text { Nakagawa et al., } \\
2011\end{array}$ \\
\hline
\end{tabular}


TABLE 2 | Continued

\begin{tabular}{|c|c|c|c|c|c|c|c|}
\hline Products & Host & Applications & Metabolic engineering strategies & Culture conditions & Titer & Yield & References \\
\hline L-DOPA & E. coli & & $\begin{array}{l}\Delta p t s l, \Delta p t s H, \Delta c r r:: k a n, \Delta / a c l, \Delta l a c Z:: \text { loxP, } \\
\text { PgalP::Ptrc, } \Delta \text { tyrR. Expressing the trc } \\
\text { promoter-controlled E. coli W hpaBC, the trc } \\
\text { promoter-controlled Zymomonas mobilis tyrC } \\
\text { and the native pheAcM on a pTrc99A plasmid. } \\
\text { Expressing the lacUV5 promoter-controlled } \\
\text { aroG }{ }^{\text {fbr }} \text { and } t k t A \text { under the control of its native } \\
\text { paomoter on a p15A origin plasmid }\end{array}$ & Batch fermentation & $1.5 \mathrm{~g} / \mathrm{L}$ & & Munoz et al., 2011 \\
\hline L-DOPA & E. coli & & 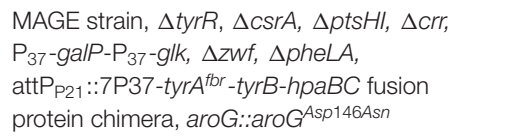 & Fed-batch fermentation & $8.67 \mathrm{~g} / \mathrm{L}$ & & Wei et al., 2016 \\
\hline L-DOPA & E. coli & & $\begin{array}{l}\Delta t y r R, \triangle p y k F, \triangle \text { serA, aroG::aroG fbr } \text {, expressing } \\
\text { E. coli W hpaBC on a pBR322 origin plasmid. } \\
\text { Expressing the lac UV5 promoter-controlled } \\
\text { tyrB-tyrA } A^{\text {tor }} \text {-aroC and the lacUV5 } \\
\text { promoter-controlled aroA-aroL on a p15A } \\
\text { origin plasmid }\end{array}$ & Fed-batch fermentation & $12.5 \mathrm{~g} / \mathrm{L}$ & & Das et al., 2018 \\
\hline \multirow[t]{2}{*}{ Dopamine } & E. coli & & $\begin{array}{l}\text { Expressing S. castaneoglobisporus tyrosinase } \\
\text { gene and } P \text {. putida KT2440 L-DOPA } \\
\text { decarboxylase gene dodc on a pET-23a } \\
\text { plasmid. Expressing tyrA } A^{\text {tbr }} \text {-aroG }{ }^{\text {tbr }} \text {-tktA-ppsA } \\
\text { on a pCOLADuet-1 plasmid }\end{array}$ & Shake-flask fermentation & $260 \mathrm{mg} / \mathrm{L}$ & & $\begin{array}{l}\text { Nakagawa et al., } \\
2011\end{array}$ \\
\hline & E. coli & & $\begin{array}{l}\Delta t y r R, \Delta c r r, \Delta p t s G, \Delta \text { pheA } \Delta p y k \text { Expressing } \\
\text { hpaB }{ }^{G 295 R} \text {-hpaC on a plasmid (pRSFDuet-1), }\end{array}$ & $\begin{array}{l}5 \mathrm{~L} \text { bioreactor fed-batch } \\
\text { fermentation }\end{array}$ & $25.53 \mathrm{~g} / \mathrm{L}$ & & Fordjour et al., 2019 \\
\hline
\end{tabular}

$P_{T 7}$-galP-P $P_{T 7}$-glk- $P_{T 7}$-ppsA-P $P_{T 7}$-tktA on a

plasmid (pETM6), aro $G^{\text {fbr }}$-tyrA $A^{\text {fbr }}$ on a

plasmid (pCDFDuet-1) 
the enhancement of the expression of the aromatic amino acid pathway as well as the deletion of the competing pathways were used to improve the production of 4HMA. The strain exhibiting the best performance produced $1 \mathrm{~g} / \mathrm{L}$ of $4 \mathrm{HMA}$ with a mass yield of 6.4\% in shake flask cultures (Reifenrath and Boles, 2018).

4-Hydroxyphenyllactic acid (4HPLA) is known to be an antifungal compound. The replacement of acs with C. necator JCM20644ldhA under the control of the T7 promoter in the LTyr producing E. coli strain resulted in the production of $7.6 \mathrm{mM}$ 4HPLA in shake flask cultures (Figure 3) (Koma et al., 2012).

Salvianic acid A (3,4-dihydroxyphenllactic acid, also known as danshensu), is a naturally occurring plant polyphenolic acid that is recognized for its superior antioxidant activities. It has a variety of other pharmacological activities, including improved cerebral blood flow, inhibition of platelet activation and arterial thrombosis, as well as anti-cancer and anti-inflammatory activities. Yao et al. developed an artificial biosynthetic pathway for salvianic acid A production in E. coli (Yao et al., 2013). 4Hydroxyphenylpyruvate was converted to salvianic acid A via D-lactate dehydrogenase (encoded by $d$-ldh from Lactobacillus pentosus) and the hydroxylase complex (encoded by hpaBC from E. coli) (Figure 3). After optimizing the pathway using a modular engineering approach and deleting the genes involved in regulatory and competing pathways, the metabolically engineered E. coli strain produced $7.1 \mathrm{~g} / \mathrm{L}$ of salvianic acid A with a yield of $0.47 \mathrm{~mol} / \mathrm{mol}$ glucose. To overcome the drawbacks caused by plasmid system, the salvianic acid A biosynthetic pathway was integrated into the chromosomal of the L-Tyr producing E. coli strain BAK5 to obtain a plasmid-free strain for the production of salvianic acid A (Zhou L. et al., 2017). The final strain BKD13 produced $5.6 \mathrm{~g} / \mathrm{L}$ salvianic acid A by fed-batch fermentation. A cell-free system was established for the production of salvianic acid A from phenylpyruvate. The cell-free system contained D-mandelate dehydrogenase from Thermococcus barophilus, phenylalanine 4-hydroxylase from Thermomonospora curvata, and Hydroxyphenylacetate 3hydroxylase from Sulfobacillus acidophilus TPY. The resulting cell-free system produced $392 \mathrm{mM}$ of salvianic acid A with a yield of $85 \%$ (Li et al., 2019a).

Rosmarinic acid is a plant-derived natural compound belong to the family of polyphenolic compounds. It is an ester of caffeic acid and salvianic acid A. It has diverse important nutraceutical and pharmaceutical values, including antioxidant, anti-inflammatory, anti-microbial, anti-tumor and anti-viral, and immune regulation activities. After comparing pathway enzymes, Bloch and Schmidt-Dannert (2014) constructed an artificial biosynthetic pathway of rosmarinic acid (Figure 3), which consisted of 2-hydroxyacid dehydrogenase (HdhA) from Lactobacillus delbrueckii, 4-hydroxyphenylacetate 3-hydroxylase complex (HpaBC) from E. coli W, Tal from Rhodobacter sphaeroides, 4-coumarate-CoA ligase 2 (4CL2) from A. thaliana and rosmarinic acid synthase from Melissa officinalis. The introduction of this pathway into E. coli by using three plasmids resulted in the de novo production of rosmarinic acid. Jiang et al. (2016) established another biosynthetic pathway of rosmarinic acid using a different set of enzymes. The recombinant E. coli strain harboring this pathway produced
$130 \mathrm{mg} / \mathrm{L}$ rosmarinic acid from caffeic acid using whole-cell biocatalysis. The biosynthetic pathway of rosmarinic acid from 4hydroxyphenylpyruvate is a diverging and converging pathway. Modular co-culture engineering with three E. coli strains was used to balance the different pathway modules for the production of rosmarinic acid (Li et al., 2019c). The three-strain coculture produced $172 \mathrm{mg} / \mathrm{L}$ rosmarinic acid, exhibiting 38-fold improvement over the mono-culture. Yan et al. (2019) established a cell-free system with ATP and CoA double regeneration for the production of rosmarinic acid, which reached $320.04 \mathrm{mg} / \mathrm{L} / \mathrm{h}$.

Tyrosol and hydroxytyrosol are two major ingredients in olive oil, and both are considered bioactive ingredients that have various biological activities. It has been reported that tyrosol plays an important role in the prevention of cardiovascular diseases, osteopenia, melanin pigmentation, as well as antiinflammatory responses (Kim et al., 2018). In addition, tyrosol can lower the risk of developing Alzheimer's disease (Kim et al., 2018). Three biosynthetic pathways have been developed for tyrosol production (Figure 3). In the first pathway, tyrosine is converted into tyramine by tyrosine decarboxylase (TDC), which is followed by the further consecutive transformation of tyramine into tyrosol by tyramine oxidase (TYO) and ADH (Satoh et al., 2012). The second pathway is known as the yeast Ehrlich pathway, wherein 4HPP is decarboxylated to 4hydroxyphenylacetaldehyde (4HPAAL), which is acted on by the endogenous enzyme ADH (Hazelwood et al., 2008; Bai et al., 2014; Xue et al., 2017). In the third pathway, tyrosine is directly converted to 4HPAAL by aromatic aldehyde synthase (AAS), and then converted to tyrosol by ADH (Chung et al., 2017; Jiang et al., 2018). The plasmid-mediated overexpression of the tyo gene from Micrococcus luteus and tyrosine decarboxylase gene from Papaver somniferum in the feaB-knockout mutant of E. coli BW25113 resulted in the production of $0.50 \mathrm{mM}$ of tyrosol (Satoh et al., 2012) in shake flask cultures. The yeast Ehrlich pathway for tyrosol production was established by the overexpression of indol-3-pyruvate/phenylpyruvate decarboxylase gene ipdC from A. brasilense NBRC102289 (Koma et al., 2012). The cooverexpression of $A$. brasilense ipdC and E. coli yahK, as well as the deletions of $f e a B$ and pheA in a Tyr-overproducing $E$. coli strain resulted in the production of $8.3 \mathrm{mM}(1.15 \mathrm{~g} / \mathrm{L})$ tyrosol in shake flask cultures (Koma et al., 2012). The yeast Ehrlich pathway for tyrosol production was also established by the overexpression of S. cerevisiae pyruvate decarboxylase gene ARO10 (Bai et al., 2014). A combination of the knock out of the competitive pathways and negative regulation, along with the enhanced expression of the pathway genes enhanced the level of tyrosol produced to $926.9 \mathrm{mg} / \mathrm{L}$. In another study, ARO10 from $S$. cerevisiae was overexpressed in the $p h e A / f e a B$ double knockouts of E. coli BL21 (DE3), which resulted in the synthesis of $4.15 \mathrm{mM}(573.4 \mathrm{mg} / \mathrm{L})$ tyrosol from glucose during 48 -h shake flask culture (Xue et al., 2017). Recently, it was demonstrated that the overexpression of the S. cerevisiae ADH gene ADH6 further increased tyrosol production (Li X. et al., 2018). The resulting E. coli strain containing the yeast Ehrlich pathway produced $1,469 \mathrm{mg} / \mathrm{L}$ of tyrosol from tyrosine and $550 \mathrm{mg} / \mathrm{L}$ of tyrosol from a simple carbon source, such as glucose. The overexpression of E. coli hpaBC in the tyrosol-overproducing 
strain led to the production of $647 \mathrm{mg} / \mathrm{L}$ hydroxytyrosol from a simple carbon source, such as glucose (Figure 3) (Li X. et al., 2018). In another recent study, the $k d c 4$ gene from P. pastoris GS115 was more efficient for the biosynthesis of tyrosol than the previously reported ARO10 gene from S. cerevisiae (Liu X. et al., 2018). After the deletion of genes involved in regulatory and competing pathways, the resulting $E$. coli strain produced $1.47 \mathrm{~g} / \mathrm{L}$ tyrosol from xylose in shake flask cultures, which is the highest titer produced so far. An AAS-derived pathway was first established for tyrosol and hydroxytyrosol production by the overexpression of the aas gene from Petroselinum crispum (Chung et al., 2017). The three different aas genes from $A$. thaliana, Petunia hybrid, and P. crispum were compared, and it was found that the P. crispum aas gene was most suitable for the production of tyrosol and hydroxytyrosol in E. coli. The deletion of $t y r R$, pheA, and feaB further increased tyrosol production. The overexpression of the aas gene from P. crispum in the tyrR/pheA/feaB knockouts of E. coli BL21 (DE3) resulted in the production of $539.4 \mathrm{mg} / \mathrm{L}$ of tyrosol in shake flask cultures (Chung et al., 2017). The authors also found that the titer of the product generated using the AAS-derived pathway was higher than that generated using the TDC-TYO-derived pathway. Hydroxytyrosol can be synthesized from tyrosol by hydroxylation (Figure 3). Chung et al. (2017) compared E. coli hpaBC and Saccharothrix espanaensis sam5 and found that the co-overexpression of E. coli hpaBC and P. crispum aas in E. coli produced greater levels of hydroxytyrosol. The plasmid overexpression of E. coli hpaBC and P. crispum aas in the tyrosol-overproducing strain resulted in the production of 208 $\mathrm{mg} / \mathrm{L}$ of hydroxytyrosol in shake flask cultures (Chung et al., 2017). Judging from the reported titers of tyrosol, the yeast Ehrlich pathway has the highest efficiency among the three pathways, subsequent to the AAS-derived pathway. Salidroside is a glucoside of tyrosol and one of the major ingredients of the medicinal herb Rhodiola. It has various biological properties, including anti-aging, anoxia resistance, and anti-inflammation activities, as well as cardiovascular disease prevention, anticancer, nerve protection, and brain cell protection properties (Bai et al., 2014). It can be synthesized from tyrosol by a uridine diphosphate dependent glycosyltransferase (UGT) (Figure 3). Salidroside was first produced by introducing the glycosyltransferase UGT73B6 from Rhodiola sachalinensis into the tyrosol-overproducing E. coli strain (Bai et al., 2014). The resulting E. coli strain produced $56.9 \mathrm{mg} / \mathrm{L}$ of salidroside in shake flask cultures. Twelve UGTs from A. thaliana were screened, and UGT85A1 was found to be the most suitable enzyme for the production of salidroside from tyrosol (Chung et al., 2017). The overexpression of A. thaliana UGT85A1 in the tyrosoloverproducing $E$. coli strain with the AAS-derived pathway resulted in the production of $287.9 \mathrm{mg} / \mathrm{L}$ salidroside in shake flask cultures. The results of the two studies described above showed that most of the tyrosol was not glycosylated into salidroside (Bai et al., 2014; Chung et al., 2017). To overcome the drawbacks observed in E. coli monocultures, a syntrophic E. coli-E. coli coculture system was developed for salidroside production (Liu X. et al., 2018). The co-culture system composed of the aglycone (AG) and the glycoside (GD) strains, which convergently accommodated the biosynthetic pathways for the production of tyrosol and salidroside, respectively. The co-culture of the AG and DG strains resulted in the production of $6.03 \mathrm{~g} / \mathrm{L}$ salidroside in a 5-L bioreactor fed-batch fermentation process (Liu X. et al., 2018). Tyrosol is a native metabolite of yeast that is derived from endogenous Ehrlich pathway. Thus, S. cerevisiae has been successfully used as a host strain for tyrosol production. An AAS-derived pathway has been successfully introduced into $S$. cerevisiae for tyrosol and salidroside production (Jiang et al., 2018). Plasmid overexpressing of aas from P. crispum in $S$. cerevisiae improved the production tyrosol to $398.9 \mathrm{mg} / \mathrm{L}$ from $170.8 \mathrm{mg} / \mathrm{L}$. Chromosomal overexpression of P. crispum aas, A. thaliana UGT85A1 as well as the enhancement of the expressions of $A R O 4^{K 229 L}, A R O 7^{G 141 S}$, and $A R O L$ resulted in the production of tyrosol and salidroside to 1394.6 and 732.5 mg/L, respectively (Jiang et al., 2018). An AAS-derived pathway containing P. crispum Aas and E. coli Adh was overexpressed for the production of tyrosol in S. cerevisiae (Guo et al., 2019). The replacement of PDC1 with E. coli tyr mutant tyrA ${ }^{M 53 I / A 354 V}$ further improved the production of tyrosol by 440 times. The introduction of tyrosine decarboxylase from $P$. somniferum, tyrosine oxidase from $M$. luteus, and 4-hydroxyphenylacetate 3monooxygenase from E. coli in a tyrosine-overproducing E. coli strain resulted in the production of $268.3 \mathrm{mg} / \mathrm{L}$ of hydroxytyrosol (Choo et al., 2018). A HpaBC mutant (HpaBC ${ }^{\text {S210T/A211M/Q212G }) ~}$ active on both tyrosol and tyramine was obtained by directed divergent evolution (Chen et al., 2019). Then, they constructed a multiple pathway network to convert tyrosine to hydroxytyrosol using the same set of enzymes. Overexpression of the $h p a B C$ mutant, tyrosine decarboxylase gene $(t d c)$ from Enterococcus faecalis and tyramine oxidase gene (tyo) from $M$. luteus in the $f e a B$ deletion $E$. coli strain enabled the production of hydroxytyrosol of $1,890 \mathrm{mg} / \mathrm{L}$ (Chen et al., 2019). A wholecell catalytic method was developed for the production of hydroxytyrosol from L-DOPA (Li et al., 2019b). Aromatic amino acid aminotransferase (TyrB) from E. coli and aldehyde reductase (YahK) from E. coli, a-keto acid decarboxylase (Kdc) from $P$. mirabilis JN458, and L-glutamate dehydrogenase (Gdh) were coexpressed in E. coli to catalyze the production of hydroxytyrosol from L-DOPA. The yield of hydroxytyrosol reached $36.33 \mathrm{mM}$ $(5.59 \mathrm{~g} / \mathrm{L})$ using whole-cell catalysis of the recombinant $E$. coli (Li et al., 2019b).

The production of 4HPAA was achieved by the overexpression of endogenous $f e a B$ and $i p d C$ from $A$. brasilense NBRC102289 in E. coli, using the Ehrlich pathway intermediates 4-hydroxyphenylacetaldehyde as precursors (Koma et al., 2012). The overexpression of $A$. brasilense $i p d C$ and $E$. coli feaB, as well as the deletion of $y a h K / p h e A$ in the Tyr-overproducing E. coli strain resulted in the production of $6.1 \mathrm{mM}(928.1$ $\mathrm{mg} / \mathrm{L}$ ) of 2-phenylacetic acid in shake flask cultures (Figure 3) (Koma et al., 2012). Our lab constructed an E. coli strain for the production of 4HPAA by applying a combinatorial strategy of directed evolution of pathway enzymes and quorum-sensing (QS)-based dynamic regulation of the pathway. The resulting strain produced $17.39 \mathrm{~g} / \mathrm{L}$ 4HPAA in 2-L bioreactor fed-batch fermentation (Shen et al., 2019). The 4HPAA titer is the highest value reported to date. 
Hydroxycinnamic acids are a class of hydroxylate aromatic acids synthesized via the phenylpropanoid pathway. They mainly include cinnamic acid, caffeic acid, $p$-coumaric acid, and ferulic acid. The biotechnological production of $\boldsymbol{p}$-coumaric acid was first achieved in $S$. cerevisiae from phenylalanine by phenylalanine ammonia lyase (PAL)-catalyzed formation of cinnamic acid and sequential hydroxylation of cinnamic acid via the cytochrome P450-dependent enzyme 4-cinnamic acid hydroxylase (C4H) (Ro and Douglas, 2004). However, the lower expression of $\mathrm{C} 4 \mathrm{H}$ led to the production of an extremely low level of $p$-coumaric acid. To improve $p$-coumaric acid production, a more straightforward route that employed tyrosine as the direct precursor was established in E. coli. The overexpression of the tyrosine ammonia lyase gene tal from $S$. espanaensis in a tyrosine-overproducing $E$. coli strain resulted in the production of $974 \mathrm{mg} / \mathrm{L}$ of $p$-coumaric acid in shake flask cultures (Figure 3) (Kang et al., 2012). The overexpression of the heterologous biosynthetic pathway of caffeic acid (including $S$. espanaensis tyrosine ammonia lyase gene tal and 4-coumarate hydroxylase gene sam5) or ferulic acid (including tyrosine ammonia lyase gene tal, 4-coumarate hydroxylase gene sam5 from $S$. espanaensis, and caffeic acid methyltransferase gene com from A. thaliana) (Figure 3) led to the production of $150 \mathrm{mg} / \mathrm{L}$ of caffeic acid or $196 \mathrm{mg} / \mathrm{L}$ ferulic acid, respectively (Kang et al., 2012). This pathway was also introduced in $S$. cerevisiae to enable the production of $1.9 \mathrm{~g} / \mathrm{L}$ of $p$-coumaric acid in a deep-well plate fed-batch fermentation process (Rodriguez et al., 2015). This titer was obtained by the inactivation of phenylpyruvate decarboxylase and pyruvate decarboxylase, in conjunction with the overexpression of genes encoding for feedback-resistant DAHP synthase, chorismate mutase, and shikimate kinase (Rodriguez et al., 2015). Then, this research group further enhanced $p$-coumaric acid titer to $3.56 \mathrm{~g} / \mathrm{L}$ by deleting the amino acid transporter gene tat 1 (Rodriguez et al., 2017). Recently, this group further enhanced the production of $p$-coumaric acid to $12.5 \mathrm{~g} / \mathrm{L}$ by introducing a phosphoketalose-based pathway to divert glycolytic flux toward erythrose 4-phosphate synthesis, and optimizing carbon distribution between glycolysis and the aromatic amino acid biosynthetic pathway by promoter replacement (Liu Q. et al., 2019). The $p$-coumaric acid titer is the highest value reported to date. This pathway has also been introduced into $P$. putida KT2440 (Calero et al., 2016) and Synechocystis PCC 6803 (Xue et al., 2014; Tantong et al., 2018) to achieve the production of $p$-coumaric acid. However, the $p$-coumaric acid titer obtained with these engineered microorganisms was lower than that obtained with $S$. cerevisiae. Caffeic acid exhibits antioxidant, anti-viral, anti-cancerous, and anti-inflammatory activities. Caffeic acid is commonly synthesized by a cytochrome P450 enzyme $p$-coumarate 3 -hydroxylase $(\mathrm{C} 3 \mathrm{H})$, which catalyzes the hydroxylation of $p$-coumaric acid (Figure 3). The overexpression of E. coli 4-hydroxyphenylacetate 3-hydroxylase gene hpaBC and Rhodobacter capsulatus tyrosine ammonia lyase gene tal in a tyrosine-overproducing $E$. coli strain expressing the $\mathrm{P}_{\mathrm{LlacO} 1^{-}}$ controlled $t y r A^{f b r}$-ppsA-tktA-aro $G^{f b r}$ resulted in the production of $50.2 \mathrm{mg} / \mathrm{L}$ of caffeic acid (Lin and Yan, 2012). The titer was further enhanced to $766.68 \mathrm{mg} / \mathrm{L}$ by increasing the availability of tyrosine (Huang et al., 2013). Inclusion of the coumaroyl$\mathrm{CoA} /$ caffeic - CoA biosynthesis route in the tyrosine ammonia lyase-4-coumarate 3-hydroxylase pathway did not improve caffeic acid production (Zhang and Stephanopoulos, 2013). The overexpression of Rhodotorula glutinis tal and S. espanaensis 4coumarate 3-hydroxylase gene in a tyrosine-overproducing $E$. coli strain yielded $106 \mathrm{mg} / \mathrm{L}$ of caffeic acid in a 2-L bioreactor batch fermentation process (Zhang and Stephanopoulos, 2013). $\mathrm{HpaB}$ from Pseudomonas aeruginosa and $\mathrm{HpaC}$ from Salmonella enterica along with Tal from Rhodosporidium toruloides was overexpressed in S. cerevisiae for the production of caffeic acid, which reached $289.4 \mathrm{mg} / \mathrm{L}$ (Liu L. et al., 2019). This is the first report on engineering $S$. cerevisiae for the production of caffeic acid. The highest level of caffeic acid $(10.2 \mathrm{~g} / \mathrm{L})$ could be produced from $p$-coumaric acid by using whole-cell catalysis of engineered E. coli (Furuya and Kino, 2014). This level was much higher than that obtained from glucose, indicating that the availability of $p$-coumaric acid and tyrosine might be key factors influencing caffeic acid production in E. coli. From the caffeic acid yield reported in the literature, the titer using whole-cell catalysis is much higher than that obtained by using fermentation. This reason may be the high toxicity of caffeic acid on host strain.

p-Hydroxystyrene is a derivative of styrene. It has the same applications as styrene. The de novo biosynthesis of $p$-hydroxystyrene from glucose was achieved in $E$. coli by the decarboxylation of p-coumaric acid (Figure 3). The LPhe overproducing strain E. coli ATCC 31884 expressing $R$. glutinis pal and the $p$-coumaric acid decarboxylase gene $p d c$ from L. plantarum produced $0.40 \mathrm{~g} / \mathrm{L}$ of $p$-hydroxystyrene in a 14-L fermenter (Qi et al., 2007). Recently, an artificial biosynthetic pathway was established in E. coli to produce p-hydroxystyrene using the tyrosine ammonia lyase gene tal from S. espanaensis and phenolic acid decarboxylase gene pad from Bacillus amyloliquefaciens (Kang et al., 2015). The overexpression of this pathway in the L-Tyr producing $E$. coli strain (chromosome-expressing aro $G^{f b r}$ and tyrA $A^{f b r}$ in the tyrA deletion strain) resulted in the production of $355 \mathrm{mg} / \mathrm{L}$ of $p$-hydroxystyrene in shake flask cultures after $36 \mathrm{~h}$. The introduction of the tal, 4-coumarate 3-hydroxylase gene sam5 from S. espanaensis and pad genes or the tal, sam5, caffeic acid methyltransferase gene com from $A$. thaliana and pad genes into the above L-Tyr producing $E$. coli strain led to the production of $63 \mathrm{mg} / \mathrm{L}$ of 3,4-dihydroxystyrene or $64 \mathrm{mg} / \mathrm{L}$ of 4-hydroxy-3-methoxystyrene in shake flask cultures after $36 \mathrm{~h}$, respectively (Kang et al., 2015). Since phenolic acid decarboxylase genes are widely distributed in various Streptomyces species, Streptomyces strains have been successfully used as the hosts for p-hydroxystyrene production. After comparing the phenolic acid decarboxylase gene pad obtained from S. sviceus, S. hygroscopicus, and S. cattleya, pad from S. sviceus and tal from R. sphaeroides were used to create the biosynthetic pathway of $p$-hydroxystyrene (Noda et al., 2015). The introduction of this pathway into the endoglucanase-screening $S$. lividans species directly yielded $250 \mathrm{mg} / \mathrm{L}$ p-hydroxystyrene from cellulose. This research group also engineered $S$. mobaraense for $p$-hydroxystyrene production, which yielded $273 \mathrm{mg} / \mathrm{L}$ of the product from glucose (Fujiwara et al., 2016a). The titer was obtained by introducing a single gene 
that encodes Tal from $R$. sphaeroides. $P$. putida $\mathrm{S} 12$ has also been used as the host strain for $p$-hydroxystyrene production. The overexpression of the bifunctional enzyme gene pal/tal from $R$. toruloides and $p d c$ from L. plantarum in the pcs knockout strain of P. putida S12 resulted in the production of $147 \mathrm{mM}(17.6 \mathrm{~g} / \mathrm{L})$ of p-hydroxystyrene in a two-phase fed-batch fermentation process (Verhoef et al., 2009).

In plants, hydroxycinnamic acids are commonly conjugated with quinic acid, shikimic acid, malic acid, and glycerol (Kim B. G. et al., 2013). Hydroxycinnamic acid conjugates have stronger anti-oxidative activity than hydroxycinnamic acid. Hydroxycinnamic acid conjugates are synthesized by hydroxycinnamoyl transferase (Figure 3). It has been demonstrated that the activity of hydroxycinnamate-CoA shikimate transferase (HST) from Nicotiana tabacum to $p$ coumaroyl-CoA is higher than that to other acyl donors (such as caffeoyl-CoA and feruloyl-CoA) (Kim B. G. et al., 2013). They also found that that activity of hydroxycinnamate-CoA quinate transferase (HQT) from N. tabacum to caffeoyl-CoA is higher than that to other acyl donors (such as coumaroyl-CoA and feruloyl-CoA). This group constructed an E. coli strain overexpressing HQT from N. tabacum and 4CL from Oryza sativa for the production of chlorogenic acid from caffeic acid for the first time (Figure 3). The recombinant E. coli strain produced $450 \mathrm{mg} / \mathrm{L}$ chlorogenic acid from caffeic acid (Kim B. G. et al., 2013). Then, this group constructed an E. coli-E. coli culture system. The chlorogenic acid producing E. coli strain was co-cultured with a caffeic acid producing E. coli strain for the de novo production of chlorogenic acid, which reached 78 $\mathrm{mg} / \mathrm{L}$ (Cha et al., 2014). They also engineered an E. coli strain for the de novo synthesis of $p$-coumaroyl shikimate, which reached $236 \mathrm{mg} / \mathrm{L}$.

Curcumin is a nature phenylpropanoid from the plant Curcuma longa. It has diverse therapeutic properties including anti-oxidant, anti-cancer, anti-inflammatory, anti-Alzeimer's, Anti-HIV, anti-Parkinson, and cholesterol-lowering activities. Rodrigues's group constructed an engineered E. coli expressing A. thaliana 4CL, C. longa diketide-CoA synthase gene (DCS) and C. longa curcumin synthase gene (CURS1) for the production of curcumin from ferulic acid (Figure 3) (Rodrigues et al., 2015). In this study, they also constructed an artificial biosynthetic pathway from L-tyrosine via caffeic acid by caffeoyl-CoA 3-O-methyl-transferase (CCoAOMT) from Medicago sativo. Curcumin can also be produced from caffeic acid, $p$-coumaric acid or tyrosine, respectively. Then, after the optimization of culture conditions, the resulting strain produced $959.3 \mathrm{mM} \mathrm{(353}$ $\mathrm{mg} / \mathrm{L}$ ) curcumin from ferulic acid in shake flask cultures (Couto et al., 2017). Recently, it was demonstrated that the curcumin titer obtained through the ferulic acid pathway by caffeic acid O-methyltransferase (COMT) was higher than that obtained through the caffeic acid by CCoAOMT (Rodrigues et al., 2020). In this study, they established a two-strain coculture system to further improve the production of curcumin from L-Tyr, which reached $43.2 \mathrm{mM}(15.9 \mathrm{mg} / \mathrm{L})$. This titer is the highest titer of curcumin obtained from L-Tyr to date. The coculture increased the production of curcumin by 6.6-fold compared to the mono-culture. An artificial curcumin biosynthetic pathway was integrated into the chromosome of the engineered LTyr overproducing E. coli $\triangle \mathrm{COS} 1$ strain for the de novo production of curcumin from glucose (Kang et al., 2018). Then, multiplex automated genome engineering (MAGE) was applied for balancing the expression of the six enzymes of the biosynthetic pathway. The resulting strain produced $3.8 \mathrm{mg} / \mathrm{L}$ curcumin from glucose in shake flask cultures.

L-DOPA is an aromatic compound derived from L-tyrosine (Figure 3). L-DOPA has been used to treat Parkinson's disease, which is caused by deficiency of the neurotransmitter dopamine. Nakagawa et al. (2011) constructed an E. coli expressing the Streptomyces castaneoglobisporus tyrosinase gene tyr and native tyr $A^{f b}, a r o G^{f b r}, t k t A$, and $p p s A$, which could produce $293 \mathrm{mg} / \mathrm{L}$ of L-DOPA from glucose. The authors also co-expressed tyr from S. castaneoglobisporus and L-DOPA decarboxylase gene dodc from $P$. putida KT2440 in the L-Tyr producing E. coli strain, resulting in the production of $260 \mathrm{mg} / \mathrm{L}$ of dopamine. Munoz et al. (2011) reported an engineered E. coli with HpaBC activity, which could produce $1.5 \mathrm{~g} / \mathrm{L}$ of L-DOPA from glucose. This titer was achieved by the overexpression of $E$. coli W hpaBC, native $t k t A$, ato $G^{f b r}$, pheA, and Zymomonas mobilis tyrC in the phosphotransferase system and tyrR knockout strain. Our group first used the singleplex genome engineering approach to create an L-DOPA-producing strain, E. coli DOPA-1 (Wei et al., 2016). MAGE based on 23 targets was then used to further improve L-DOPA production. The resulting strain, $E$. coli DOPA-30N, produced $8.67 \mathrm{~g} / \mathrm{L}$ of L-DOPA within $60 \mathrm{~h}$ in a $5 \mathrm{~L}$ fed-batch fermentation process (Wei et al., 2016). Overexpression of $E$. coli W $h p a B C$ along with the enhancement of the expression level of the downstream tyrosine biosynthetic pathway of shikimate in the $t y r R /$ pheA/serA knockout E. coli strain resulted in producing $12.5 \mathrm{~g} / \mathrm{L} \mathrm{L}-\mathrm{DOPA}$ in a 5 -L bioreactor fed-batch fermentation (Das et al., 2018). To increase the catalytic efficiency of $\mathrm{HpaBC}, \mathrm{HpaB}$ from E. coli was directly evolved and three mutants with higher activity were obtained (Fordjour et al., 2019). Overexpression of the mutant $h p a B^{G 295 R} C$ in an L-Tyr producing $E$. coli strain produced $25.53 \mathrm{~g} / \mathrm{L}$ L-DOPA in a $5-\mathrm{L}$ bioreactor fed-batch fermentation.

\section{Tryptophan Derivatives}

L-Trp is a common precursor for the production of many important aromatic chemicals (Figure 4). A few L-Trp derivatives that have been synthesized by engineering microorganisms are listed in Table 3.

Indirubin, also known as couraupitine B, is an indole alkaloid that is a major bioactive ingredient of a traditional oriental medicine called Danggui Longhui Wan. It is currently used as a drug to treat chronic granulocytic leukemia and may have therapeutic value in the treatment of cancer and Alzheimer's disease. Indirubin is derived from L-Trp, which is converted into indole by native tryptophanase, then reduced to 2-hydroxyindole (2HID) and 3-hydroxyindole (3HID) by heterologous monooxygenase or dioxygenase, and finally undergoes spontaneous dimerization with 3HID and 2HID to form indirubin (Figure 4). Recently, an artificial de novo biosynthetic pathway was developed for the production of $56 \mathrm{mg} / \mathrm{L}$ indirubin and $640 \mathrm{mg} / \mathrm{L}$ indigo from glucose (Du et al., 2018). The 


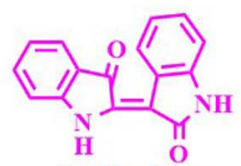

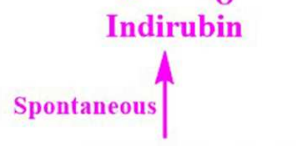

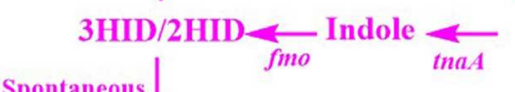
Spontaneous $\rfloor$<smiles>O=C1/C(=C2/Nc3ccccc3C2=O)Nc2ccccc21</smiles>

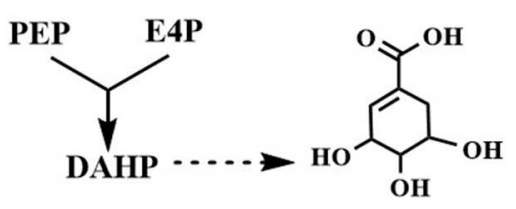

Shikimic acid<smiles>CC(C)[C@@H](C)[C@@H](C)[C@H](C)Cl</smiles>

Chorismate

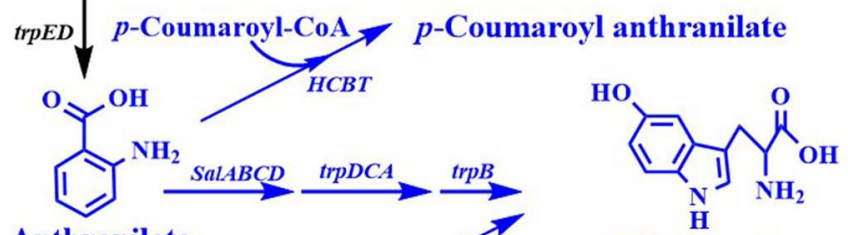

Anthranilate

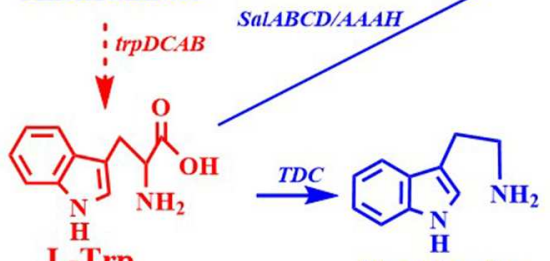

L-Trp

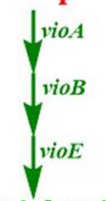

Protodeoxyviolaceinic acid

$$
\text { Tryptamine }
$$

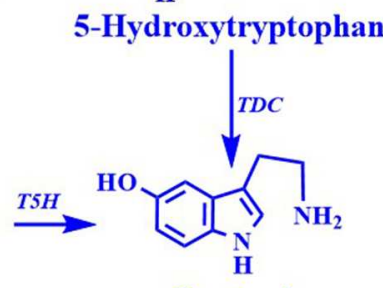

Serotonin

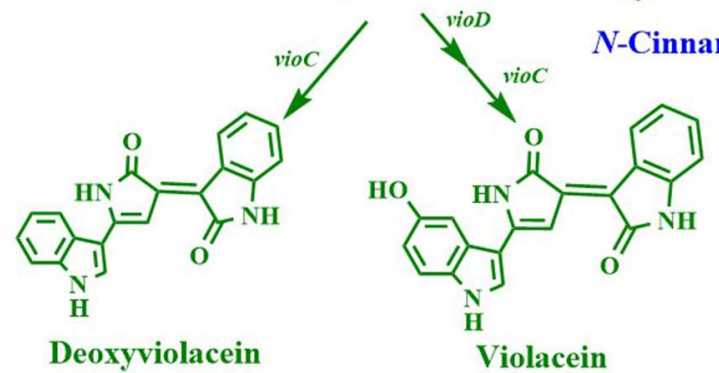

FIGURE 4 | Biosynthesis of L-tryptophan derivatives. HCBT, anthranilate N-hydroxycinnamoyl/benzoyltransferase gene; salABCD, salicylate 5-hydroxylase gene; $A A A H$, aromatic amino acid hydroxylase gene; TDC, tryptophan decarboxylase gene; $T 5 H$, tryptamine 5-hydroxylase gene; thaA, tryptophanase gene; fmo, flavin-containing monooxygenase gene; HCTT, hydroxycinnamoyl-CoA:tryptamine N-hydroxycinnamoyl transferase gene; vioA, tryptophan

2-monooxygenase/L-tryptophan oxidase gene; vioB, 2-imino-3-(indol-3-yl)propanoate dimerase gene; vioE, violacein biosynthesis protein gene; vioC, violacein synthase gene; vioD, protodeoxyviolaceinate monooxygenase gene.

titer was achieved by the overexpression of Methylophaga aminisulfidivorans flavin-containing monooxygenase gene fmo and $E$. coli tryptophanase gene tnaA as well as by enhancing the expression of the feedback-resistant $a r o G^{f b r}$ and $\operatorname{trp} E^{f b r}$ in the $\operatorname{trpR} / p y k F A$ knockout $E$. coli strain. This was the first report about the direct production of indirubin from glucose in a shake flask culture.

Violacein and deoxyviolacein are secondary metabolites that receives high interest due to their biological activities such as anti-microbial, anti-cancer, anti-viral, trypanocidal, anti-protozoan, and anti-oxidant activities (Fang et al., 2015). E. coli expressing the vioABCE cluster from Chromobacterium violaceum under control of the inducible araC system produced $180 \mathrm{mg} / \mathrm{L}$ deoxyviolacein from glucose (Figure 4) (Rodrigues et al., 2013). System-level analysis for the serine, chorismate and L-Trp biosynthesis and the non-oxidative pentose phosphate pathway revealed the bottlenecks in L-Trp biosynthesis. After eliminating the bottlenecks in L-Trp supply, the deoxyviolacein titer was further improved to $320 \mathrm{mg} / \mathrm{L}$. Moreover, co-expression of the vioD from $C$. violaceum in the above deoxyviolacein 
TABLE 3 | De novo production of tryptophan derivatives by engineered microorganisms.

\begin{tabular}{|c|c|c|c|c|c|c|c|}
\hline Product & Host & Application & Strategies & Culture conditions & Titer & Yield & References \\
\hline \multirow[t]{2}{*}{ Anthranilic acid } & $\begin{array}{l}\text { E. coli W3110 } \\
\text { trpD9923 }\end{array}$ & $\begin{array}{l}\text { Synthesizing aromatic } \\
\text { compounds }\end{array}$ & Expression aroG $G^{\text {tbr }}$ and $t k t A$ on a plasmid & Fed-batch fermentation & $14 \mathrm{~g} / \mathrm{L}$ & & $\begin{array}{l}\text { Balderas-Hernandez } \\
\text { et al., } 2009\end{array}$ \\
\hline & P. putida & & $\begin{array}{l}\Delta \operatorname{trp} D C \triangle \mathrm{pheA} \text { Expressing aro } G^{D 146 \mathrm{~N}} \\
\text { and } \operatorname{trp} E^{S 40 F} G\end{array}$ & Fed-batch fermentation & $1.54 \mathrm{~g} / \mathrm{L}$ & & Kuepper et al., 2015 \\
\hline \multirow[t]{2}{*}{ Serotonin } & E. coli & $\begin{array}{l}\text { Treating various } \\
\text { diseases related to } \\
\text { serotonin imbalance }\end{array}$ & $\begin{array}{l}\text { Expressing Catharanthus roseus tryptophan } \\
\text { decarboxylase gene (TDC) and } O \text {. sativa } \\
\text { tryptamine 5-hydroxylase gene (T5H) }\end{array}$ & & 24 mg/L & & Park et al., 2011 \\
\hline & & E. coli & $\begin{array}{l}\text { 5-hydroxytryptophan producing strain: L-Trp } \\
\text { producing strain S028, } \Delta \text { trpR, expressing } \\
\text { pterin-4 alpha-carbinolamine } \\
\text { dehydratase (PCD) and dihydropteridine } \\
\text { reductase (DHPR) from human; expressing } \\
\text { aromatic amino acid hydroxylase mutant } \\
\text { (AAAH }^{F 197 / / E 219 C)} \text { from } \\
\text { Cupriavidus taiwanensis Serotonin producing } \\
\text { strain: } \Delta \text { tnaA, expressing C. roseus TDC }\end{array}$ & $\begin{array}{l}1.5 \mathrm{~L} \text { bioreactor stepwise } \\
\text { fermentation }\end{array}$ & $154.3 \mathrm{mg} / \mathrm{L}$ & & $\begin{array}{l}\text { Mora-Villalobos and Zeng, } \\
2018\end{array}$ \\
\hline $\begin{array}{l}\text { N-Cinnamoyl } \\
\text { tryptamine }\end{array}$ & E. coli BL 21(DE3) & $\begin{array}{l}\text { Antioxidant, } \\
\text { anti-inflammatory, } \\
\text { anti-atherogenic and } \\
\text { skin-whitening agents }\end{array}$ & $\begin{array}{l}\triangle t y r R \text { Expressing PAL from A. thaliana on a } \\
\text { PACYCDuet-1 plasmid. Expressing } 4 C L \text { from } \\
\text { O. sativa and } \\
\text { hydroxycinnamoyl-CoA:tryptamine } \\
\mathrm{N} \text {-hydroxycinnamoyl transferase gene }(H C T T) \\
\text { from Capsicum annuumon on a pCDFDuet-1 } \\
\text { plasmid. Expressing tryptophan decarboxylase } \\
\text { gene }(t d c) \text { from Bacillus atrophaeus on a } \\
\text { pGEX5X-3 plasmid }\end{array}$ & Shake-flask fermentation & $110.6 \mathrm{mg} / \mathrm{L}$ & & Lee et al., 2017 \\
\hline $\begin{array}{l}p \text {-coumaroyl } \\
\text { anthranilate }\end{array}$ & E. coli BL 21(DE3) & $\begin{array}{l}\text { Antioxidant, } \\
\text { anti-inflammatory, } \\
\text { anti-atherogenic, and } \\
\text { skin-whitening agents }\end{array}$ & $\begin{array}{l}\Delta t y r R, \Delta t r p D \text { Expressing } 4 C L \text { from O. sativa } \\
\text { and anthranilate } \\
\text { N-hydroxycinnamoyl/benzoyltransferase } \\
\text { (HCBT) from Dianthus caryophyllus on a } \\
\text { pCDFDuet-1 plasmid. Expressing aroG, } S \text {. } \\
\text { espanaensis tal and tyrA on a pACYCDuet-1 } \\
\text { plasmid. Expressing trpEG on a } \\
\text { pETDuet-1 plasmid }\end{array}$ & Shake-flask fermentation & $317.2 \mathrm{mg} / \mathrm{L}$ & & Lee et al., 2018 \\
\hline \multirow[t]{2}{*}{ 5-Hydroxytryptophan } & $\begin{array}{l}\text { E. coli SO28 (L-Trp } \\
\text { producing strain) }\end{array}$ & Synthesizing serotonin & $\begin{array}{l}\Delta t r p R \text {, expressing PCD and DHPR from } \\
\text { human; expressing AAAHF197L/E219C from } \\
\text { C. taiwanensis }\end{array}$ & $\begin{array}{l}1.5 \mathrm{~L} \text { bioreactor fed-batch } \\
\text { fermentation }\end{array}$ & 962 mg/L & & $\begin{array}{l}\text { Mora-Villalobos and Zeng, } \\
2018\end{array}$ \\
\hline & E. coli BL 21(DE3) & & 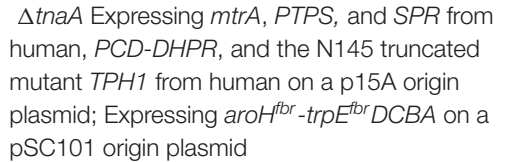 & $\begin{array}{l}10 \mathrm{~L} \text { bioreactor fed-batch } \\
\text { fermentation }\end{array}$ & $5.1 \mathrm{~g} / \mathrm{L}$ & & Wang et al., 2018 \\
\hline
\end{tabular}




\begin{tabular}{|c|c|c|c|c|c|c|c|}
\hline Product & Host & Application & Strategies & Culture conditions & Titer & Yield & References \\
\hline Indirubin & E. coli & $\begin{array}{l}\text { Drugs for treating } \\
\text { chronic granulocytic } \\
\text { leukemia, cancer, and } \\
\text { Alzheimer's disease }\end{array}$ & $\begin{array}{l}\Delta t r p R, \Delta p y k F A, P_{t k t A}:: P_{t r c} \text {. Expressing the trc } \\
\text { promoter-controlled Methylophaga } \\
\text { aminisulfidivorans flavin-containing } \\
\text { monooxygenase gene fmo and the trc } \\
\text { promoter-controlled } E \text {. coli tryptophanase gene } \\
\text { thaA on a pTrc99A plasmid. Expressing the tac } \\
\text { promoter-controlled aroG } G^{\text {tbr }} \text {, the tac } \\
\text { promoter-controlled trpE }{ }^{\text {tro }} \text { and the tac } \\
\text { promoter-controlled aroL on a p15A } \\
\text { origin plasmid }\end{array}$ & Fed-batch fermentation & 56 mg/L & & Du et al., 2018 \\
\hline Indigo & E. coli & Dye & $\begin{array}{l}\Delta \operatorname{trp} R, \triangle p y k F A, P_{t k t A}:: P_{t r c} . \text { Expressing the trc } \\
\text { promoter-controlled } M \text {. aminisulfidivorans } \\
\text { flavin-containing monooxygenase gene fmo } \\
\text { and the trc promoter-controlled } E \text {. coli } \\
\text { tryptophanase gene thaA on a pTrc99A } \\
\text { plasmid. Expressing the tac } \\
\text { promoter-controlled aro } G^{\text {fbr }} \text {, the tac } \\
\text { promoter-controlled trpE }{ }^{\text {tbr }} \text { and the tac } \\
\text { promoter-controlled aroL on a p15A } \\
\text { origin plasmid }\end{array}$ & Fed-batch fermentation & 640 mg/L & & Du et al., 2018 \\
\hline \multirow[t]{5}{*}{ Violacein } & E. coli & $\begin{array}{l}\text { Antioxidant, } \\
\text { anti-microbial, } \\
\text { anticancer, antiviral, } \\
\text { trypanocidal, } \\
\text { antiprotozoan agents }\end{array}$ & 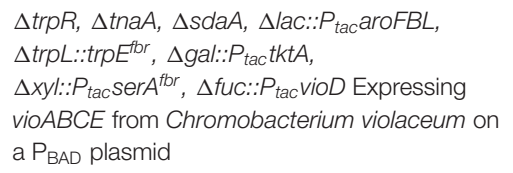 & $\begin{array}{l}1 \mathrm{~L} \text { bioreactor fed-batch } \\
\text { fermentatio }\end{array}$ & 710 mg/L & & Rodrigues et al., 2013 \\
\hline & & & $\begin{array}{l}\triangle \operatorname{trpR} \text { Expressing the vioABCDE gene cluster } \\
\text { from Duganella sp. B2 on a pRSFDuet plasmid } \\
\text { Expressing trpE } E^{\text {fbr-trpD on pACYCDuet plasmid }}\end{array}$ & $\begin{array}{l}5 \mathrm{~L} \text { bioreactor batch } \\
\text { fermentation }\end{array}$ & $1.75 \mathrm{~g} / \mathrm{L}$ & $0.116 \mathrm{~g} / \mathrm{g}$ & Fang et al., 2015 \\
\hline & & & 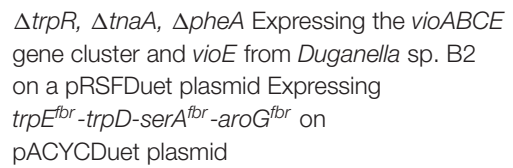 & $\begin{array}{l}5 \mathrm{~L} \text { bioreactor fed-batch } \\
\text { fermentation }\end{array}$ & $4.45 \mathrm{~g} / \mathrm{L}$ & & Zhou et al., 2018 \\
\hline & E. coli BL21(DE3) & & $\begin{array}{l}\text { Plackett-Burman and Box-Behnken design } \\
\text { was used to optimize the expression of the } \\
\text { vioA, vioB, vioC, vioD, and vioE from } \\
\text { C.violaceum } 12472\end{array}$ & $\begin{array}{l}2 \mathrm{~L} \text { bioreactor fed- batch } \\
\text { fermentation }\end{array}$ & $1.31 \mathrm{~g} / \mathrm{L}$ & & Xu et al., 2017 \\
\hline & E. coli BL21 (DE3) & & $\begin{array}{l}\text { Expressing C.violaceum vioABDE on a ColE1 } \\
\text { origin plasmid, Janthinobacterium lividum vioC } \\
\text { on a p15A origin plasmid Knocking down ytfR } \\
\text { using synthetic SRNA }\end{array}$ & $\begin{array}{l}1.2 \mathrm{~L} \text { bioreactor fed-batch } \\
\text { fermentation }\end{array}$ & $5.19 \mathrm{~g} / \mathrm{L}$ & & Yang et al., 2019 \\
\hline
\end{tabular}


producing strain dVio-6 led to the production of $710 \mathrm{mg} / \mathrm{L}$ violacein from glucose in a fed-batch fermentation (Rodrigues et al., 2013). In their further study (Rodrigues et al., 2014), the L-arabinose metabolism of the above deoxyviolacein producing strain dVio-6 was eliminated to prevent catabolism of the inducer $\mathrm{L}$-arabinose by knocking the $\operatorname{araBAD}$ genes. The resulting $E$. coli strain dVio-8 produced $1.6 \mathrm{~g} / \mathrm{L}$ deoxyviolacein from glycerol in a fed-batch fermentation (Rodrigues et al., 2014). Using another vioABCE cluster from Duganella sp. B2, an engineered E. coli strain was used to produce violacein (Fang et al., 2015). Cooverexpression of this gene cluster, $\operatorname{trp} E^{M 293 T / S 40 L}$ and $\operatorname{trpD}$ in the $\operatorname{trpR}$ deletion $E$. coli strain led to the production of $1.75 \mathrm{~g} / \mathrm{L}$ violacein in a $5 \mathrm{~L}$ bioreactor batch fermentation (Fang et al., 2015). This group then developed an intermediate sensorassisted push-pull strategy (InterSPPS) (Fang et al., 2016). In this study, an L-Trp biosensor was first developed. Then the L-Trp biosensor was used to sequentially enhance the upstream and downstream modular of L-Trp in the deoxyviolacein biosynthetic pathway. By this means, the deoxyviolacein titer was increased by 4.4 -fold (1.92 g/L) (Fang et al., 2016). This group's study also demonstrated that VioE is the rate-limiting enzyme for the violacein biosynthesis (Zhou et al., 2018). Overexpression of the vioE further improved the production of violacein. The final recombinant $E$. coli strain produced $4.45 \mathrm{~g} / \mathrm{L}$ violacein in 5-L bioreactor fed-batch fermentation (Zhou et al., 2018). A statistical model-based multivariate regulator strategy was developed to improve metabolic pathway efficiency (Xu et al., 2017). A combination of Plackett-Burman design with BoxBehnken design was used to optimize the expression levels of the violacein biosynthetic pathway genes by using different strength promoters. The final E. coli strain produced $1.31 \mathrm{~g} / \mathrm{L}$ of violacein in a $2 \mathrm{~L}$ bioreactor fed-batch fermentation (Xu et al., 2017). Constraints-based flux balance analysis (FBA) identified tryptophan biosynthesis and NADPH availability as limiting (Immanuel et al., 2018). The recombinant E. coli strain based on FBA produced a 6 -fold increase in violacein yield. The synthetic small regulatory RNA (sRNA) technology has been successfully used for genome-scale screening of beneficial knockdown gene targets in a violacein producing E. coli strain (Yang et al., 2019). As a result, knocking down $y t f R$ (encoding sugar ABC transporter) increased $600 \%$ violacein titer. The $y t f R$ knockdown strain produced $5.19 \mathrm{~g} / \mathrm{L}$ violacein in fed-batch fermentation. Corynebacterium glutamicum has been successfully used as a host strain for the production of violacein. Introduction of the vio operon from $C$. violaceum into the L-Trp producer $C$. glutamicum ATCC 2185 led to the production of $5.436 \mathrm{~g} / \mathrm{L}$ violacein in a $3 \mathrm{~L}$ bioreactor fed-batch fermentation (Sun et al., 2016). The value is the highest to date.

\section{PRODUCTION OF STILBENES}

Stilbenes are composed of a skeleton with two aromatic rings joined by a methylene bridge. They are biosynthesized through the condensation of Co-A-linked cinnamic acids with three molecules of malonyl-CoA catalyzed by stilbene synthase (Figure 5, Table 4). Pinosylvin, resveratrol, and piceatannol 


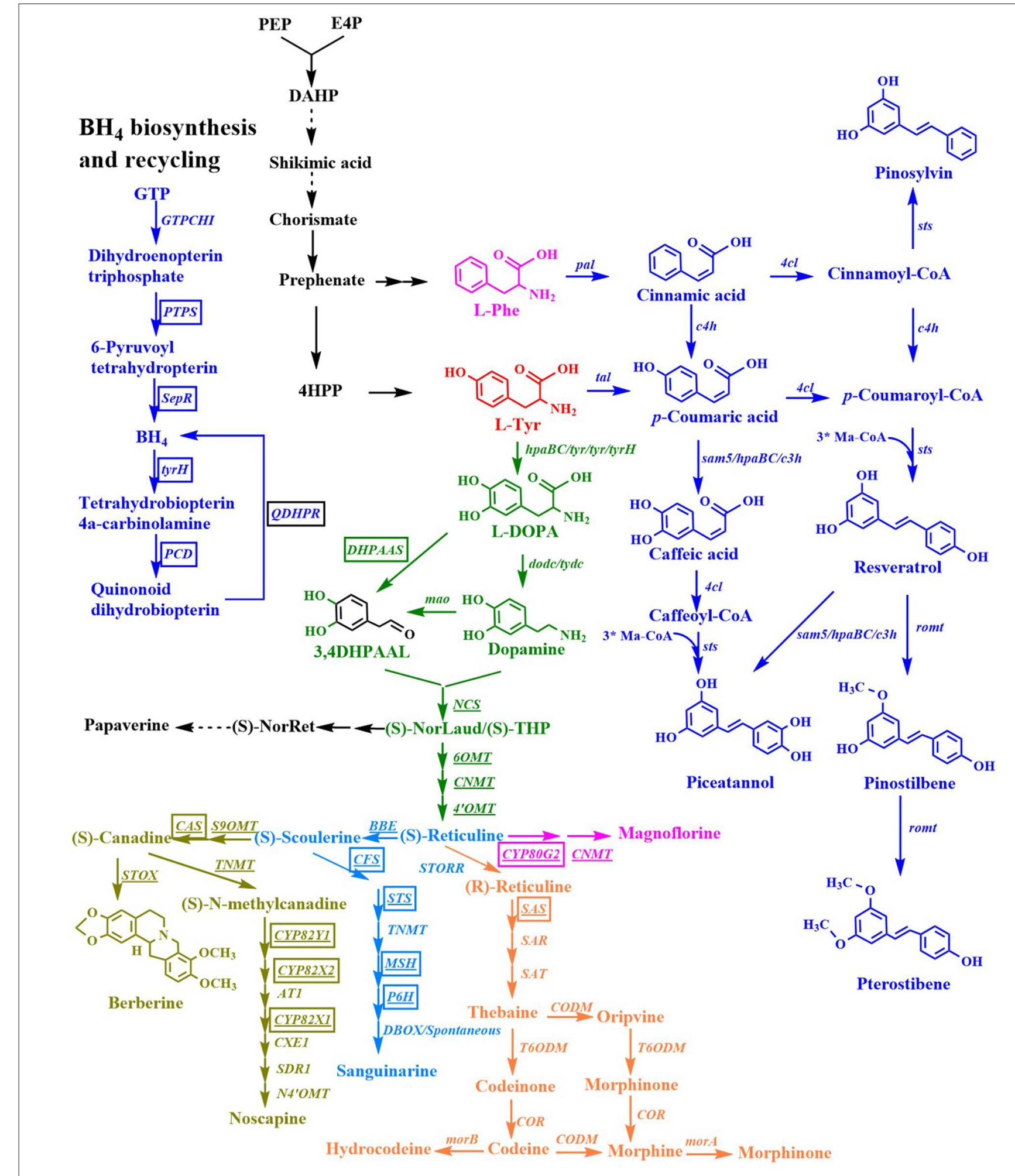

FIGURE 5 | Biosynthesis of stilbenes, benzylisoquinoline alkaloids. Black, microorganism genes; Boxed genes, mammalian (Rattus norvegicus/ Bombyx mori) genes; Underlinded, plant genes; Boxed and underlined genes, cytochrome P450 genes; Ma-CoA, malonyl-CoA; (S)-NorLaud, (S)-norlaudanosoline; (S)-THP, (S)-tetrahydropapaveroline; (S)-NorRet, (S)-norreticuline; $\mathrm{BH}_{4}$, tetrahydrobiopterin; pal, phenylalanine ammonia lyase gene; 4cl, 4-coumaroyl-coenzyme A ligase gene; sts, stilbene synthase gene; c4h, 4-cinnamic acid hydroxylase gene; sam5, 4-coumarate hydroxylase gene; c3h, p-coumarate 3-hydroxylase gene; romt, resveratrol O-methyltransferase; tyr/tyrH, tyrosinase gene; DHPAAS, 3,4-dihydroxyphenylacetaldehyde synthase gene; dodc, DOPA decarboxylase gene; tydc, tyrosine 
FIGURE 5 | decarboxylase gene; mao, monoamine oxidase gene; NCS, norcoclaurine synthase gene; $6 O M T$, norcoclaurine 6-O-methyltransferase gene; CNMT, coclaurine- $\mathrm{N}$-methyltransferase gene; 4'-OMT, 3'-hydroxy-N-methylcoclaurine-4'-O-methyltransferase gene; CYP80G2, corytuberine synthase gene; BBE, berberine bridge enzyme gene; GTPCHI, GTP cyclohydrolase I gene; PTPS, 6-pyruvoyl-tetrahydropterin synthase gene; SepR, sepiapterin reductase gene; PCD, pterin-4 $\alpha$-carbinolamine dehydratase gene; QDHPR, quinonoid dihydropteridine reductase gene; S9OMT, scoulerine 9-O-methyltransferase gene; CAS, canadine synthase gene; $C P R$, cytochrome P450 reductase gene; TNMT, tetrahydroprotoberberine cis- $\mathrm{N}$-methyltransferase gene; CYP82Y1, 1-hydroxy-N-methylcanadine synthase gene; CYP82X2, 1- hydroxy-N-methylcanadine 13-hydroxylase gene; AT1, 1,13-dihydroxy-N-methylcandine 13-O-acetyltransferase gene; CYP82X1, 1-hydroxy-13-O-acetyl-N-methylcanadine 8-hydroxylase gene; CXE1, 3-O-acetylpapaveroxine carboxylesterase gene; SDR1, short-chain dehydrogenase/reductase gene; N4'-OMT, narcotoline-4'-O-methyltransferase gene; CFS, cheilanthifoline synthase gene; STS, stylopine synthase gene; TNMT, tetrahydroprotoberberine $\mathrm{N}$-methyltransferase gene; $\mathrm{MSH}$, cis-N-methylstylopine 14-hydroxylase gene; $\mathrm{P} 6 \mathrm{H}$, protopine 6-hydroxylase gene; DBOX, dihydrobenzophenanthridine oxidase gene; STOX, (S)-tetrahydroprotoberberine oxidase gene; STORR, (S)-reticuline isomerase gene; SAS, salutaridine synthase gene; SAR, salutaridinol reductase gene; SAT, salutaridinol acetyltransferase gene; CODM, codeine-O-demethylase gene; T6OMT, thebaine 6-O-demethylase gene; COR, codeinone reductase gene; morA, morphine dehydrogenase; morB, morphine reductase.

are the three stilbenoids derived from cinnamic acid, $p$ coumaric acid, and caffeic acid, respectively. Recently, some 4-coumaroyl-coenzyme A ligases (4CLs) and stilbene synthase (STS) were introduced into microorganisms for the production of resveratrol, pterostilbene, piceatannol, and pinosylvin (Shrestha et al., 2019; Thapa et al., 2019). In most studies, resveratrol was produced from $p$-coumaric acid by the co-expression of $4 \mathrm{CL}$ and STS (Beekwilder et al., 2006; Watts et al., 2006; Katsuyama et al., 2007b; Lim et al., 2011), or from L-Tyr (or L-Phe) by the coexpression of Tal (or Pal), 4CL, and STS (Katsuyama et al., 2007a; Wu et al., 2013; Wang S. Y. et al., 2015). The highest titer (2.3 g/L) of resveratrol was obtained from $p$-coumaric acid by engineered E. coli BW27784 containing the $4 c 11$ gene from A. thaliana and sts gene from Vitis vinifera in the presence of $0.05 \mathrm{mM}$ cerulenin (Lim et al., 2011). The authors also demonstrated that the combination of 4CL from $A$. thaliana and STS from $V$. vinifera was the most suitable combination for resveratrol production. The de novo biosynthesis of resveratrol from glucose was reported for the first time by Liu et al. (2016). The tal gene from $R$. glutinis, $4 c l$ gene from P. crispum, and sts gene from V. vinifera were site-specifically integrated into the loci of the genes tyrR and trpED within the chromosome of E. coli BW25113 (DE3). The engineered strain produced $4.612 \mathrm{mg} / \mathrm{L}$ of resveratrol from glucose in shake flask cultures (Liu et al., 2016). A co-culture of $p$ coumaric acid producing E. coli and resveratrol producing E. coli was used to improve resveratrol production from glycerol to 22.6 $\mathrm{mg} / \mathrm{L}$ in a 1-L bioreactor batch fermentation process (CamachoZaragoza et al., 2016). Recently, the CRISPRi system was used to repress fabFBID involved in the fatty acid biosynthetic pathway, which improved the amount of resveratrol produced from glucose to $304.5 \mathrm{mg} / \mathrm{L}$ (Wu et al., 2017b). The titer was obtained by the introduction of the malonate assimilation pathway from Rhizobium trifolii and the repression of the fatty acid biosynthetic pathway using CRISPRi. Since 2003, S. cerevisiae has been successfully used as the host strain for stilbene production from $p$-coumaric acid, by the introduction of the 4CL216 gene from a hybrid poplar and the vst 1 gene from $V$. vinifera (Becker et al., 2003). Li et al. (2015) first reported an engineered $S$. cerevisiae capable of the de novo biosynthesis of resveratrol from glucose. The introduction of the tal gene from Herpetosiphon aurantiacus, $4 c l$ gene from $A$. thaliana, and sts gene from $V$. vinifera in an engineered $S$. cerevisiae overexpressing the feedback-insensitive alleles of $A R O 4$ and $A R O 7$ resulted in the de novo production of resveratrol from glucose (Li et al., 2015). The overexpression of the inactivation-resistant variant of acetyl-CoA carboxylase (Acc1p $\mathrm{p}^{\mathrm{S} 659 \mathrm{~A} / \mathrm{S} 1157 \mathrm{~A}}$ ) to abolish its phosphorylation, and the increase in the copy number of the heterologous resveratrol biosynthetic pathway via tyrosine further improved the amount of resveratrol produced from glucose to 415.65 $\mathrm{mg} / \mathrm{L}$, or that produced from ethanol to $532.42 \mathrm{mg} / \mathrm{L}$, in a fed-batch fermentation process. The authors then applied a strategy involving pull-push-block stain engineering to further improve the amount of resveratrol produced from glucose in a fed-batch fermentation process to $812 \mathrm{mg} / \mathrm{L}$ (Li M. et al., 2016). The titer was obtained by the multiple integrations of the heterologous pathway genes via phenylalanine, enhancement of P450 activity, upregulation of the expression levels of the feedback-insensitive alleles of $A R O 4$ and $A R O 7$, and the inactivation-resistant variant of acetyl-CoA carboxylase $\left(\right.$ Acc1p $\mathrm{S}^{\mathrm{6} 59 \mathrm{~A} / \mathrm{S} 1157 \mathrm{~A}}$ ), along with blockage of the decarboxylation of phenylpyruvate. Kallscheuer et al. (2016) constructed a C. glutamicum platform strain for the production of resveratrol from glucose. The heterologous biosynthetic pathway genes containing the sts gene from Arachis hypogaea, $4 \mathrm{cl}$ gene from P. crispum and tal gene from Flavobacterium johnsoniae, and the $a r o H$ gene from $E$. coli were introduced into the four gene cluster knockout $C$. glutamicum strain. The final strain produced $59 \mathrm{mg} / \mathrm{L}$ of resveratrol from glucose in the presence of $25 \mu \mathrm{M}$ of cerulenin in shake flask cultures (Kallscheuer et al., 2016). Then, this group found that increasing the intracellular acetylCoA availability through the reduction of citrate synthase activity further improved the production of resveratrol to $112 \mathrm{mg} / \mathrm{L}$ (Milke et al., 2019). A RppA-coupled malonyl-CoA biosensor was developed for high-throughput screening of targets increasing the malonyl-CoA pool (Yang et al., 2018). The authors applied the biosensor to screen an 1858 synthetic sRNA library and found 14 knockdown targets that generally enhanced malonylCoA level in E. coli. The pabA knockdown using sRNA increased resveratrol production by 4.2 -fold, which achieved $51.8 \mathrm{mg} / \mathrm{L}$ (Yang et al., 2018). After screening pathway genes from various species and exploring their expression pattern, an artificial resveratrol biosynthetic pathway was created and was introduced into E. coli strain for the production of resveratrol (Zhao et al., 2018). Co-overexpression of chaperone protein genes (groesgroEL), transport gene (ompF), and malony-CoA biosynthetic pathway genes (accBC-dtsR1) from C. glutamicum along with antisense inhibiting $f a b D$ significantly increased the production of resveratrol from L-Tyr, which reached $238.71 \mathrm{mg} / \mathrm{L}$.

Resveratrol is sensitive to light and oxygen, which limits its bioavailability and bioactivity. Both properties can be enhanced 
TABLE 4 | Production of stilbenes and benzylisoquinoline alkaloids by engineered microorganism.

\begin{tabular}{|c|c|c|c|c|c|c|}
\hline Products & Host & Genes expressed/deleted & Precursor & Culture conditions & Titer (mg/L) & References \\
\hline \multicolumn{7}{|l|}{ Stilbenes } \\
\hline Resveratrol & E. coli BW27784 & $\begin{array}{l}\text { Expressing Arabidopsis thaliana } 4 C \text { land Vitis } \\
\text { vinifera sts on a pUC18 plasmid }\end{array}$ & $p$-coumaric acid & $\begin{array}{l}\text { Shake-flask fermentation in } \\
\text { the presence of } 0.05 \mathrm{mM} \\
\text { cerulenin }\end{array}$ & $2.3 \mathrm{~g} / \mathrm{L}$ & Lim et al., 2011 \\
\hline Resveratrol & $\begin{array}{l}\text { E. coli BW25113 } \\
\text { (DE3) }\end{array}$ & $\Delta t y r R:: P_{T 7}-s t s, \Delta t r p E D:: P_{T 7}$-tal- $P_{T 7}-4 C l$ & Glucose & Shake-flask fermentation & $4.612 \mathrm{mg} / \mathrm{L}$ & Liu et al., 2016 \\
\hline Resveratrol & E. coli-E. coli & $\begin{array}{l}\text { The pheA knockout strain of W } 3110 \\
\text { expressing the aroG } G^{\text {ftr }} \text { and } t k t A \text { on a } \\
\text { pACYC184 origin plasmid, and the pal gene } \\
\text { from R. glutinis on a pTrc99A plasmid; Another } \\
\text { W } 3110 \text { strain expressing the } 4 C L \text { gene from } S \text {. } \\
\text { coelicolor A2 and the STS gene from } A \text {. } \\
\text { hypogaea on a pTrc99A plasmid }\end{array}$ & Glycerol & $\begin{array}{l}1 \mathrm{~L} \text { bioreactor batch } \\
\text { coculture fermentation }\end{array}$ & 22.6 mg/L & $\begin{array}{l}\text { Camacho-Zaragoza } \\
\text { et al., } 2016\end{array}$ \\
\hline \multirow[t]{2}{*}{ Resveratrol } & E. coli BL21 (DE3) & $\begin{array}{l}\Delta l a c Z:: P_{T 7} \text { aro } G^{\text {fbr }} \text {-tyrA fbr } \\
\text { Expressing tal from Trichosporon cutaneum } \\
\text { and } 4 C \text { from P. crispum on a CloDF13 origin } \\
\text { plasmid. Expressing sts from V. vinifera on a } \\
\text { pET22b plasmid. Expressing matB and matC } \\
\text { from Rhizobium trifolii on a pACYCDuet-1 } \\
\text { plasmid. Repressing fabF, fabl, fabB, and fabD } \\
\text { using CRISPRi }\end{array}$ & Glucose & Shake-flask fermentation & $304.5 \mathrm{mg} / \mathrm{L}$ & Wu et al., 2017b \\
\hline & E. coli BL21 (DE3) & $\begin{array}{l}\text { Expressing TAL from Phanerochaete } \\
\text { chrysosporium and } 4 C L \text { from } A \text {. thaliana on } \\
\text { pRSFDuet-1 plasmid. Expressing } V \text {. vinifera } \\
\text { STS on pCDFDuet-1 plasmid. Expressing } \\
\text { groES-groEL on pACYC origin plasmid. } \\
\text { Expressing } C \text {. glutamicum accBC-dtsR } 1, P_{T 7} \\
\text { anti-fabD, and ompF on pETDuet-1 plasmid }\end{array}$ & L-Tyr & Shake-flask fermentation & 238.71 mg/L & Zhao et al., 2018 \\
\hline Resveratrol & S. cerevisiae & $\begin{array}{l}\text { Chromosomal expressing } P_{T E F 1}-A R O 7^{G 141 S} \text {, } \\
P_{P G K 1}-A R O 4^{K 229 L} \text {, and } \\
P_{T E F 1}-A C C 1^{S 659 A / S 1157 A} \text {, multiple-integration of } \\
\text { the heterologous pathway genes consisted of } \\
\text { the tal gene from Herpetosiphon aurantiacus, } \\
\text { the } 4 C l \text { gene from A. thaliana and the sts gene } \\
\text { from } V \text {. vinifera }\end{array}$ & Glucose & $\begin{array}{l}1-\mathrm{L} \text { bioreactor fed-batch } \\
\text { fermentation }\end{array}$ & $415.65 \mathrm{mg} / \mathrm{L}$ & Li et al., 2015 \\
\hline Resveratrol & S. cerevisiae & 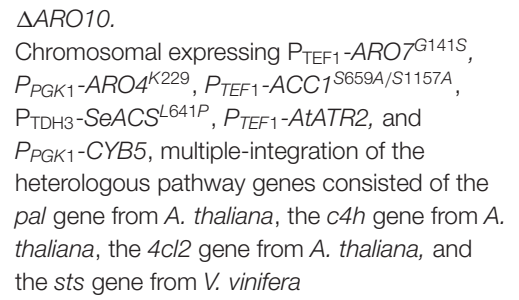 & Glucose & Fed-batch fermentation & 812 mg/L & Li M. et al., 2016 \\
\hline
\end{tabular}


TABLE 4 | Continued

\begin{tabular}{|c|c|c|c|c|c|c|}
\hline Products & Host & Genes expressed/deleted & Precursor & Culture conditions & Titer (mg/L) & References \\
\hline \multirow[t]{2}{*}{ Resveratrol } & $\begin{array}{l}\text { C. glutamicum } \\
\text { ATCC } 13032\end{array}$ & $\begin{array}{l}\Delta c g 0344-47, \Delta c g 2625-40, \Delta c g 1226, \\
\Delta c g 0502 . \\
\text { Expressing stillbene syntase gene from Arachis } \\
\text { hypogaea and 4-coumarate CoA ligase gene } \\
\text { from P. crispum on a pMKEx2 plasmid. } \\
\text { Expressing aroH from E. coli and tyrosine } \\
\text { ammonia lyase gene from Flavobacterium } \\
\text { johnsoniae on a pEKEx3 plasmid }\end{array}$ & Glucose & $\begin{array}{l}\text { Shake-flask fermentation } \\
\text { with cerulenin } \\
\text { supplementation }\end{array}$ & 59 mg/L & Kallscheuer et al., 2016 \\
\hline & $\begin{array}{l}\text { C. glutamicum } \\
\text { ATCC } 13032\end{array}$ & $\begin{array}{l}\Delta c g 0344-47, \Delta c g 2625-40, \Delta c g 1226, \\
\Delta c g 0502, \Delta c g 0344-47: P T 7-\mathrm{Pc} 4 \mathrm{cl} \\
\text { Expressing A. hypogaea sts and } P . \text { crispum } 4 c l \\
\text { on a plasmid. Expressing } E . \text { coli aroH and } F . \\
\text { johnsoniae tal on another plasmid } \\
\text { Replacing the native gltA promotor with the } \\
\text { dapA promotor variant } \mathrm{C} 7\end{array}$ & Glucose & $\begin{array}{l}2 \mathrm{~L} \text { bioreactor batch } \\
\text { fermentation }\end{array}$ & $112 \mathrm{mg} / \mathrm{L}$ & Milke et al., 2019 \\
\hline Pinostillbene & S. cerevisiae & 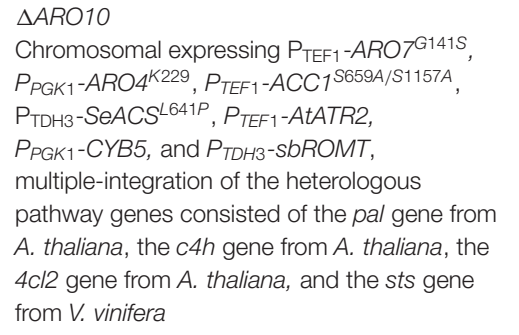 & Glucose & $\begin{array}{l}\text { Feed-in-time medium in } \\
\text { m2p microbioreactor }\end{array}$ & $5.52 \mathrm{mg} / \mathrm{L}$ & Li M. et al., 2016 \\
\hline Pterostilbene & S. cerevisiae & 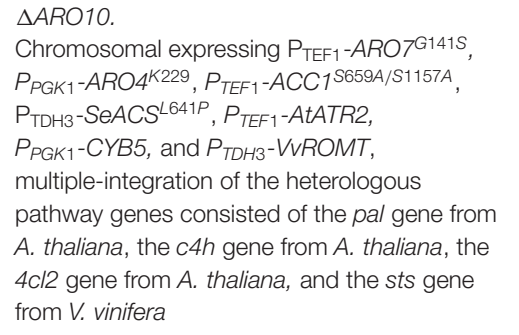 & Glucose & $\begin{array}{l}\text { Feed-in-time medium in } \\
\text { m2p microbioreactor }\end{array}$ & $34.93 \mathrm{mg} / \mathrm{L}$ & Li M. et al., 2016 \\
\hline Pterostillbene & E. coli C41(DE3) & $\begin{array}{l}\Delta t y r R:: t y r A^{f b r} \text {-aroG } G^{\text {tbr }} \text {. } \\
\text { Expressing the codon-optimized tyrosine } \\
\text { ammonia lyase gene from S. espanaensis, } \\
p \text {-coumarate:CoA ligase gene from } N \text {. } \\
\text { tabacum, caffeic acid O-methyltransferase } \\
\text { gene from } A \text {. thaliana, and stilbene synthase } \\
\text { gene from } V \text {. vinifera on a pET-28a }(+) \text { vector }\end{array}$ & Glucose & $\begin{array}{l}\text { Shake-flask fermentation } \\
\text { with L-methionine } \\
\text { supplementation }\end{array}$ & $33.6 \mathrm{mg} / \mathrm{L}$ & Heo et al., 2017 \\
\hline
\end{tabular}




\begin{tabular}{|c|c|c|c|c|c|c|}
\hline Products & Host & Genes expressed/deleted & Precursor & Culture conditions & Titer $(\mathrm{mg} / \mathrm{L})$ & References \\
\hline Pinosylvin & E. coli & $\begin{array}{l}\text { Expressing Pinus strobus stilbene synthase } \\
\text { T248A mutant with an N-terminal His } 6 \text { tag, the } \\
\text { 4-coumarate:CoA ligase A294G mutant from } \\
\text { S. coelicolor and the phenylalanine } \\
\text { ammonialyase gene from P. crispum on a RSR } \\
\text { origin plasmid (pRSFDuet1) }\end{array}$ & Glucose & $\begin{array}{l}\text { Shake-flask fermentation } \\
\text { with the addition of } \\
\text { cerulenin and L-Phe }\end{array}$ & $91 \mathrm{mg} / \mathrm{L}$ & $\begin{array}{l}\text { van Summeren- } \\
\text { Wesenhagen and } \\
\text { Marienhagen, } 2015\end{array}$ \\
\hline Pinosylvin & $\begin{array}{l}\text { E. coli } \\
\text { ATCC31884- E. } \\
\text { coli DH5 } \alpha\end{array}$ & $\begin{array}{l}\text { L-Phe producer expressing R. glutini pal on a } \\
\text { pBR322 origin plasmid (pQE30). E. coli DH5a } \\
\text { expressing A. thaliana } 4 C l, V \text {. vinifera rs on a } \\
\text { pBR322 origin plasmid (pQE30). The } \\
\text { repression of fabD using CRISPRi }\end{array}$ & Glycerol & & $47.5 \mathrm{mg} / \mathrm{L}$ & Liang et al., 2016 \\
\hline Pinosylvin & E. coli BL21 (DE) & 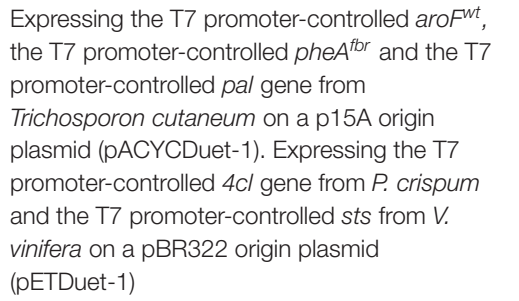 & glucose & Shake-flask fermentation & $281 \mathrm{mg} / \mathrm{L}$ & Wu et al., $2017 a$ \\
\hline Piceatannol & E. coli & $\begin{array}{l}\text { Expressing E. coli W hpaBC on a pZE12-luc } \\
\text { plasmid }\end{array}$ & Resveratrol & Shake-flask fermentation & $1.2 \mathrm{~g} / \mathrm{L}$ & Lin and Yan, 2014 \\
\hline \multicolumn{7}{|c|}{ Benzylisoquinoline } \\
\hline (R,S)-Reticuline & E. coli & $\begin{array}{l}\text { Expressing the T7 promoter-controlled Coptis } \\
\text { japonica norcoclaurine synthase gene (NCS) } \\
\text { and the tac promoter-controlled M. luteus } \\
\text { monoamine oxidase gene (mao) on a } \\
\text { pKK223-3 plasmid (pBR322 ori). Expressing } \\
\text { the T7 promoter-controlled C. japonica } \\
\text { norcoclaurine 6-O-methyltransferase gene } \\
(6 \mathrm{MT}) \text {, the T7 promoter-controlled C. } \\
\text { japonica 3'-hydroxy-N-methylcoclaurine-4'-O- } \\
\text { methyltransferase gene (4'OMT) and the T7 } \\
\text { promoter-controlled C. japonica } \\
\text { coclaurine-N-methyltransferase gene (CNMT) } \\
\text { on a pACYC184 plasmid }\end{array}$ & Dopamine & Shake-flask fermentation & $11 \mathrm{mg} / \mathrm{L}$ & Minami et al., 2008 \\
\hline Magnoflorine & $\begin{array}{l}\text { E. coli- } S \text {. } \\
\text { cerevisiae }\end{array}$ & $\begin{array}{l}\text { E. coli: Expressing the T7 promoter-controlled } \\
\text { C. japonica NCS and the tac } \\
\text { promoter-controlled M. Iuteus mao on a } \\
\text { pKK223-3 plasmid (pBR322 ori). Expressing } \\
\text { the T7 promoter-controlled C. japonica 6OMT, } \\
\text { the T7 promoter-controlled C. japonica 4'OMT } \\
\text { and the T7 promoter-controlled C. japonica } \\
\text { CNMT on a pACYC184 plasmid. } \\
\text { S. cerevisiae: Expressing CYP80G2 and CNMT } \\
\text { from C. japonica on a pGYR plasmid. }\end{array}$ & Dopamine & $\begin{array}{l}\text { Shake-flask E. coli- } S \text {. } \\
\text { cerevisiae culture }\end{array}$ & $7.2 \mathrm{mg} / \mathrm{L}$ & Minami et al., 2008 \\
\hline
\end{tabular}




\begin{tabular}{|c|c|c|c|c|c|c|}
\hline Products & Host & Genes expressed/deleted & Precursor & Culture conditions & Titer (mg/L) & References \\
\hline Scoulerine & $\begin{array}{l}\text { E. coli- S. } \\
\text { cerevisiae }\end{array}$ & $\begin{array}{l}\text { E. coli: Expressing the T7 promoter-controlled } \\
\text { C. japonica NCS and the tac } \\
\text { promoter-controlled M. luteus mao on a } \\
\text { pKK223-3 plasmid (pBR322 ori). Expressing } \\
\text { the } T 7 \text { promoter-controlled C. japonica } 6 O M T \text {, } \\
\text { the } T 7 \text { promoter-controlled C. japonica } 4{ }^{\prime} O M T \\
\text { and the T7 promoter-controlled C. japonica } \\
\text { CNMT on a pACYC184 plasmid. } \\
\text { S. cerevisiae: Expressing berberine bridge } \\
\text { enzyme gene (BBE) from C. japonica on a } \\
\text { pYES2 plasmid. }\end{array}$ & Dopamine & $\begin{array}{l}\text { Shake-flask E. coli- } S \text {. } \\
\text { cerevisiae culture }\end{array}$ & $8.3 \mathrm{mg} / \mathrm{L}$ & Minami et al., 2008 \\
\hline Reticuline & E. coli BL21 (DE3) & $\begin{array}{l}\text { Expressing the T7 promoter-controlled } C \text {. } \\
\text { japonica NCS and the T7 promoter-controlled } \\
\text { M. luteus mao on a pCDFPL plasmid (CloDF13 } \\
\text { ori). Expressing the T7 promoter-controlled C. } \\
\text { japonica } 6 O M T \text {, the } T 7 \text { promoter-controlled } C \text {. } \\
\text { japonica } 4 \text { 'OMT and the T7 } \\
\text { promoter-controlled C. japonica CNMT on a } \\
\text { pACYC184 plasmid. }\end{array}$ & Dopamine & Shake-flask fermentation & $54 \mathrm{mg} / \mathrm{L}$ & Kim J. S. et al., 2013 \\
\hline \multirow[t]{2}{*}{ (S)-Reticuline } & E. coli BL21 (DE3) & 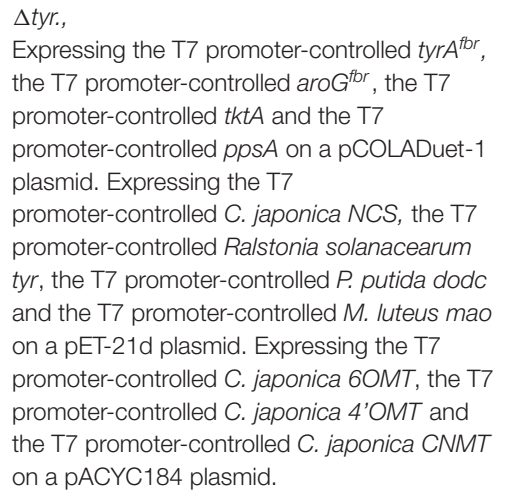 & Glycerol & Fed-batch fermentation & 46 mg/L & Nakagawa et al., 2011 \\
\hline & E. coli BL21 (DE3) & $\begin{array}{l}\Delta t y r R \\
\text { Expressing } 6 O M T, C N M T, D O D C \text {, and } 4^{\prime} O M T \\
\text { in pACYC184 plasmid, NCS and MAO in } \\
\text { pET-23a plasmid, Bacillus subtilis GTP } \\
\text { cyclohydrolase gene ( } m \text { trA), rat } \\
\text { 6-pyruvoyl-tetrahydropterin synthase gene } \\
\text { (PTPS), rat sepiapterin reductase gene }(S P R), \\
\text { and Drosophila melanogaster tryrosine } \\
\text { hydroxylase (TH2) in pCDFPL plasmid, and } \\
\text { tyrA } A^{\text {tor }} \text {, aroG } G^{\text {tbr }}, t \text { ktA, and ppsA in } \\
\text { pCOLADuet-1 plasmid }\end{array}$ & & Fed-batch fermentation & $163.5 \mathrm{mg} / \mathrm{L}$ & Matsumura et al., 2018 \\
\hline
\end{tabular}




\section{TABLE 4 | Continued}

\begin{tabular}{|c|c|c|c|c|c|c|}
\hline Products & Host & Genes expressed/deleted & Precursor & Culture conditions & Titer (mg/L) & References \\
\hline (S)-Reticuline & S. cerevisiae & $\begin{array}{l}\text { Chromosomal integration of ARO4 } 4^{\text {tbr }} \text {, Bete } \\
\text { vilgaris CYP76AD 1 W13L/F309L, } P \text {. putida dodc } \\
\text { and P. somniferum NCS; plasmid-expressing of } \\
\text { 6OMT, CNMT and 4'OMT from P. somniferum, } \\
\text { and Eschscholzia californica CYP8OB1 on a } \\
\text { CEN6/ARS4 plasmid. }\end{array}$ & Glucose & Shake-flask fermentation & $80.6 \mu \mathrm{g} / \mathrm{L}$ & DeLoache et al., 2015 \\
\hline (S)-Reticuline & $\begin{array}{l}\text { S. cerevisiae } \\
\text { CEN.PK2-1D }\end{array}$ & 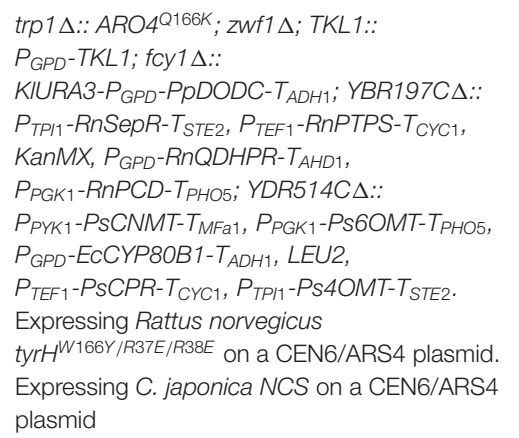 & Glucose & Shake-flask fermentation & $19.2 \mu \mathrm{g} / \mathrm{L}$ & Trenchard et al., 2015 \\
\hline Noscapine & S. cerevisiae & 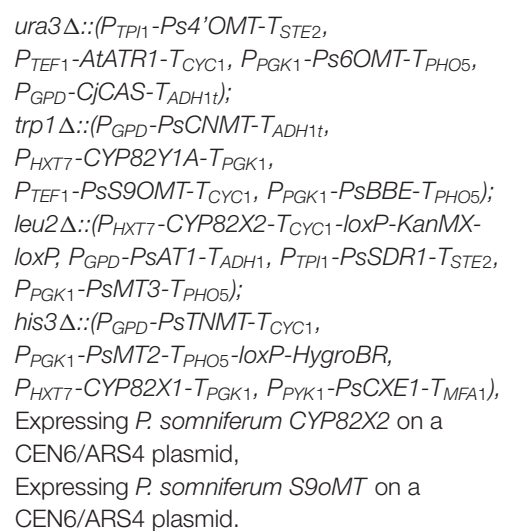 & Norlaudanosoline & $\begin{array}{l}500-\mu L \text { 96-deep well plate } \\
\text { fermentation }\end{array}$ & $1.64 \mathrm{mM}$ & Li and Smolke, 2016 \\
\hline
\end{tabular}


TABLE 4 | Continued

\begin{tabular}{|c|c|c|c|c|c|c|}
\hline Products & Host & Genes expressed/deleted & Precursor & Culture conditions & Titer (mg/L) & References \\
\hline Noscapine & S. cerevisiae & 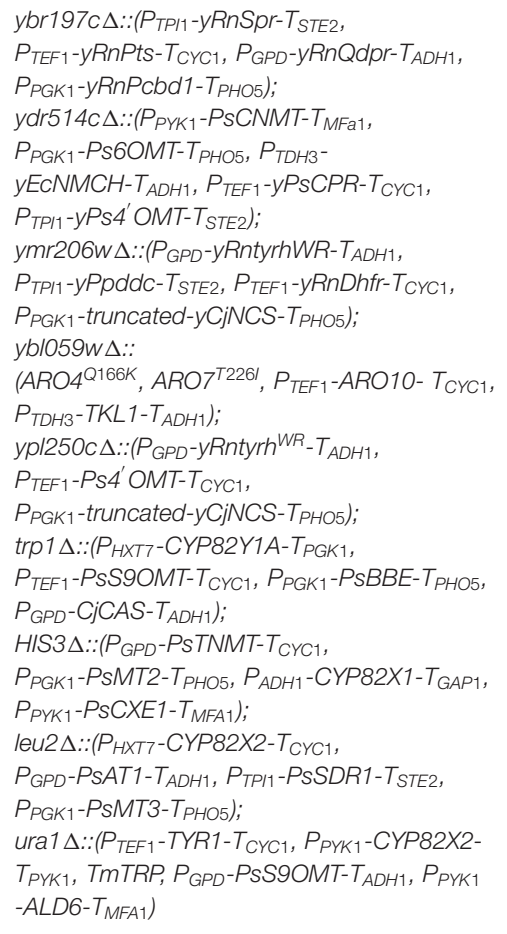 & Glycerol & Shake-flask fermentation & $2.2 \mathrm{mg} / \mathrm{L}$ & LiX. et al., 2018 \\
\hline Sanguinarine & S. cerevisiae & 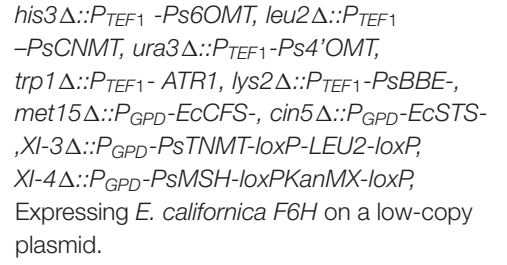 & (R,S)-norlaudanosoline & & $80 \mu \mathrm{g} / \mathrm{L}$ & $\begin{array}{l}\text { Trenchard and Smolke, } \\
2015\end{array}$ \\
\hline
\end{tabular}


TABLE 4 | Continued

\begin{tabular}{|c|c|c|c|c|c|c|}
\hline Products & Host & Genes expressed/deleted & Precursor & Culture conditions & Titer (mg/L) & References \\
\hline (S)-Canadine & S. cerevisiae & 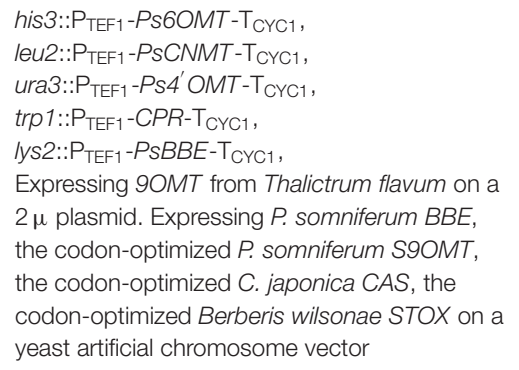 & (R,S)-norlaudanosoline & Shake-flask fermentation & $1.8 \mathrm{mg} / \mathrm{L}$ & $\begin{array}{l}\text { Galanie and Smolke, } \\
2015\end{array}$ \\
\hline (S)-Berberine & S. cerevisiae & 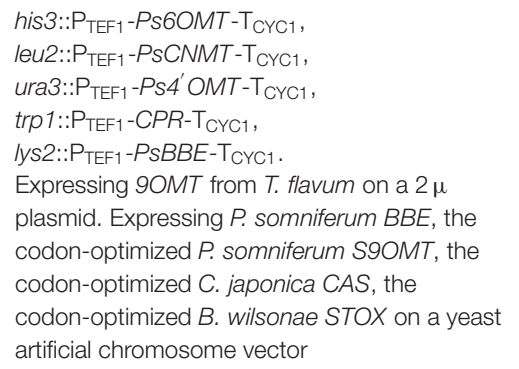 & (R,S)-norlaudanosoline & Shake-flask fermentation & $6.5 \mu \mathrm{g} / \mathrm{L}$ & $\begin{array}{l}\text { Galanie and Smolke, } \\
2015\end{array}$ \\
\hline $\begin{array}{l}\text { Opioid (Oxycodone, } \\
\text { hydrocodone, etc) }\end{array}$ & S. cerevisiae & $\begin{array}{l}\text { ura3 } \triangle:: \mathrm{P}_{\mathrm{GPD}}-T 6 O D M-\mathrm{T}_{\mathrm{CYC1}}, \\
\text { his3 } \Delta:: \mathrm{P}_{\mathrm{GPD}}-\mathrm{T} 6 \mathrm{OOM}-\mathrm{T}_{\mathrm{CYC1}} \text {. } \\
\text { Expressing the codon-optimized } P \text {. somniferum } \\
\text { T6ODM and the codon-optimized morB from } P \text {. } \\
\text { putida } \mathrm{M} 10 \text { on a yeast artificial chromosome } \\
\text { vector }\end{array}$ & Thebaine & $\begin{array}{l}\text { Parallel } 0.25-\mathrm{L} \text { closed-batch } \\
\text { fermentation }\end{array}$ & $131 \mathrm{mg} / \mathrm{L}$ & Thodey et al., 2014 \\
\hline $\begin{array}{l}\text { Opioid } \\
\text { (14-hydroxycodeine, } \\
\text { neopine, etc) }\end{array}$ & & 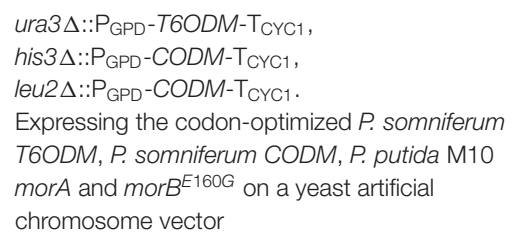 & Thebaine & $\begin{array}{l}\text { Parallel } 0.25-\mathrm{L} \text { closed-batch } \\
\text { fermentation }\end{array}$ & 74 mg/L & Thodey et al., 2014 \\
\hline $\begin{array}{l}\text { Opioid } \\
\text { (14-hydroxycodeine, } \\
\text { codeine, morphine, } \\
\text { etc) }\end{array}$ & S. cerevisiae & $\begin{array}{l}\text { ura3 } \triangle:: \mathrm{P}_{\mathrm{GPD}}-T 6 O D M-\mathrm{T}_{\mathrm{CYC1}}, \\
\text { his3 } \Delta:: \mathrm{P}_{\mathrm{GPD}}-C O D M-\mathrm{T}_{\mathrm{CYC}}, \\
\text { leu2 } \Delta:: \mathrm{P}_{\mathrm{GPD}}-C O D M-T_{\mathrm{CYC}} \text {. } \\
\text { Expressing the codon-optimized } P \text {. somniferum } \\
\text { T6ODM, COR1.3-ER1, and CODM on a yeast } \\
\text { artificial chromosome vector }\end{array}$ & Thebaine & $\begin{array}{l}\text { Parallel } 0.25-\mathrm{L} \text { closed-batch } \\
\text { fermentation }\end{array}$ & 42 mg/L & Thodey et al., 2014 \\
\hline
\end{tabular}


TABLE 4 | Continued

\begin{tabular}{|c|c|c|c|c|c|c|}
\hline Products & Host & Genes expressed/deleted & Precursor & Culture conditions & Titer (mg/L) & References \\
\hline Thebaine & S. cerevisiae & 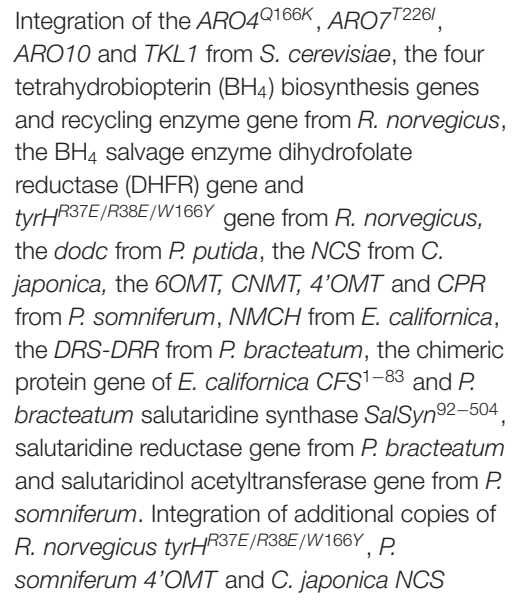 & Dextrose & $\begin{array}{l}0.5-\mathrm{mL} 96-\text { well plate } \\
\text { fermentation }\end{array}$ & $6.4 \mu \mathrm{g} / \mathrm{L}$ & Galanie et al., 2015 \\
\hline Hydrocodone & S. cerevisiae & $\begin{array}{l}\text { Integration of the } A R O 4^{Q 166 K}, A R O 7^{T 226 I} \text {, } \\
A R O 10 \text {, and } T K L 1 \text { from S. cerevisiae, the four } \\
\text { tetrahydrobiopterin }\left(\mathrm{BH}_{4}\right) \text { biosynthesis genes } \\
\text { and recycling enzyme gene from R. norvegicus, } \\
\text { the } \mathrm{BH}_{4} \text { salvage enzyme dihydrofolate } \\
\text { reductase (DHFR) gene and tyr P37E/R38E/W166Y } \\
\text { from } R \text {. norvegicus, the dodc from P. putida, } \\
\text { the } N C S \text { from C. japonica, the } 6 O M T, C N M T \text {, } \\
4^{\prime} O M T \text { and } C P R \text { from } P \text {. somniferum, NMCH } \\
\text { from E. californica, the DRS-DRR from } P \text {. } \\
\text { bracteatum, the chimeric protein of }\end{array}$ & Dextrose & $\begin{array}{l}\text { 0.5-mL } 96 \text {-well plate } \\
\text { fermentation }\end{array}$ & $0.3 \mu \mathrm{g} / \mathrm{L}$ & Galanie et al., 2015 \\
\hline
\end{tabular}


TABLE 4 | Continued

\begin{tabular}{|c|c|c|c|c|c|c|}
\hline Products & Host & Genes expressed/deleted & Precursor & Culture conditions & Titer (mg/L) & References \\
\hline & & $\begin{array}{l}\text { E. californica } C F S^{1-83} \text { and } P \text {. bracteatum } \\
\text { salutaridine synthase SalSyn }{ }^{92-504} \text {, salutaridine } \\
\text { reductase gene from } P \text {. bracteatum and } \\
\text { salutaridinol acetyltransferase gene from } P \text {. } \\
\text { somniferum. Integration of additional copies of } \\
R \text {. norvegicus tyr } H^{R 37 E / R 38 E / W 166 Y}, P \text {. } \\
\text { somniferum } 4^{\prime} O M T \text { and } C \text {. japonica } N C S \text {. } \\
\text { Expression of T6ODM from } P \text {. somniferum and } \\
\text { morB from } P \text {. putida M10 on a yeast artificial } \\
\text { chromosome vector }\end{array}$ & & & & \\
\hline Thebaine & E. coli-E. coli & $\begin{array}{l}\text { The dopamine producer: } \Delta t y r R \text {. Expressing } \\
\text { tyrA } A^{\text {tbr }} \text {, tktA and ppsA on a pCOLADuet-1 } \\
\text { plasmid, expressing tyrosinase gene from } R \text {. } \\
\text { solanacearum and dodc from P. putida on a } \\
\text { pET32a plasmid. The (R,S)-THP producer: } \\
\text { Expressing mao from M. luteus on a pGS21 } \\
\text { plasmid. } \\
\text { The (R,S)-reticuline producer: Expressing } \\
\text { CNMT and 4'OMT from C. japonica on a } \\
\text { pET23a plasmid. } \\
\text { The thebaine producer: Expressing the } \\
\text { N-terminal truncated SalS from P. somniferum } \\
\text { on a pET23a plasmid. Expressing ATR2 from } \\
\text { A. thaliana, SalAT and SalR from P. somniferum } \\
\text { on a pCDF23 plasmid }\end{array}$ & Glycerol & $\begin{array}{l}\text { Stepwise culture of four } \\
\text { engineered strains }\end{array}$ & $2.1 \mathrm{mg} / \mathrm{L}$ & Nakagawa et al., 2016 \\
\hline Hydrocodone & E. coli-E. coli & $\begin{array}{l}\text { The dopamine, (R,S)-THP and (R,S)-reticuline } \\
\text { producers are the same as that for the thebaine }\end{array}$ & Glycerol & $\begin{array}{l}\text { Stepwise culture of four } \\
\text { engineered strains }\end{array}$ & $0.36 \mathrm{mg} / \mathrm{L}$ & Nakagawa et al., 2016 \\
\hline
\end{tabular}

the $\mathrm{N}$-terminal trunebaine producer: Expressing

engineered strains 
by the substitution of hydroxyl groups with methoxy groups. Resveratrol methyltransferase from A. thaliana (Heo et al., 2017), O. sativa (Katsuyama et al., 2007a), Sorghum bicolor (Jeong et al., 2014; Li M. et al., 2016), Vitis riparia (Jeong et al., 2014), and V. vinifera (Wang Y. C. et al., 2015; Li M. et al., 2016; Kallscheuer et al., 2017; Wang et al., 2018) were used to convert resveratrol to pinostilbene/pterostilbene (Figure 5). The methyltransferase from $O$. sativa methylated the hydroxy groups at positions 3 and 5 of resveratrol to form pinostilbene/pterostilbene (Katsuyama et al., 2007a). The methylation of resveratrol by the methyltransferase from $S$. bicolor yielded pinostilbene as the major product and a very small amount of pterostilbene, whereas the methyltransferase from $V$. riparia showed very low methylation activity when resveratrol was used as a substrate (Jeong et al., 2014). The expression of the methyltransferase enzyme from $V$. vinifera or $A$. thaliana led to the production of the major product pterostilbene from resveratrol, and a very small amount of pinostilbene (Wang Y. C. et al., 2015; Li M. et al., 2016; Heo et al., 2017; Wang et al., 2018). The titer of pterostilbene $(50 \mathrm{mg} / \mathrm{L})$ produced from $p$ coumaric acid by the methyltransferase from $V$. vinifera (Wang Y. C. et al., 2015) was higher than that $(10 \mathrm{mg} / \mathrm{L})$ produced by the methyltransferase from A. thaliana (Heo et al., 2017), indicating that the methyltransferase from $V$. vinifera is more beneficial for the production of pterostilbene. The de novo biosynthesis of pinostilbene or pterostilbene from glucose was achieved for the first time by the introduction of the methyltransferase from S. bicolor or $V$. vinifera, respectively, into resveratrol producing yeast (Li M. et al., 2016). The engineered S. cerevisiae containing the methyltransferase from S. bicolor produced 5.52 $\mathrm{mg} / \mathrm{L}$ of pinostilbene from glucose. The engineered S. cerevisiae containing the methyltransferase from $V$. vinifera produced $34.93 \mathrm{mg} / \mathrm{L}$ of pterostilbene and $1.96 \mathrm{mg} / \mathrm{L}$ of pinostilbene from glucose. Heo et al. (2017) also engineered E. coli for the de novo biosynthesis of pterostilbene from glucose by the overexpression of caffeic acid O-methyltransferase from A. thaliana, tyrosine ammonia lyase from $S$. espanaensis, p-coumarate: CoA ligase from $N$. tabacum, and stilbene synthase from $V$. vinifera in the LTyr-overproducing E. coli strain. The resulting E. coli produced $33.6 \mathrm{mg} / \mathrm{L}$ of pterostilbene from glucose in shake flask cultures containing additional L-methionine medium.

Pinosylvin is a natural resveratrol analog that lacks a hydroxyl group at the C-4 position. It is synthesized from L-Phe in three enzymatic steps (Figure 5). L-Phe is first transformed to cinnamic acid by L-Phe ammonia lyase. Subsequently, the enzyme 4-coumarate/cinnamate:coenzyme A ligase converts the cinnamic acid to cinnamoyl-CoA. Finally, the enzyme stilbene synthase catalyzes the stepwise condensation of three molecules of malonyl-CoA with one molecule of cinnamoyl-CoA, yielding one molecule of pinosylvin. The production of pinosylvin was achieved from L-Phe for the first time by the co-expression of the phenylalanine ammonia lyase gene from Rhodotorula rubra, the 4-coumarate:CoA ligase gene from Lithospermum erythrorhizon, the stilbene synthase gene from A. hypogaea, and the acetylCoA carboxylase gene from C. glutamicum (Katsuyama et al., 2007a). The resulting E. coli strain produced $20 \mathrm{mg} / \mathrm{L}$ pinosylvin from L-Phe. De novo biosynthesis of pinosylvin was achieved for the first time by the co-expression of the stilbene synthase gene from Pinus strobus, the 4-coumarate: CoA ligase gene from $S$. coelicolor, and the phenylalanine ammonia lyase gene from $P$. crispum (van Summeren-Wesenhagen and Marienhagen, 2015). The addition of cerulenin to increase the intracellular malonylCoA pools and the directed evolution of stilbene synthase from $P$. strobus further enhanced pinosylvin production. The final engineered $E$. coli strain produced $91 \mathrm{mg} / \mathrm{L}$ of pinosylvin from glucose after the addition of cerulenin and L-Phe (van Summeren-Wesenhagen and Marienhagen, 2015). Cerulenin is expensive and its use is not cost-effective for a large-scale fermentation process. In seeking a better alternative, the CRISPRi system was used to repress the $f a d D$ gene, which increased the availability of malonyl-CoA and resulted in the production of $47.5 \mathrm{mg} / \mathrm{L}$ of pinosylvin from glycerol (Liang et al., 2016). A rational modular design approach was used to improve pinosylvin production from glucose in E. coli (Wu et al., 2017a). The overall pinosylvin synthetic pathway was divided into two modules that were separated at cinnamic acid. The combined optimization of the transcriptional and translational levels of these two modules by modifying the plasmid copy numbers, promoter strength, and 5' region of the mRNA secondary structure increased the titer of pinosylvin by 16 times. The CRISPRi system was also used to repress $f a b B, f a b F, a d h E$, eno, fumC, and sucC to improve pinosylvin production. The resulting E. coli produced $281 \mathrm{mg} / \mathrm{L}$ of pinosylvin, which was the highest titer directly obtained from glucose without the provision of supplementation with any additional precursors (Wu et al., 2017a). The metabolic engineering strategy based on the post-translational modification of proteins was used to optimize the lysine acylation of the stilbene synthase and to improve pinosylvin production by $220 \%$ (Xu et al., 2018).

Piceatannol is another natural resveratrol analog with an additional phenolic hydroxyl group at the C-3 position. It can be synthesized from caffeic acid or resveratrol (Figure 5). E. coli $\mathrm{W}$ endogenous non-P450 monooxygenase $(\mathrm{HpaBC})$ catalyzed the ortho-hydroxylation of resveratrol to piceatannol, which resulted in the maximal titer of $1.2 \mathrm{~g} / \mathrm{L}$ from resveratrol with a nearly 100\% molar yield (Lin and Yan, 2014). An engineered C. glutamicum was constructed for the production of pinosylvin or piceatannol from cinnamic acid or caffeic acid, respectively, by the introduction of stilbene synthase from $A$. hypogaea (Kallscheuer et al., 2016).

\section{PRODUCTION OF BENZYLISOQUINOLINE ALKALOIDS}

Benzylisoquinoline alkaloids (BIAs) are a large family of Ltyrosine-derived plant-specialized compounds with a variety of therapeutic uses. This class of compounds includes the opioid analgesics morphine and codeine, the antibiotics sanguinarine and berberine, the muscle relaxants (+)tubocurarine and papaverine, and the cough suppressant noscapine. BIA synthesis begins with the condensation of dopamine and 4-hydroxyphenylacetaldehyde or 3,4di hydroxyphenylacetaldehyde to form (S)-norcoclaurine 
or (S)-norlaudanosoline ((S)-NorLaud, also known as (S)-tetrahydropapaveroline, (S)-THP) in engineered microorganisms (Figure 5, Table 4) (Diamond and DesgagnePenix, 2016; Narcross et al., 2016b). Both (S)-norcoclaurine and (S)-norlaudanosoline are unstable end-products, because they are subject to enzymatic oxidation as well as spontaneous oxidation at alkaline pHs. Thus, reticuline is frequently used as the key branch-point intermediate for the de novo synthesis of BIAs. Reticuline was produced in E. coli for the first time by the overexpression of monoamine oxidase (Mao) from $M$. luteus, norcoclaurine synthase (NCS) from Coptis japonica, norcoclaurine 6-O-methyltransferase (6OMT) from C. japonica, coclaurine-N-methyltransferase (CNMT) from C. japonica, and 3'-hydroxy-N-methylcoclaurine-4'-O-methyltransferase (4'OMT) from C. japonica (Figure 5) (Minami et al., 2008). Since some plant enzymes are not well-expressed in E. coli in an active form, various types of BIAs were then synthesized from reticuline using engineered S. cerevisiae. Co-cultures of E. coli expressing the reticuline biosynthetic genes and $S$. cerevisiae expressing $C$. japonica CYP80G2 and CNMT, or the C. japonica berberine bridge enzyme (BBE) were used to produce magnoflorine or scoulerine, respectively, from dopamine (Figure 5) (Minami et al., 2008). The overall yield of magnoflorine or scoulerine from dopamine was 1.9 or $2.2 \%$, respectively. After optimizing the fermentation conditions and the gene copy numbers, the reticuline titer generated from dopamine was increased by 5 -fold to $54 \mathrm{mg} / \mathrm{L}$ (Kim J. S. et al., 2013). Recently, this group comparatively analyzed the effect of the three methyltransferases on the biosynthesis of reticuline and found that the combination of 6OMT from P. somniferum, CNMT from P. somniferum, and 4'OMT from C. japonica was the most suitable combination for reticuline production (Matsumura et al., 2017). The de novo biosynthesis of reticuline was achieved for the first time by the co-expression of tyrosinase from Ralstonia solanacearum, DOPA decarboxylase (Dodc) from P. putida strain KT2440, Mao from M. luteus, NCS from C. japonica, 6OMT from C. japonica, CNMT from C. japonica, and the 4'OMT from C. japonica in the L-Tyr overproducing E. coli strain (Nakagawa et al., 2011). The final strain produced $46 \mathrm{mg} / \mathrm{L}$ (S)-reticuline from glycerol in a fed-batch fermentation process. Then, this group further improved the (S)-reticuline titer to $163.5 \mathrm{Mg} / \mathrm{L}$ by an engineered E. coli strain EM353, which possessed a tyrosine-overproducing pathway, a pathway producing dopamine from L-Tyr along with the $\mathrm{BH} 4$-synthesis pathway, and a pathway producing (S)reticuline from dopamine (Matsumura et al., 2018). In the above studies, tetrahydropapaveroline (THP), a reticuline precursor, is synthesized by Mao and Dodc. Recently, an insect Bombyx mori 3,4-dihydroxyphenylacetaldehyde synthase (DHPAAS) and its variants with Phe79Tyr, Tyr80Phe, and Asn192His were identified to replace Mao and Dodc for direct production $(\mathrm{R}, \mathrm{S})$-THP in a single enzyme system from L-DOPA (Vavricka et al., 2019).

S. cerevisiae is a more attractive host for BIA synthesis, due to its superior ability to express the plant enzymes and the cytochrome P450s, which are prevalent in BIA biosynthesis. The synthesis of reticuline in S. cerevisiae was initially achieved with a yield of $10 \%$ from norlaudanosoline by the overexpressions of $P$. somniferum 6OMT, CNMT, and 4'OMT (Hawkins and Smolke, 2008). S. cerevisiae strains were also engineered for the production of the protoberberine intermediate (S)-canadine and the morphinan intermediate salutaridine from (R,S)-norlaudanosoline (Hawkins and Smolke, 2008). The yield of reticuline obtained from norlaudanosoline in $S$. cerevisiae was then increased to $20 \%$ (Fossati et al., 2014). These two research groups constructed a de novo biosynthetic pathway for producing reticuline from glucose via norcoclaurine and reported their results at the same time (DeLoache et al., 2015; Trenchard et al., 2015). To solve the issue of the poor activity of tyrosine hydroxylase in yeast, an enzyme-coupled biosensor of L-DOPA was developed. Using this sensor, a mutant (W13L/F309L) of CYP76AD1 from Bete vilgaris was obtained to improve its L-DOPA yield by 2.8 -fold via directed evolution (DeLoache et al., 2015). The co-expression of the feedbackinsensitive Aro4, the CYP76AD1 variant, DOPA decarboxylase (DODC) from $P$. putida, a newly identified NCS from $P$. somniferum, 6OMT, CNMT, and 4'OMT from $P$. somniferum, and the cytochrome P450 N-methylcoclaurine hydroxylase (NMCH) from Eschscholzia californica in S. cerevisiae resulted in the de novo production of $80.6 \mu \mathrm{g} / \mathrm{L}$ of reticuline from glucose (DeLoache et al., 2015). In the study by the research group led by Smolke, the mammalian tyrosine hydroxylase mutant (W166Y/R37E/R38E) from Rattus norvegicus, the four tetrahydrobiopterin $\left(\mathrm{BH}_{4}\right)$ biosynthesis and recycling enzymes from $R$. norvegicus, and bacterial DOPA decarboxylase from $P$. putida were introduced in the L-Tyr overproducing $S$. cerevisiae strain for the production of norcoclaurine (Trenchard et al., 2015). The co-expression of optimized NCS from C. japonica, the three methyltransferases (6OMT, CNMT, and $4^{\prime} \mathrm{OMT}$ ) from P. somniferum, the cytochrome P450 (CYP80B1) from E. californica, and its reductase partner (CPR) from $P$. somniferum in the aforementioned engineered $S$. cerevisiae strain resulted in the de novo production of $19.2 \mathrm{mg} / \mathrm{L}$ of reticuline from glucose in a shake flask fermentation process (Trenchard et al., 2015).

Noscapine has long been used as a cough suppressant. Due to its long-established safety record, noscapine is a compelling candidate anti-cancer drug and has been used off-label to treat cancers in some countries. Noscapine is synthesized from L-Tyr through scoulerine (Figure 5). The synthetic pathway of noscapine with the 10-gene cluster was discovered in P. somniferum (Winzer et al., 2012). A 14-step biosynthetic pathway for the production of noscapine from norlaudanosoline was engineered for the first time in yeast ( $\mathrm{Li}$ and Smolke, 2016). After the optimization of the expression of 16 plant enzymes involved in this biosynthetic pathway, the engineered $S$. cerevisiae strain produced $1.64 \mathrm{mM}$ of noscapine. This group subsequently reported the de novo production of noscapine in $S$. cerevisiae, through the reconstruction of a biosynthetic pathway comprising 37 enzymes from plants, bacteria, mammals, and yeasts (Li Y. et al., 2018). After engineering rate-limiting pathway enzymes, optimizing enzyme expression levels, introducing modifications to the endogenous yeast metabolism to enhance $\mathrm{NADPH}$ availability, and optimizing fermentation conditions, 
the noscapine titer was improved by over 18,000 -fold to $\sim 2.2 \mathrm{mg} / \mathrm{L}$.

Sanguinarine is a BIA with recognized antimicrobial activities. It may have potential as an anti-neoplastic drug. Fossati et al. constructed a 10 -gene plant pathway in $S$. cerevisiae that allowed the production of the sanguinarine precursor dihydrosanguinarine from $(\mathrm{R}, \mathrm{S})$-norlaudanosoline, which resulted in a yield of $1.5 \%$ (Figure 5) (Fossati et al., 2014). The spontaneous oxidation of dihydrosanguinarine to sanguinarine was observed in this study. The 10 enzymatic steps included four reactions catalyzed by plant cytochrome P450s (Fossati et al., 2014). After optimizing the expression of the cytochrome P450s (including P450 enzymatic variants, the pairing of CPRs with $\mathrm{P} 450$ enzymatic variants, gene number copy and promoter) and culture conditions, $80 \mu \mathrm{g} / \mathrm{L}$ sanguinarine was produced from $(\mathrm{R}, \mathrm{S})$-norlaudanosoline in the engineered S. cerevisiae (Trenchard and Smolke, 2015). This titer was achieved by the expression of $P$. somniferum 6OMT, CNMT, 4'OMT, BBE, CPR, TNMT, and MSH, E. californica CFS, STS, and $P 6 H$, and $A$. thaliana ATR1. Mining of transcriptome libraries identified the superior cytochrome P450 enzymes CFS and SPS (Narcross et al., 2016a). They improved the level of molar conversion of norlaudanosoline to dihydrosanguinarine to $10 \%$. This study demonstrated that the mining of transcriptome libraries combined with gene synthesis is an effective strategy for pathway engineering.

Hawkins and Smolke reconstructed the biosynthetic pathway for the berberine precursor (S)-canadine in S. cerevisiae to achieve the microbial biosynthesis of $(\mathrm{S})$-canadine from $(\mathrm{R}, \mathrm{S})$ norlaudanosoline (Figure 5) (Hawkins and Smolke, 2008). Then, this group optimized cytochrome $\mathrm{P} 450$ oxidoreductase (canadine synthase CAS), scoulerine 9-O-methyltransferase S9OMT, and culture conditions, which improved the canadine and berberine production from $(\mathrm{R}, \mathrm{S})$-norlaudanosoline to 1.8 and $6.5 \mathrm{mg} / \mathrm{L}$, respectively (Galanie and Smolke, 2015). Their studies also demonstrated that canadine can be easily and spontaneously converted to berberine. The de novo synthesis of berberine has not been achieved in microorganisms to date. The abovementioned strategies as reported by Li Y. et al. (2018), which were used for the de novo synthesis of noscapine, can be used for berberine production, because berberine and noscapine have the same precursor, i.e., (S)-canadine.

Thodey et al. (2014) engineered S. cerevisiae strains to convert thebaine to codeine, morphine, hydromorphone, hydrocodone, and oxycodone, by expressing the thebaine 6-O-demethylase (T6ODM), codeine-O-demethylase (CODM), and codeinone reductase (COR1.3) from $P$. somniferum and MorAB from P. putida M10. The authors improved the total opioid titers to $130 \mathrm{mg} / \mathrm{L}$ by titrating gene copy number, applying a spatial engineering strategy, and optimizing culture conditions. In another study, a seven-gene pathway was constructed in $S$. cerevisiae for the production of codeine from (R)reticuline (Fossati et al., 2015). These seven genes included salutaridine synthase gene $(S A S)$, salutaridine reductase gene $(S A R)$, salutaridinol acetyltransferase gene (SAT), and T6ODM, COR1.3, and CODM from $P$. somniferum. Another research group engineered 21-gene and 23-gene pathways in S. cerevisiae for the de novo production of thebaine and hydrocodone, respectively, from dextrose (Galanie et al., 2015). The genes of the 21-gene pathway for thebaine synthesis composed 5 modules: (1) precursor overproduction modular, (2) tetrahydrobiopterin $\left(\mathrm{BH}_{4}\right)$ modular, (3) (S)-norcoclaurine modular, (4) (S)-reticuline modular, (5) thebaine modular (Figure 5, Table 4). And they also demonstrated that the (S)-reticuline modular is the key pathway for opioid production (Galanie et al., 2015). Integrating additional gene copies of the (S)-reticuline modular increased reticuline production to $82 \mu \mathrm{g} / \mathrm{L}$ from $20 \mu \mathrm{g} / \mathrm{L}$. The integration of 21 genes of the thebaine synthetic pathway and additional copies of the (S)-reticuline modular (TyrH, 4'OMT, and NCS) in $S$. cerevisiae resulted in the production of $6.4 \mu \mathrm{g} / \mathrm{L}$ thebaine. The authors also described that the overexpression of T6ODM from P. somniferum and MorB from P. putida M10 in a yeast artificial chromosome vector in the above thebaine producing yeast stain resulted in the production of $\sim 0.3 \mu \mathrm{g} / \mathrm{L}$ of hydrocodone (Galanie et al., 2015). A stepwise culture strategy was used for the de novo production of opiates from glycerol using four $E$. coli strains (Nakagawa et al., 2016). These four E. coli strains included dopamine, (R,S)-THP, (R,S)-reticuline, and thebaine producing $E$. coli strains. The stepwise culture of the four engineered $E$. coli strains yielded $2.1 \mathrm{mg} / \mathrm{L}$ of thebaine from glycerol, which corresponded to a 300-fold increase from the yield observed with the developed yeast system (Nakagawa et al., 2016). After the introduction of T6ODM obtained from $P$. somniferum and morB from $P$. putida into the thebaine producing E. coli strain, $0.36 \mathrm{mg} / \mathrm{L}$ of hydrocodone was produced using the four-step culture system (Nakagawa et al., 2016). A neopinone isomerase gene (NISO) was recently identified from opium poppy (P. somniferum) (Dastmalchi et al., 2019b). Overexpression of this NISO in an engineered yeast significantly improved the production of codeine and hydrocodone, respectively. Recently, nine benzylisoquinoline alkaloid uptake permease genes (BUPs) were also identified from $P$. somniferum (Dastmalchi et al., 2019a). Overexpression of BUP in an engineered yeast further enhanced the production of (S)-reticuline, thebaine, codeine, and morphine, respectively.

\section{CONCLUDING REMARKS AND FUTURE PROSPECTS}

With the rapid development of metabolic engineering and synthetic biology, as well as the increased knowledge regarding the native biosynthetic pathways of aromatic natural compounds, heterologous biosynthesis of aromatic products in microorganisms has become a promising alternative for the production of aromatics and their derivatives. However, their titers and yields are still too low for industrial production. The following may be new directions that can enhance the production of aromatic amino acid derivatives.

First, many aromatic compounds have anti-microbial activity and are highly toxic to microbial host cells, thus limiting the microbial production of aromatic chemicals. Adaptive laboratory evolution (ALE) is a general approach for improving the tolerance of host cells. However, $t$ improvements in tolerance 
cannot guarantee an increase in yield. The biosensor-driven ALE approaches can rapidly screen the highly efficient evolved strain from the ALE libraries tolerant to the aromatic compounds. Some biosensors of aromatic compounds have been developed (Li et al., 2017; Wang et al., 2017). Shikimic acid and resveratrol biosensors have been developed and applied to increase the production of shikimic acid (Li et al., 2017) and resveratrol (Xiong et al., 2017), respectively. Liu et al. (2017) developed an L-Phe biosensor and applied the biosensor to improve L-Phe production, by screening hyperproducing strains from a ribonucleotide binding site library and random mutagenesis library.

Second, whole-cell biocatalysis may be a powerful strategy for the production of aromatic chemicals. The whole-cell biocatalysis processes consist of two stages: cell culture and the conversion of the substrates (Lin and Tao, 2017). After cells are cultured, cells are harvested and then suspended in the desired buffer to convert substrates into products. Because the whole-cell biocatalysis process separates the cell growth from the formation of target products, it is unnecessary to consider the cytotoxicity of products. It has been successfully used for the production of LPLA from L-Phe (Hou et al., 2019), D-phenylglycine from L-Phe (Zhou Y. et al., 2017), rosmarinic acid from caffeic acid (Jiang et al., 2016), L-DOPA from hydroxytyrosol (Li et al., 2019b), and caffeic acid from $p$-coumaric acid (Furuya and Kino, 2014). It can also be used for the de novo biosynthesis of products when cells harbor the de novo biosynthetic pathway. Using wholecell biocatalysis of the engineered C. glutamicum resulted in the highest shikimic acid titer and yield attained by microbial production reported so far $(141 \mathrm{~g} / \mathrm{L}$ and $0.49 \mathrm{~g}$ of shikimic acid per g of glucose (Kogure et al., 2016).

Third, because regulation mechanisms of aromatic amino acid formation have been quite well-known and thus do no longer present obstacles in increasing the aromatic amino acid availability. The identification of better enzymes of the heterogeneous pathway and the further improvement of these enzymes will play important roles in further improving the production of aromatic compounds. A mutant of A. thaliana 4CL1 exhibiting a higher catalytic efficiency was obtained by directed evolution via error-prone PCR (Xiong et al., 2017). The use of this mutant improved resveratrol production by 4.7 -fold in E. coli.

Fourth, modular co-cultures might be a useful approach for improving the production titer of aromatic compounds. This approach divides a complete biosynthetic pathway into separate serial modules and uses selected microbial strains to accommodate individual modules for biosynthesis. There are a number of main benefits of using this approach. These include: (1) reduction of the metabolic burden on each host strain; (2) allowing the selection of a suitable host strain and culture conditions for each module that meets the requirements of specific biosynthetic steps; (3) reduction in the undesirable interference from different pathways; (4) maintenance of an easy balance of the biosynthetic pathway among individual pathway modules, by simply changing the strain-to-strain ratio; (5) highefficiency utilization of complex materials containing multiple active substrates; and (6) support provided for the plug-and-play biosynthesis of various target products (Zhang and Wang, 2016). Co-culture engineering strategies can significantly improve the production of salidroside (Liu X. et al., 2018) and resveratrol (Camacho-Zaragoza et al., 2016). BIAs are tyrosine derivatives. Strategies for improving the production of tyrosine in E. coli and $S$. cerevisiae are similar, but the highest published titers of aromatic amino acids in E. coli are currently an order of magnitude higher than that in S. cerevisiae. Moreover, plant enzymes and cytochrome P450s are more efficiently expressed in $S$. cerevisiae than in E. coli. Thus, the modular co-culture of E. coli and $S$. cerevisiae-during which E. coli expresses the microbial genes for synthesizing (S)-THP and S. cerevisiae express the plant enzymes and cytochrome P450s required for synthesizing BIAs-might be an efficient strategy for the biotechnological production of BIAs. Minami et al. (2008) constructed a co-culture system involving $E$. coli and $S$. cerevisiae for the production of magnoflorine or scoulerine from dopamine.

Fifth, most of the studies that have been discussed used the plasmid system to achieve the expression of heterologous pathways. Drawbacks that include the instability and the necessity of use of antibiotics in plasmid expression systems limit the industrial use of plasmid expression systems. To overcome these drawbacks associated with plasmid expression systems, a chemically inducible chromosomal evolution (CIChE) system (Tyo et al., 2009) and an auxotrophic system (Shukal et al., 2019) were developed to achieve high gene copy expression. However, the constructed CIChE strains contained an antibiotic resistance marker (chloramphenicol resistance) (Tyo et al., 2009). Subsequently, we modified CIChE strains and developed an approach that involves triclosan inducible chromosomal evolution (Chen et al., 2013). We applied this approach to engineer a lycopene (Chen et al., 2013) and shikimic acid (Cui et al., 2014) hyperproducing E. coli strains that do not carry a plasmid or antibiotic marker.

The final, as in the cases for developing strains overproducing other compounds, systems metabolic engineering will also be used for developing microbial strains efficiently producing various aromatic chemicals. This approach, which integrates metabolic engineering with systems biology, might represent another efficient strategy to improve the production of aromatic compounds. Comparative analyses using omics might lead to the identification of unknown bottlenecks and help overcome them, and might enable the use of reverse engineering, i.e., the application of novel targets in existing aromatic-producing strains. Although systems metabolic engineering has successfully been applied to engineer microorganisms as a way of improving the production of chemicals (Cho et al., 2015; Shen et al., 2016; Li and Liu, 2017), there are few reports regarding the production of aromatic compounds.

\section{AUTHOR CONTRIBUTIONS}

Y-PS, F-XN, and Y-BH provided draft text for the section Production of Aromatic Amino Acid Derivatives. Z-BY provided draft text for the section Production of Stilbens. LF provided draft text for the section Production of Benzylisoquinoline Alkaloids. J-ZL conceived, reviewed the literature and extracted data, plotted figures and wrote the manuscript. All authors read and approved the final manuscript. 


\section{FUNDING}

This work was funded by the National Natural Science Foundation of China (Grant No. 21808248 and 31901024), the Natural Science Foundation of Guangdong Province

\section{REFERENCES}

Averesch, N. J. H., and Kromer, J. O. (2018). Metabolic engineering of the shikimate pathway for production of aromatics and derived compoundspresent and future strain construction strategies. Front. Bioeng. Biotechnol. 6:32. doi: $10.3389 /$ fbioe.2018.00032

Bai, Y. F., Bi, H. P., Zhuang, Y. B., Liu, C., Cai, T., Liu, X. N., et al. (2014). Production of salidroside in metabolically engineered Escherichia Coli. Sci. Rep. 4:6640. doi: 10.1038/srep06640

Balderas-Hernandez, V. E., Sabido-Ramos, A., Silva, P., Cabrera-Valladares, N., Hernandez-Chavez, G., Baez-Viveros, J. L., et al. (2009). Metabolic engineering for improving anthranilate synthesis from glucose in Escherichia coli. Microb. Cell Fact. 8:19. doi: 10.1186/1475-2859-8-19

Bang, H. B., Lee, K., Lee, Y. J., and Jeong, K. J. (2018). High-level production of trans-cinnamic acid by fed-batch cultivation of Escherichia coli. Process Biochem. 68, 30-36. doi: 10.1016/j.procbio.2018.01.026

Becker, J. V. W., Armstrong, G. O., Van der Merwe, M. J., Lambrechts, M. G., Vivier, M. A., and Pretorius, I. S. (2003). Metabolic engineering of Saccharomyces cerevisiae for the synthesis of the wine-related antioxidant resveratrol. FEMS Yeast Res. 4, 79-85. doi: 10.1016/S1567-1356(03)00157-0

Beekwilder, J., Wolswinkel, R., Jonker, H., Hall, R., de Vos, C. H. R., and Bovy, A. (2006). Production of resveratrol in recombinant microorganisms. Appl. Environ. Microb. 72, 5670-5672. doi: 10.1128/AEM.00609-06

Bloch, S. E., and Schmidt-Dannert, C. (2014). Construction of a chimeric biosynthetic pathway for the de novo biosynthesis of rosmarinic acid in Escherichia coli. Chem. Biol. Chem. 15, 2393-2401. doi: 10.1002/cbic.201402275

Calero, P., Jensen, S. I., and Nielsen, A. T. (2016). Broad-host-range ProUser vectors enable fast characterization of inducible promoters and optimization of p-coumaric acid production in Pseudomonas Putida KT2440. ACS Synth. Biol. 5, 741-753. doi: 10.1021/acssynbio.6b00081

Camacho-Zaragoza, J. M., Hernandez-Chavez, G., Moreno-Avitia, F., RamirezIniguez, R., Martinez, A., Bolivar, F., et al. (2016). Engineering of a microbial coculture of Escherichia coli strains for the biosynthesis of resveratrol. Microb. Cell Fact. 15:163. doi: 10.1186/s12934-016-0562-Z

Cao, M. F., Gao, M. R., Suastegui, M., Mei, Y. Z., and Shao, Z. Y. (2020). Building microbial factories for the production of aromatic amino acid pathway derivatives: from commodity chemicals to plant-sourced natural products. Metab. Eng. 58, 94-132. doi: 10.1016/j.ymben.2019.08.008

Cha, M. N., Kim, H. J., Kim, B. G., and Ahn, J. H. (2014). Synthesis of chlorogenic acid and p-coumaroyl shikimates from glucose using engineered Escherichia coli. J. Microbiol. Biotechnol. 24, 1109-1117. doi: 10.4014/jmb.1403.03033

Chen, W., Yao, J., Meng, J., Han, W. J., Tao, Y., Chen, Y. H., et al. (2019). Promiscuous enzymatic activity-aided multiple-pathway network design for metabolic flux rearrangement in hydroxytyrosol biosynthesis. Nat. Commun. 10:960. doi: 10.1038/s41467-019-08781-2

Chen, Y. Y., Shen, H. J., Cui, Y. Y., Chen, S. G., Weng, Z. M., Zhao, M., et al. (2013). Chromosomal evolution of Escherichia coli for the efficient production of lycopene. BMC Biotechnol. 13:6. doi: 10.1186/1472-6750-13-6

Cho, C., Choi, S. Y., Luo, Z. W., and Lee, S. Y. (2015). Recent advances in microbial production of fuels and chemicals using tools and strategies of systems metabolic engineering. Biotechnol. Adv. 33, 1455-1466. doi: 10.1016/j.biotechadv.2014.11.006

Choo, H. J., Kim, E. J., Kim, S. Y., Lee, Y., Kim, B. G., and Ahn, J. H. (2018). Microbial synthesis of hydroxytyrosol and hydroxysalidroside. Appl. Biol. Chem. 61, 295-301. doi: 10.1007/s13765-018-0360-x

Chung, D., Kim, S. Y., and Ahn, J. H. (2017). Production of three phenylethanoids, tyrosol, hydroxytyrosol, and salidroside, using plant genes expressing in Escherichia coli. Sci. Rep. 7:2578. doi: 10.1038/s41598-017-0 2042-2
(No. 2018A030310255), the Open Fund Project of Shenzhen Innovation Institute of Synthetic Biology (DWKF20190003), and the Fundamental Research Funds for the Central Universities (19lgpy133) for their financial support.
Couto, M. R., Rodrigue, J. L., and Rodrigues, L. R. (2017). Optimization of fermentation conditions for the production of curcumin by engineered Escherichia coli. J. R. Soc. Interface 14:20170470. doi: 10.1098/rsif.2017.0470

Cui, Y. Y., Ling, C., Zhang, Y. Y., Huang, J., and Liu, J. Z. (2014). Production of shikimic acid from Escherichia coli through chemically inducible chromosomal evolution and cofactor metabolic engineering. Microb. Cell Fact. 13:21. doi: 10.1186/1475-2859-13-21

Das, A., Tyagi, N., Verma, A., Akhtar, S., and Mukherjee, K. J. (2018). Metabolic engineering of Escherichia coli w3110 strain by incorporating genome-level modifications and synthetic plasmid modules to enhance L-dopa production from glycerol. Prep. Biochem. Biotech. 48, 671-682. doi: 10.1080/10826068.2018.1487851

Dastmalchi, M., Chang, L. M., Chen, R. J., Yu, L. S., Chen, X., Hagel, J. M., et al. (2019a). Purine permease-type benzylisoquinoline alkaloid transporters in opium poppy. Plant Physiol. 181, 916-933. doi: 10.1104/pp.19. 00565

Dastmalchi, M., Chen, X., Hagel, J. M., Chang, L. M., Chen, R. J., Ramasamy, S., et al. (2019b). Neopinone isomerase is involved in codeine and morphine biosynthesis in opium poppy. Nat. Chem. Biol. 15, 384-390. doi: 10.1038/s41589-019-0247-0

Dell, K., and Frost, J. (1993). Identification and removal of impediments to biocatalytic synthesis of aromatics from D-glucose: rate-limiting enzymes in the common pathway of aromatic amino acid biosynthesis. J. Am. Chem. Soc. 115, 11581-11589. doi: 10.1021/ja00077a065

DeLoache, W. C., Russ, Z. N., Narcross, L., Gonzales, A. M., Martin, V. J. J., and Dueber, J. E. (2015). An enzyme-coupled biosensor enables (s)reticuline production in yeast from glucose. Nat. Chem. Biol. 11, 465-471. doi: 10.1038/nchembio.1816

Diamond, A., and Desgagne-Penix, I. (2016). Metabolic engineering for the production of plant isoquinoline alkaloids. Plant Biotechnol. J. 14, 1319-1328. doi: $10.1111 /$ pbi. 12494

Du, J., Yang, D., Luo, Z. W., and Lee, S. Y. (2018). Metabolic engineering of Escherichia coli for the production of indirubin from glucose. J. Biotechnol. 267, 19-28. doi: 10.1016/j.jbiotec.2017.12.026

Fang, M. Y., Wang, T. M., Zhang, C., Bai, J. L., Zheng, X., Zhao, X. J., et al. (2016). Intermediate-sensor assisted push-pull strategy and its application in heterologous deoxyviolacein production in Escherichia coli. Metab. Eng. 33, 41-51. doi: 10.1016/j.ymben.2015.10.006

Fang, M. Y., Zhang, C., Yang, S., Cui, J. Y., Jiang, P. X., Lou, K., et al. (2015). High crude violacein production from glucose by Escherichia coli engineered with interactive control of tryptophan pathway and violacein biosynthetic pathway. Microb. Cell Fact. 14:8. doi: 10.1186/s12934-015-0192-x

Fordjour, E., Adipah, F. K., Zhou, S. H., Du, G. C., and Zhou, J. W. (2019). Metabolic engineering of Escherichia coli BL21 (DE3) for de novo production of L-DOPA from D-glucose. Microb. Cell Fact. 18:74.

Fossati, E., Ekins, A., Narcross, L., Zhu, Y., Falgueyret, J. P., Beaudoin, G. A. W., et al. (2014). Reconstitution of a 10-gene pathway for synthesis of the plant alkaloid dihydrosanguinarine in Saccharomyces cerevisiae. Nat. Commun. 5:3283. doi: $10.1038 /$ ncomms 4283

Fossati, E., Narcross, L., Ekins, A., Falgueyret, J. P., and Martin, V. J. J. (2015). Synthesis of morphinan alkaloids in Saccharomyces cerevisiae. PLoS ONE 10:e124459. doi: 10.1371/journal.pone.01 24459

Fujita, T., Nguyen, H. D., Ito, T., Zhou, S. M., Osada, L., Tateyama, S., et al. (2013). Microbial monomers custom-synthesized to build true bio-derived aromatic polymers. Appl. Microbiol. Biot. 97, 8887-8894. doi: 10.1007/s00253-013-5078-4

Fujiwara, R., Noda, S., Kawai, Y., Tanaka, T., and Kondo, A. (2016a). 4-vinylphenol production from glucose using recombinant Streptomyces mobaraense 
expressing a tyrosine ammonia lyase from Rhodobacter sphaeroides. Biotechnol. Lett. 38, 1543-1549. doi: 10.1007/s10529-016-2126-z

Fujiwara, R., Noda, S., Tanaka, T., and Kondo, A. (2016b). Styrene production from a biomass-derived carbon source using a coculture system of phenylalanine ammonia lyase and phenylacrylic acid decarboxylaseexpressing Streptomyces lividans transformants. J. Biosci. Bioeng. 122, 730-735. doi: 10.1016/j.jbiosc.2016.05.005

Furuya, T., and Kino, K. (2014). Catalytic activity of the two-component flavin-dependent monooxygenase from Pseudomonas aeruginosa toward cinnamic acid derivatives. Appl. Microbiol. Biol. 98, 1145-1154. doi: 10.1007/s00253-013-4958-y

Galanie, S., and Smolke, C. D. (2015). Optimization of yeast-based production of medicinal protoberberine alkaloids. Microb. Cell Fact. 14:144. doi: 10.1186/s12934-015-0332-3

Galanie, S., Thodey, K., Trenchard, I. J., Interrante, M. F., and Smolke, C. D. (2015). Complete biosynthesis of opioids in yeast. Science 349, 1095-1100. doi: 10.1126/science.aac9373

Gottardi, M., Grun, P., Bode, H. B., Hoffmann, T., Schwab, W., Oreb, M., et al. (2017). Optimisation of trans-cinnamic acid and hydrocinnamyl alcohol production with recombinant Saccharomyces cerevisiae and identification of cinnamyl methyl ketone as a by-product. FEMS Yeast Res. 17:fox091. doi: 10.1093/femsyr/fox091

Guo, D. Y., Zhang, L. H., Kong, S. J., Liu, Z. J., Li, X., and Pan, H. (2018). Metabolic engineering of Escherichia coli for production of 2-phenylethanol and 2-phenylethyl acetate from glucose. J. Agr. Food Chem. 66, 5886-5891. doi: 10.1021/acs.jafc.8b01594

Guo, W., Huang, Q. L., Liu, H., Hou, S. L., Niu, S. H., Jiang, Y., et al. (2019). Rational engineering of chorismate-related pathways in Saccharomyces Cerevisiae for improving tyrosol production. Front. Bioeng. Biotechnol. 7:152. doi: 10.3389/fbioe.2019.00152

Hawkins, K. M., and Smolke, C. D. (2008). Production of benzylisoquinoline alkaloids in Saccharomyces cerevisiae. Nat. Chem. Biol. 4, 564-573. doi: $10.1038 /$ nchembio. 105

Hazelwood, L. A., Daran, J. M., van Maris, A. J. A., Pronk, J. T., and Dickinson, J. R. (2008). The ehrlich pathway for fusel alcohol production: a century of research on Saccharomyces cerevisiae metabolism. Appl. Environ. Microb. 74, 2259-2266. doi: 10.1128/AEM.02625-07

Heo, K. T., Kang, S. Y., and Hong, Y. S. (2017). De novo biosynthesis of pterostilbene in an Escherichia coli strain using a new resveratrol o-methyltransferase from Arabidopsis. Microb. Cell Fact. 16:30. doi: 10.1186/s12934-017-0644-6

Hou, Y., Gao, B., Cui, J. D., Tan, Z. L., Qiao, C. S., and Jia, S. R. (2019). Combination of multi-enzyme expression fine-tuning and co-substrates addition improves phenyllactic acid production with an Escherichia coli wholecell biocatalyst. Bioresour. Technol. 287:121423. doi: 10.1016/j.biortech.2019.1 21423

Huang, Q., Lin, Y. H., and Yan, Y. J. (2013). Caffeic acid production enhancement by engineering a phenylalanine over-producing Escherichia coli strain. Biotechnol. Bioeng. 110, 3188-3196. doi: 10.1002/bit.24988

Huccetogullari, D., Luo, Z. W., and Lee, S. Y. (2019). Metabolic engineering of microorganisms for production of aromatic compounds. Microb. Cell Fact. 18:41. doi: 10.1186/s12934-019-1090-4

Immanuel, S. R. C., Banerjee, D., Rajankar, M. P., and Raghunathan, A. (2018). Integrated constraints based analysis of an engineered violacein pathway in Escherichia coli. Biosystems 171, 10-19. doi: 10.1016/j.biosystems.2018.06.002

Jeong, Y. J., An, C. H., Woo, S. G., Jeong, H. J., Kim, Y. M., Park, S. J., et al. (2014). Production of pinostilbene compounds by the expression of resveratrol o-methyltransferase genes in Escherichia coli. Enzyme Microb. Tech. 54, 8-14. doi: 10.1016/j.enzmictec.2013.09.005

Jiang, J., Bi, H., Zhuang, Y., Liu, S., Liu, T., and Ma, Y. (2016). Engineered synthesis of rosmarinic acid in Escherichia coli resulting production of a new intermediate, caffeoyl-phenyllactate. Biotechnol. Lett. 38, 81-88. doi: 10.1007/s10529-015-1945-7

Jiang, J. J., Yin, H., Wang, S. A., Zhuang, Y. B., Liu, S. W., Liu, T., et al. (2018). Metabolic engineering of Saccharomyces cerevisiae for high-level production of salidroside from glucose. J. Agr. Food Chem. 66, 4431-4438. doi: 10.1021/acs.jafc.8b01272
Kallscheuer, N., Vogt, M., Bott, M., and Marienhagen, J. (2017). Functional expression of plant-derived o-methyltransferase, flavanone 3-hydroxylase, and flavonol synthase in Corynebacterium glutamicum for production of pterostilbene, kaempferol, and quercetin. J. Biotechnol. 258, 190-196. doi: 10.1016/j.jbiotec.2017.01.006

Kallscheuer, N., Vogt, M., Stenzel, A., Gatgens, J., Bott, M., and Marienhagen, J. (2016). Construction of a Corynebacterium glutamicum platform strain for the production of stilbenes and (2s)-flavanones. Metab. Eng. 38, 47-55. doi: 10.1016/j.ymben.2016.06.003

Kang, S. Y., Choi, O., Lee, J. K., Ahn, J. O., Ahn, J. S., Hwang, B. Y., et al. (2015). Artificial de novo biosynthesis of hydroxystyrene derivatives in a tyrosine overproducing Escherichia coli strain. Microb. Cell Fact. 14:78. doi: 10.1186/s12934-015-0268-7

Kang, S. Y., Choi, O., Lee, J. K., Hwang, B. Y., Uhm, T. B., and Hong, Y. S. (2012). Artificial biosynthesis of phenylpropanoic acids in a tyrosine overproducing Escherichia coli strain. Microb. Cell Fact. 11:153. doi: 10.1186/1475-2859-11-153

Kang, S. Y., Heo, K. T., and Hong, Y. S. (2018). Optimization of artificial curcumin biosynthesis in $E$. coli by randomized 5'-UTR sequences to control the multienzyme pathway. ACS Synth. Biol. 7, 2054-2062. doi: 10.1021/acssynbio.8b00198

Kang, Z., Zhang, C. Z., Du, G. C., and Chen, J. (2014). Metabolic engineering of Escherichia coli for production of 2-phenylethanol from renewable glucose. Appl. Biochem. Biotechnol. 172, 2012-2021. doi: 10.1007/s12010-013-0659-3

Katsuyama, Y., Funa, N., and Horinouchi, S. (2007a). Precursor-directed biosynthesis of stilbene methyl ethers in Escherichia coli. Biotechnol. J. 2, 1286-1293. doi: 10.1002/biot.200700098

Katsuyama, Y., Funa, N., Miyahisa, I., and Horinouchi, S. (2007b). Synthesis of unnatural flavonoids and stilbenes by exploiting the plant biosynthetic pathway in Escherichia coli. Chem. Biol. 14, 613-621. doi: 10.1016/j.chembiol.2007.05.004

Kim, B., Cho, B. R., and Hahn, J. S. (2014). Metabolic engineering of Saccharomyces cerevisiae for the production of 2-phenylethanol via ehrlich pathway. Biotechnol. Bioeng. 111, 115-124. doi: 10.1002/bit.24993

Kim, B. G., Jung, W. D., Mok, H., and Ahn, J. H. (2013). Production of hydroxycinnamoyl-shikimates and chlorogenic acid in Escherichia coli: production of hydroxycinnamic acid conjugates. Microb. Cell Fact. 12:15. doi: 10.1186/1475-2859-12-15

Kim, J. S., Nakagawa, A., Yamazaki, Y., Matsumura, E., Koyanagi, T., Minami, H., et al. (2013). Improvement of reticuline productivity from dopamine by using engineered Escherichia coli. Biosci. Biotechnol. Biochem. 77, 2166-2168. doi: 10.1271/bbb.130552

Kim, S. Y., Song, M. K., Jeon, J. H., and Ahn, J. H. (2018). Current status of microbial phenylethanoid biosynthesis. J. Microbiol. Biotechnol. 28, 1225-1232. doi: 10.4014/jmb.1805.05021

Kim, T. Y., Lee, S. W., and Oh, M. K. (2014). Biosynthesis of 2-phenylethanol from glucose with genetically engineered Kluyveromyces marxianus. Enzyme Microb. Tech. 61-62:44-47. doi: 10.1016/j.enzmictec.2014.04.011

Kogure, T., Kubota, T., Suda, M., Hiraga, K., and Inui, M. (2016). Metabolic engineering of Corynebacterium glutamicum for shikimate overproduction by growth-arrested cell reaction. Metab. Eng. 38, 204-216. doi: 10.1016/j.ymben.2016.08.005

Koma, D., Yamanaka, H., Moriyoshi, K., Ohmoto, T., and Sakai, K. (2012). Production of aromatic compounds by metabolically engineered Escherichia coli with an expanded shikimate pathway. Appl. Environ. Microb. 78, 6203-6216. doi: 10.1128/AEM.01148-12

Kong, S., Pan, H., Liu, X., Li, X., and Guo, D. (2020). De novo biosynthesis of 2-phenylethanol in engineered Pichia pastoris. Enzyme Microb. Technol. 133:109459. doi: 10.1016/j.enzmictec.2019.109459

Kuepper, J., Dickler, J., Biggel, M., Behnken, S., Jager, G., Wierckx, N., et al. (2015). Metabolic engineering of Pseudomonas putida kt2440 to produce anthranilate from glucose. Front. Microbiol. 6:1310. doi: 10.3389/fmicb.2015.01310

Lee, K., Bang, H. B., Lee, Y. H., and Jeong, K. J. (2019). Enhanced production of styrene by engineered Escherichia coli and in situ product recovery (ISPR) with an organic solvent. Microb. Cell Fact. 18:79. doi: 10.1186/s12934-019-1129-6

Lee, S. J., Sim, G. Y., Kang, H., Yeo, W. S., Kim, B. G., and Ahn, J. H. (2018). Synthesis of avenanthramides using engineered Escherichia coli. Microb. Cell Fact. 17:46. doi: 10.1186/s12934-018-0896-9 
Lee, S. J., Sim, G. Y., Lee, Y., Kim, B. G., and Ahn, J. H. (2017). Engineering of Escherichia coli for the synthesis of n-hydroxycinnamoyl tryptamine and serotonin. J. Ind. Microbiol. Biot. 44, 1551-1560. doi: 10.1007/s10295-017-1975-3

Li, C., Jia, P., Bai, Y. J., Fan, T. P., Zheng, X. H., and Cai, Y. J. (2019b). Efficient synthesis of hydroxytyrosol from 1-3,4-dihydroxyphenylalanine using engineered Escherichia coli whole cells. J. Agric. Food Chem. 67, 6867-6873. doi: 10.1021 acs.jafc.9b01856

Li, C., Zhang, Z., and Wang, J. (2019a). A thermophilic biofunctional multienzyme cascade reaction for cell-free synthesis of salvianic acid a and 3,4-dihydroxymandelic acid. ACS Sustain. Chem. Eng. 7, 18247-18253. doi: 10.1021/acssuschemeng.9b05496

Li, F. F., Zhao, Y., Li, B. Z., Qiao, J. J., and Zhao, G. R. (2016). Engineering Escherichia coli for production of 4-hydroxymandelic acid using glucose-xylose mixture. Microb. Cell Fact. 15:90. doi: 10.1186/s12934-016-0489-4

Li, H., Liang, C. N., Chen, W., Jin, J. M., Tang, S. Y., and Tao, Y. (2017). Monitoring in vivo metabolic flux with a designed whole-cell metabolite biosensor of shikimic acid. Biosens. Bioelectron. 98, 457-465. doi: 10.1016/j.bios.2017.07.022

Li, M., Kildegaard, K. R., Chen, Y., Rodriguez, A., Borodina, I., and Nielsen, J. (2015). De novo production of resveratrol from glucose or ethanol by engineered Saccharomyces cerevisiae. Metab. Eng. 32, 1-11. doi: 10.1016/j.ymben.2015.08.007

Li, M., Schneider, K., Kristensen, M., Borodina, I., and Nielsen, J. (2016). Engineering yeast for high-level production of stilbenoid antioxidants. Sci. Rep. 6:36827. doi: 10.1038/srep36827

Li, X., Chen, Z., Wu, Y., Yan, Y., Sun, X., and Yuan, Q. (2018). Establishing an artificial pathway for efficient biosynthesis of hydroxytyrosol. ACS Synth. Biol. 7, 647-654. doi: 10.1021/acssynbio.7b00385

Li, Y., Li, S., Thodey, K., Trenchard, I., Cravens, A., and Smolke, C. D. (2018). Complete biosynthesis of noscapine and halogenated alkaloids in yeast. Proc. Natl. Acad. Sci. U.S.A. 115, E3922-E3931. doi: 10.1073/pnas.1721469115

Li, Y. R., and Smolke, C. D. (2016). Engineering biosynthesis of the anticancer alkaloid noscapine in yeast. Nat. Commun. 7:12137. doi: 10.1038/ncomms12137

Li, Z., and Liu, J. Z. (2017). Transcriptomic changes in response to putrescine production in metabolically engineered Corynebacterium glutamicum. Front. Microbiol. 8:1987. doi: 10.3389/fmicb.2017.01987

Li, Z., Wang, X., and Zhang, H. (2019c). Balancing the non-linear rosmarinic acid biosynthetic pathway by modular co-culture engineering. Metab. Eng. 54, 1-11. doi: 10.1016/j.ymben.2019.03.002

Liang, J. L., Guo, L. Q., Lin, J. F., He, Z. Q., Cai, F. J., and Chen, J. F. (2016). A novel process for obtaining pinosylvin using combinatorial bioengineering in Escherichia coli. World J. Microb. Biol. 32:102. doi: 10.1007/s11274-016-2062-z

Liang, L. Y., Liu, R. M., Foster, K. E. O., Alakshchoudhury, Cook, S., Cameron, J. C., et al. (2020). Genome engineering of $E$. coli for improved styrene production. Metab. Eng. 57, 74-84. doi: 10.1016/j.ymben.2019.09.007

Lim, C. G., Fowler, Z. L., Hueller, T., Schaffer, S., and Koffas, M. A. G. (2011). High-yield resveratrol production in engineered Escherichia coli. Appl. Environ. Microb. 77, 3451-3460. doi: 10.1128/AEM.02186-10

Lin, B. X., and Tao, Y. (2017). Whole-cell biocatalysts by design. Microb. Cell Fact. 16:106. doi: 10.1186/s12934-017-0724-7

Lin, Y. H., and Yan, Y. J. (2012). Biosynthesis of caffeic acid in Escherichia coli using its endogenous hydroxylase complex. Microb. Cell Fact. 11:42. doi: 10.1186/1475-2859-11-42

Lin, Y. H., and Yan, Y. J. (2014). Biotechnological production of plantspecific hydroxylated phenylpropanoids. Biotechnol. Bioeng. 111, 1895-1899. doi: 10.1002/bit.25237

Liu, C. Q., Men, X., Chen, H. L., Li, M. J., Ding, Z. R., Chen, G. Q., et al. (2018). A systematic optimization of styrene biosynthesis in Escherichia coli BL21(DE3). Biotechnol. Biofuels 11:14. doi: 10.1186/s13068-018-1017-Z

Liu, J. B., Jiang, J., Bai, Y. J., Fan, T. P., Zhao, Y., Zheng, X. H., et al. (2018). Mimicking a new 2-phenylethanol production pathway from Proteus mirabilis JN458 in Escherichia coli. J. Agric. Food. Chem. 66, 3498-3504. doi: 10.1021/acs.jafc.8b00627

Liu, L., Liu, H., Zhang, W., Yao, M. D., Li, B. Z., Liu, D., et al. (2019). Engineering the biosynthesis of caffeic acid in Saccharomyces cerevisiae with heterologous enzyme combinations. Engineering 5, 287-295. doi: 10.1016/j.eng.2018. 11.029
Liu, Q., Yu, T., Li, X. W., Chen, Y., Campbell, K., Nielsen, J., et al. (2019). Rewiring carbon metabolism in yeast for high level production of aromatic chemicals. Nat. Commun. 10:4976. doi: 10.1038/s41467-019-12961-5

Liu, S. P., Liu, R. X., El-Rotail, A. A., Ding, Z. Y., Gu, Z. H., Zhang, L., et al. (2014). Heterologous pathway for the production of L-phenylglycine from glucose by E. coli. J. Biotechnol. 186, 91-97. doi: 10.1016/j.jbiotec.2014.06.033

Liu, X., Li, X. B., Jiang, J. L., Liu, Z. N., Qiao, B., Li, F. F., et al. (2018). Convergent engineering of syntrophic Escherichia coli coculture for efficient production of glycosides. Metab. Eng. 47, 243-253. doi: 10.1016/j.ymben.2018.03.016

Liu, X. L., Lin, J., Hu, H. F., Zhou, B., and Zhu, B. Q. (2016). De novo biosynthesis of resveratrol by site-specific integration of heterologous genes in Escherichia coli. FEMS Microbiol. Lett. 363:fnw061. doi: 10.1093/femsle/fnw061

Liu, Y. F., Zhuang, Y. Y., Ding, D. Q., Xu, Y. R., Sun, J. B., and Zhang, D. W. (2017). Biosensor-based evolution and elucidation of a biosynthetic pathway in Escherichia coli. ACS Synth. Biol. 6, 837-848. doi: 10.1021/acssynbio.6b00328

Lukito, B. R., Sekar, B. S., Wu, S., and Li, Z. (2019). Mandelic acid-whole cellbased cascade biotransformation for the production of (S)-mandelic acid from styrene, L-phenylalanine, glucose, or glycerol. Adv. Synth. Catal. 361, 3560-3568. doi: 10.1002/adsc.201900373

Machas, M. S., McKenna, R., and Nielsen, D. R. (2017). Expanding upon styrene biosynthesis to engineer a novel route to 2-phenylethanol. Biotechnol. J. 12:1700310. doi: 10.1002/biot.201700310

Matsumura, E., Nakagawa, A., Tomabechi, Y., Ikushiro, S., Sakaki, T., Katayama, T., et al. (2018). Microbial production of novel sulphated alkaloids for drug discovery. Sci. Rep. 8:7980. doi: 10.1038/s41598-018-26306-7

Matsumura, E., Nakagawa, A., Tomabechi, Y., Koyanagi, T., Kumagai, H., Yamamoto, K., et al. (2017). Laboratory-scale production of (s)reticuline, an important intermediate of benzylisoquinoline alkaloids, using a bacterial-based method. Biosci. Biotechenol. Biochem. 81, 396-402. doi: 10.1080/09168451.2016.1243985

McKenna, R., Moya, L., McDaniel, M., and Nielsen, D. R. (2015). Comparing in situ removal strategies for improving styrene bioproduction. Bioproc. Biosyst. Eng. 38, 165-174. doi: 10.1007/s00449-014-1255-9

McKenna, R., and Nielsen, D. R. (2011). Styrene biosynthesis from glucose by engineered E. coli. Metab. Eng. 13, 544-554. doi: 10.1016/j.ymben.2011.06.005

McKenna, R., Thompson, B., Pugh, S., and Nielsen, D. R. (2014). Rational and combinatorial approaches to engineering styrene production by Saccharomyces cerevisiae. Microb. Cell Fact. 13:123. doi: 10.1186/s12934-014-0123-2

Milke, L., Ferreira, P., Kallscheuer, N., Braga, A., Vogt, M., Kappelmann, J., et al. (2019). Modulation of the central carbon metabolism of Corynebacterium glutamicum improves malonyl-CoA availability and increases plant polyphenol synthesis. Biotechnol. Bioeng. 116, 1380-1391. doi: 10.1002/bit. 26939

Minami, H., Kim, J. S., Ikezawa, N., Takemura, T., Katayama, T., Kumagai, H., et al. (2008). Microbial production of plant benzylisoquinoline alkaloids. Proc. Natl. Acad. Sci. U.S.A. 105, 7393-7398. doi: 10.1073/pnas.0802981105

Mora-Villalobos, J. A., and Zeng, A. P. (2018). Synthetic pathways and processes for effective production of 5-hydroxytryptophan and serotonin from glucose in Escherichia coli. J. Biol. Eng. 12:3. doi: 10.1186/s13036-018-0094-7

Muller, U., van Assema, F., Gunsior, M., Orf, S., Kremer, S., Schipper, D., et al. (2006). Metabolic engineering of the E-coli L-phenylalanine pathway for the production of D-phenylglycine (D-Phg). Metab. Eng. 8, 196-208. doi: 10.1016/j.ymben.2005.12.001

Munoz, A. J., Hernandez-Chavez, G., de Anda, R., Martinez, A., Bolivar, F., and Gosset, G. (2011). Metabolic engineering of Escherichia coli for improving L-3,4-dihydroxyphenylalanine (L-DOPA) synthesis from glucose. J. Ind. Microbiol. Biot. 38, 1845-1852. doi: 10.1007/s10295-011-0973-0

Nakagawa, A., Matsumura, E., Koyanagi, T., Katayama, T., Kawano, N., Yoshimatsu, K., et al. (2016). Total biosynthesis of opiates by stepwise fermentation using engineered Escherichia coli. Nat. Commun. 7:10390. doi: 10.1038/ncomms 10390

Nakagawa, A., Minami, H., Kim, J. S., Koyanagi, T., Katayama, T., Sato, F., et al. (2011). A bacterial platform for fermentative production of plant alkaloids. Nat. Commun. 2:326. doi: 10.1038/ncomms1327

Narcross, L., Bourgeois, L., Fossati, E., Burton, E., and Martin, V. J. J. (2016a). Mining enzyme diversity of transcriptome libraries through DNA synthesis for benzylisoquinoline alkaloid pathway optimization in yeast. ACS Synth. Biol. 5, 1505-1518. doi: 10.1021/acssynbio.6b00119 
Narcross, L., Fossati, E., Bourgeois, L., Dueber, J. E., and Martin, V. J. J. (2016b). Microbial factories for the production of benzylisoquinoline alkaloids. Trends Biotechnol. 34, 228-241. doi: 10.1016/j.tibtech.2015.12.005

Noda, S., Kawai, Y., Tanaka, T., and Kondo, A. (2015). 4-Vinylphenol biosynthesis from cellulose as the sole carbon source using phenolic acid decarboxylase- and tyrosine ammonia lyase-expressing Streptomyces lividans. Bioresour.Technol. 180, 59-65. doi: 10.1016/j.biortech.2014.12.064

Osipenkov, N., Kulik, A., and Mast, Y. (2018). Characterization of the phenylglycine aminotransferase PglE from Streptomyces pristinaespiralis. J. Biotechnol. 278, 34-38. doi: 10.1016/j.jbiotec.2018.05.007

Park, S., Kang, K., Lee, S. W., Ahn, M. J., Bae, J. M., and Back, K. (2011). Production of serotonin by dual expression of tryptophan decarboxylase and tryptamine 5-hydroxylase in Escherichia coli. Appl. Microbiol. Biot. 89, 1387-1394. doi: 10.1007/s00253-010-2994-4

Qi, W. W., Vannelli, T., Breinig, S., Ben-Bassat, A., Gatenby, A. A., Haynie, S. L., et al. (2007). Functional expression of prokaryotic and eukaryotic genes in Escherichia coli for conversion of glucose to p-hydroxystyrene. Metab. Eng. 9, 268-276. doi: 10.1016/j.ymben.2007.01.002

Reifenrath, M., and Boles, E. (2018). Engineering of hydroxymandelate synthases and the aromatic amino acid pathway enables de novo biosynthesis of mandelic and 4-hydroxymandelic acid with Saccharomyces cerevisiae. Metab. Eng. 45, 246-254. doi: 10.1016/j.ymben.2018.01.001

Ro, D. K., and Douglas, C. J. (2004). Reconstitution of the entry point of plant phenylpropanoid metabolism in yeast (Saccharomyces cerevisiae) - implications for control of metabolic flux into the phenylpropanoid pathway. J. Biol. Chem. 279, 2600-2607. doi: 10.1074/jbc.M309951200

Rodrigues, A. L., Becker, J., Lima, A. O. D. S., Porto, L. M., and Wittmann, C. (2014). Systems metabolic engineering of Escherichia coli for gram scale production of the antitumor drug deoxyviolacein from glycerol. Biotechnol. Bioeng. 111, 2280-2289. doi: 10.1002/bit.25297

Rodrigues, A. L., Trachtmann, N., Becker, J., Lohanatha, A. F., Blotenberg, J., Bolten, C. J., et al. (2013). Systems metabolic engineering of Escherichia coli for production of the antitumor drugs violacein and deoxyviolacein. Metab. Eng. 20, 29-41. doi: 10.1016/j.ymben.2013.08.004

Rodrigues, J. L., Araujo, R. G., Prather, K. L. J., Kluskens, L. D., and Rodrigues, L. R. (2015). Production of curcuminoids from tyrosine by a metabolically engineered Escherichia coli using caffeic acid as an intermediate. Biotechnol. J. 10, 599-609. doi: 10.1002/biot.201400637

Rodrigues, J. L., Gomes, D., and Rodrigues, L. R. (2020). A combinatorial approach to optimize the production of curcuminoids from tyrosine in Escherichia coli. Front. Bioeng. Biotechnol. 8:59. doi: 10.3389/fbioe.2020.00059

Rodriguez, A., Chen, Y., Khoomrung, S., Ozdemir, E., Borodina, I., and Nielsen, J. (2017). Comparison of the metabolic response to over-production of p-coumaric acid in two yeast strains. Metab. Eng. 44, 265-272. doi: 10.1016/j.ymben.2017.10.013

Rodriguez, A., Kildegaard, K. R., Li, M. J., Borodina, I., and Nielsen, J. (2015). Establishment of a yeast platform strain for production of p-coumaric acid through metabolic engineering of aromatic amino acid biosynthesis. Metab. Eng. 31, 181-188. doi: 10.1016/j.ymben.2015.08.003

Romagnoli, G., Knijnenburg, T. A., Liti, G., Louis, E. J., Pronk, J. T., and Daran, J. M. (2015). Deletion of the Saccharomyces cerevisiae ARO8 gene, encoding an aromatic amino acid transaminase, enhances phenylethanol production from glucose. Yeast 32, 29-45. doi: 10.1002/yea.3015

Satoh, Y., Tajima, K., Munekata, M., Keasling, J. D., and Lee, T. S. (2012). Engineering of a tyrosol-producing pathway, utilizing simple sugar and the central metabolic tyrosine, in Escherichia coli. J. Agric. Food Chem. 60, 979-984. doi: 10.1021/jf203256f

Shen, H. J., Cheng, B. Y., Zhang, Y. M., Tang, L., Li, Z., Bu, Y. F., et al. (2016). Dynamic control of the mevalonate pathway expression for improved zeaxanthin production in Escherichia coli and comparative proteome analysis. Metab. Eng. 38, 180-190. doi: 10.1016/j.ymben.2016. 07.012

Shen, Y. P., Fong, L. S., Yan, Z. B., and Liu, J. Z. (2019). Combining directed evolution of pathway enzymes and dynamic pathway regulation using a quorum-sensing circuit to improve the production of 4hydroxyphenylacetic acid in Escherichia coli. Biotechnol. Biofuels 12:94. doi: $10.1186 / \mathrm{s} 13068-019-1438-3$
Shrestha, A., Pandey, R. P., and Sohng, J. K. (2019). Biosynthesis of resveratrol and piceatannol in engineered microbial strains: achievements and perspectives. Appl. Microbiol. Biotechnol. 103, 2959-2972. doi: 10.1007/s00253-019-09672-8

Shukal, S., Chen, X. X., and Zhang, C. Q. (2019). Systematic engineering for highyield production of viridiflorol and amorphadiene in auxotrophic Escherichia coli. Metab. Eng. 55, 170-178. doi: 10.1016/j.ymben.2019.07.007

Sun, H. N., Zhao, D. D., Xiong, B., Zhang, C. Z., and Bi, C. H. (2016). Engineering Corynebacterium glutamicum for violacein hyper production. Microb. Cell Fact. 15:148. doi: 10.1186/s12934-016-0545-0

Sun, Z., Ning, Y., Liu, L., Liu, Y., Sun, B., Jiang, W., et al. (2011). Metabolic engineering of the 1-phenylalanine pathway in Escherichia coli for the production of s- or r-mandelic acid. Microb. Cell Fact. 10:71. doi: 10.1186/1475-2859-10-71

Tantong, S., Nuengchamnong, N., Kumphune, S., Incharoensakdi, A., Lindblad, P., and Sirikantaramas, S. (2018). Synechocystis pcc 6803 cells heterologously expressing bacterial tyrosine ammonia lyase can use exogenous tyrosine for p-coumaric acid production. J. Plant Biochem. Biot. 27, 118-122. doi: 10.1007/s13562-017-0416-8

Thapa, S. B., Pandey, R. P., Park, Y. I., and Sohng, J. K. (2019). Biotechnological advances in resveratrol production and its chemical diversity. Molecules 24:2571. doi: $10.3390 /$ molecules 24142571

Thodey, K., Galanie, S., and Smolke, C. D. (2014). A microbial biomanufacturing platform for natural and semisynthetic opioids. Nat. Chem. Biol. 10, 837-844. doi: 10.1038/nchembio. 1613

Trenchard, I. J., Siddiqui, M. S., Thodey, K., and Smolke, C. D. (2015). De novo production of the key branch point benzylisoquinoline alkaloid reticuline in yeast. Metab. Eng. 31, 74-83. doi: 10.1016/j.ymben.2015.06.010

Trenchard, I. J., and Smolke, C. D. (2015). Engineering strategies for the fermentative production of plant alkaloids in yeast. Metab. Eng. 30, 96-104. doi: 10.1016/j.ymben.2015.05.001

Tyo, K. E. J., Ajikumar, P. K., and Stephanopoulos, G. (2009). Stabilized gene duplication enables long-term selection-free heterologous pathway expression. Nat. Biotechnol. 27, 760-U115. doi: 10.1038/nbt.1555

van Summeren-Wesenhagen, P. V., and Marienhagen, J. (2015). Metabolic engineering of Escherichia coli for the synthesis of the plant polyphenol pinosylvin. Appl. Environ. Microb. 81, 840-849. doi: 10.1128/AEM.02966-14

Vavricka, C. J., Yoshida, T., Kuriya, Y., Takahashi, S., Ogawa, T., Ono, F., et al. (2019). Mechanism-based tuning of insect 3,4-dihydroxyphenylacetaldehyde synthase for synthetic bioproduction of benzylisoquinoline alkaloids. Nat. Commun. 10:2015. doi: 10.1038/s41467-019-09610-2

Verhoef, S., Wierckx, N., Westerhof, R. G. M., de Winde, J. H., and Ruijssenaars, H. J. (2009). Bioproduction of $p$-hydroxystyrene from glucose by the solventtolerant bacterium Pseudomonas putida s12 in a two-phase water-decanol fermentation. Appl. Environ. Microb. 75, 931-936. doi: 10.1128/AEM.02 $186-08$

Wang, H. J., Liu, W. Q., Shi, F., Huang, L., Lian, J. Z., Qu, L., et al. (2018). Metabolic pathway engineering for high-level production of 5-hydroxytryptophan in Escherichia coli. Metab. Eng. 48, 279-287. doi: 10.1016/j.ymben.2018.06.007

Wang, J., Shen, X. L., Rey, J., Yuan, Q. P., and Yan, Y. J. (2018). Recent advances in microbial production of aromatic natural products and their derivatives. Appl. Microbiol. Biot. 102, 47-61. doi: 10.1007/s00253-017-8599-4

Wang, Q. Z., Tang, S. Y., and Yang, S. (2017). Genetic biosensors for smallmolecule products: design and applications in high-throughput screening. Front. Chem. Sci. Eng. 11, 15-26. doi: 10.1007/s11705-017-1629-z

Wang, S. Y., Zhang, S. W., Xiao, A. F., Rasmussen, M., Skidmore, C., and Zhan, J. X. (2015). Metabolic engineering of Escherichia coli for the biosynthesis of various phenylpropanoid derivatives. Metab. Eng. 29, 153-159. doi: 10.1016/j.ymben.2015.03.011

Wang, Y. C., Bhuiya, M. W., Zhou, R., and Yu, O. (2015). Pterostilbene production by microorganisms expressing resveratrol o-methyltransferase. Ann. Microbiol. 65, 817-826. doi: 10.1007/s13213-014-0922-z

Watts, K. T., Lee, P. C., and Schmidt-Dannert, C. (2006). Biosynthesis of plantspecific stilbene polyketides in metabolically engineered Escherichia coli. BMC Biotechnol. 6:22. doi: 10.1186/1472-6750-6-22

Wei, T., Cheng, B. Y., and Liu, J. Z. (2016). Genome engineering Escherichia coli for L-DOPA overproduction from glucose. Sci. Rep. 6:30080. doi: $10.1038 /$ srep30080 
Winzer, T., Gazda, V., He, Z., Kaminski, F., Kern, M., Larson, T. R., et al. (2012). A papaver somniferum 10-gene cluster for synthesis of the anticancer alkaloid noscapine. Science 336, 1704-1708. doi: 10.1126/science.1220757

Wu, F. L., Cao, P., Song, G. T., Chen, W. J., and Wang, Q. H. (2018). Expanding the repertoire of aromatic chemicals by microbial production. J. Chem. Technol. Biot. 93, 2804-2816. doi: 10.1002/jctb.5690

Wu, J. J., Liu, P. R., Fan, Y. M., Bao, H., Du, G. C., Zhou, J. W., et al. (2013). Multivariate modular metabolic engineering of Escherichia coli to produce resveratrol from 1-tyrosine. J. Biotechnol. 167, 404-411. doi: 10.1016/j.jbiotec.2013.07.030

Wu, J. J., Zhang, X., Zhu, Y. J., Tan, Q. Y., He, J. C., and Dong, M. S. (2017a). Rational modular design of metabolic network for efficient production of plant polyphenol pinosylvin. Sci. Rep. 7:1459. doi: 10.1038/s41598-017-01700-9

Wu, J. J., Zhou, P., Zhang, X., and Dong, M. S. (2017b). Efficient de novo synthesis of resveratrol by metabolically engineered Escherichia coli. J. Ind. Microbiol. Biot. 44, 1083-1095. doi: 10.1007/s10295-017-1937-9

Xiong, D. D., Lu, S. K., Wu, J. Y., Liang, C. N., Wang, W., Wang, W. Z., et al. (2017). Improving key enzyme activity in phenylpropanoid pathway with a designed biosensor. Metab. Eng. 40, 115-123. doi: 10.1016/j.ymben.2017.01.006

Xu, J. Y., Xu, Y., Chu, X. H., Tan, M. J., and Ye, B. C. (2018). Protein acylation affects the artificial biosynthetic pathway for pinosylvin production in engineered E. coli. ACS Chem. Biol. 13, 1200-1208. doi: 10.1021/acschembio.7b01068

Xu, P., Rizzoni, E. A., Sul, S. Y., and Stephanopoulos, G. (2017). Improving metabolic pathway efficiency by statistical model-based multivariate regulatory metabolic engineering. ACS Synth. Biol. 6, 148-158. doi: 10.1021/acssynbio.6b00187

Xue, Y., Zhang, Y., Cheng, D., Daddy, S., and He, Q. F. (2014). Genetically engineering Synechocystis sp pasteur culture collection 6803 for the sustainable production of the plant secondary metabolite $p$-coumaric acid. Proc. Natl. Acad. Sci. U.S.A. 111, 9449-9454. doi: 10.1073/pnas.1323725111

Xue, Y. X., Chen, X. Z., Yang, C., Chang, J. Z., Shen, W., and Fan, Y. (2017). Engineering Eschericha coli for enhanced tyrosol production. J. Agric. Food Chem. 65, 4708-4714. doi: 10.1021/acs.jafc.7b01369

Yan, Y., Jia, P., Bai, Y. J., Fan, T. P., Zheng, X. H., and Cai, Y. J. (2019). Production of rosmarinic acid with ATP and CoA double regenerating system. Enzyme Microb. Technol. 131:109392. doi: 10.1016/j.enzmictec.2019.109392

Yang, D., Kim, W. J., Yoo, S. M., Choi, J. H., Ha, S. H., Lee, M. H., et al. (2018). Repurposing type III polyketide synthase as a malonyl-CoA biosensor for metabolic engineering in bacteria. Proc. Natl. Acad. Sci. U.S.A. 115, 9835-9844. doi: $10.1073 /$ pnas. 1808567115

Yang, D., Yoo, S. M., Gu, C., Ryu, J. Y., Lee, J. E., and Lee, S. Y. (2019). Expanded synthetic small regulatory RNA expression platforms for rapid and multiplex gene expression knockdown. Metab. Eng. 54, 180-190. doi: 10.1016/j.ymben.2019.04.003

Yao, Y. F., Wang, C. S., Qiao, J. J., and Zhao, G. R. (2013). Metabolic engineering of Escherichia coli for production of salvianic acid a via an artificial biosynthetic pathway. Metab. Eng. 19, 79-87. doi: 10.1016/j.ymben.2013.06.001

Zhang, H. R., and Stephanopoulos, G. (2013). Engineering E. coli for caffeic acid biosynthesis from renewable sugars. Appl. Microbiol. Biot. 97, 3333-3341. doi: 10.1007/s00253-012-4544-8

Zhang, H. R., and Wang, X. N. (2016). Modular co-culture engineering, a new approach for metabolic engineering. Metab. Eng. 37, 114-121. doi: 10.1016/j.ymben.2016.05.007

Zhao, Y., Wu, B. H., Liu, Z. N., Qiao, J. J., and Zhao, G. R. (2018). Combinatorial optimization of resveratrol production in engineered E-coli. J. Agric. Food Chem. 66, 13444-13453. doi: 10.1021/acs.jafc.8b05014

Zhou, L., Ding, Q., Jiang, G. Z., Liu, Z. N., Wang, H. Y., and Zhao, G. R. (2017). Chromosome engineering of Escherichia coli for constitutive production of salvianic acid A. Microb. Cell Fact. 16:84. doi: 10.1186/s12934-0170700-2

Zhou, Y., Wu, S. K., and Li, Z. (2016). Cascade biocatalysis for sustainable asymmetric synthesis: from biobased L-phenylalanine to high-value chiral chemicals. Angew. Chem. Int. Ed. 55, 11647-11650. doi: 10.1002/anie.201606235

Zhou, Y., Wu, S. K., and Li, Z. (2017). One-pot enantioselective synthesis of D-phenylglycines from racemic mandelic acids, styrenes, or biobased Lphenylalanine via cascade biocatalysis. Adv. Synth. Catal. 359, 4305-4316. doi: 10.1002/adsc.201700956

Zhou, Y. K., Fang, M. Y., Li, G., Zhang, C., and Xing, X. H. (2018). Enhanced production of crude violacein from glucose in Escherichia coli by overexpression of rate-limiting key enzyme(s) involved in violacein biosynthesis. Appl. Biochem. Biotechnol. 186, 909-916. doi: $10.1007 /$ s12010-018-2787-2

Conflict of Interest: The authors declare that the research was conducted in the absence of any commercial or financial relationships that could be construed as a potential conflict of interest.

Copyright (C) 2020 Shen, Niu, Yan, Fong, Huang and Liu. This is an open-access article distributed under the terms of the Creative Commons Attribution License (CC $B Y)$. The use, distribution or reproduction in other forums is permitted, provided the original author(s) and the copyright owner(s) are credited and that the original publication in this journal is cited, in accordance with accepted academic practice. No use, distribution or reproduction is permitted which does not comply with these terms. 